\title{
Recent Developments in Chitosan-Based Adsorbents for the Removal of Pollutants from Aqueous Environments
}

\author{
Daniele C. da Silva Alves ${ }^{1,2}{ }^{(0)}$, Bronach Healy ${ }^{1}$, Luiz A. de Almeida Pinto ${ }^{2}{ }^{\circledR}$, Tito R. Sant' Anna Cadaval, $\mathrm{Jr}^{2}{ }^{2}$ and \\ Carmel B. Breslin 1,* (D) \\ 1 Department of Chemistry, Maynooth University, W23 F2H6 Maynooth, Co. Kildare, Ireland; \\ DANIELE.COSTADASILVAALVES.2021@MUMAIL.IE (D.C.d.S.A.); bronach.healy.2017@mumail.ie (B.H.) \\ 2 School of Chemistry and Food, Federal University of Rio Grande, Rio Grande, RS 96203-900, Brazil; \\ dqmpinto@furg.br (L.A.d.A.P.); titoeq@gmail.com (T.R.S.C.J.) \\ * Correspondence: Carmel.Breslin@mu.ie
}

Citation: da Silva Alves, D.C.; Healy, B.; Pinto, L.A.d.A.; Cadaval, T.R.S., Jr.; Breslin, C.B. Recent Developments in Chitosan-Based Adsorbents for the Removal of Pollutants from Aqueous Environments. Molecules 2021, 26 , 594. https://doi.org/10.3390/ molecules26030594

Academic Editors: Chiara Bisio and Monica Pica

Received: 7 December 2020

Accepted: 21 January 2021

Published: 23 January 2021

Publisher's Note: MDPI stays neutral with regard to jurisdictional claims in published maps and institutional affiliations.

Copyright: (c) 2021 by the authors. Licensee MDPI, Basel, Switzerland This article is an open access article distributed under the terms and conditions of the Creative Commons Attribution (CC BY) license (https:// creativecommons.org/licenses/by/ $4.0 /)$.

\begin{abstract}
The quality of water is continuously under threat as increasing concentrations of pollutants escape into the aquatic environment. However, these issues can be alleviated by adsorbing pollutants onto adsorbents. Chitosan and its composites are attracting considerable interest as environmentally acceptable adsorbents and have the potential to remove many of these contaminants. In this review the development of chitosan-based adsorbents is described and discussed. Following a short introduction to the extraction of chitin from seafood wastes, followed by its conversion to chitosan, the properties of chitosan are described. Then, the emerging chitosan/carbon-based materials, including magnetic chitosan and chitosan combined with graphene oxide, carbon nanotubes, biochar, and activated carbon and also chitosan-silica composites are introduced. The applications of these materials in the removal of various heavy metal ions, including $\mathrm{Cr}(\mathrm{VI}), \mathrm{Pb}(\mathrm{II}), \mathrm{Cd}(\mathrm{II}), \mathrm{Cu}(\mathrm{II})$, and different cationic and anionic dyes, phenol and other organic molecules, such as antibiotics, are reviewed, compared and discussed. Adsorption isotherms and adsorption kinetics are then highlighted and followed by details on the mechanisms of adsorption and the role of the chitosan and the carbon or silica supports. Based on the reviewed papers, it is clear, that while some challenges remain, chitosan-based materials are emerging as promising adsorbents.
\end{abstract}

Keywords: chitosan; adsorbent; carbon; graphene oxide; silica; magnetic separation; dyes; heavy metals; adsorption; Langmuir isotherm

\section{Introduction}

Improving water quality is one of the major environmental challenges worldwide to be solved, since water resources are increasingly scarce due to population growth, climate change and increased demand for water in industrial and agricultural activities [1]. In addition, the inappropriate disposal of organic and inorganic contaminants combined with disinformation and neglect in the treatment of these compounds can result in irreversible damage to the aquatic environment and, consequently, to humans [2,3]. Dyes, phenolic compounds, metallic ions and micropollutants, such as pesticides and drugs, have all been detected in wastewaters, surface and even drinking water, indicating that the conventional methods used in treatment plants are not optimised for their removal [4]. Consequently, the removal of these pollutants with high toxicity, even when present at low concentrations, has been increasingly studied in the scientific world $[5,6]$.

Several techniques have been developed based on hybrid systems [7], membrane filtration [8] and biological degradation [9] to reduce the content of pollutants in water. However, the slow response, sensitivity and high energy demand are some of the disadvantages of such techniques. In addition, they are not very efficient when the effluent has a low content of suspended colloidal particle and a high load of organic matter. A promising alternative to the treatments mentioned is adsorption, due to its simplicity of operation and 
effectiveness [10]. Therefore, the search for new adsorbent materials that can be used to remedy aquatic contamination has been stimulated. The biopolymer chitosan is attracting considerable interest as a matrix for adsorbent material development, since this biopolymer has a high density of hydroxyl groups $(-\mathrm{OH})$ and primary amines $\left(-\mathrm{NH}_{2}\right)$ that act as active adsorption sites, making it an efficient adsorbent [11].

Chitosan ( $\beta-(1-4)-D-$ glucosamine) is a polysaccharide that possesses two types of monomers, one containing an acetamido group (2-acetamido-2-deoxy- $\beta$-D-glucopyranose residues), and another containing an amino group (2-amino-2-deoxy- $\beta$-D-glucopyranose residues). Chitosan is not available directly in the environment, it is obtained from chitin ( $\beta-(1-4)-N$-acetyl-D-glucosamine), usually by the alkaline or enzymatic $N$-deacetylation of chitin [12-14]. The characteristic that differentiates the structure of chitin and chitosan is the substitution of the acetamide group at position 2 . This directly influences the solubility properties of these compounds, with chitin being insoluble and inert, and chitosan soluble in weak acids $[13,15]$.

Currently, chitin and chitosan are produced commercially in Japan, United States, India, Poland, Australia, and Norway, and to a lesser extent, in Canada, Italy, Chile and Brazil $[16,17]$. The annual production of chitin in nature has been estimated to be as high as $1 \times 10^{10}$ to $1 \times 10^{12}$ tonnes [18], which makes this biopolymer a cheap and available resource. However, as the biodegradation rate of chitin is slow, the production of high amounts through shrimp and seafood processing creates an environmental problem, and the conversion of this waste material into high-value products, such as chitosan, can be an attractive solution [19].

During the past few decades, many researchers have focused on the development of chitosan-based materials to solve problems in environmental and biomedical engineering fields, and in the development of innovative products for other different applications [20-22]. From 2010 to 2015, more than 15,000 articles and about 20 books on chitosan were published worldwide. This ever increasing interest is connected with the attractive properties of chitosan, such as biodegradability, low toxicity and biocompatibility, coupled with the availability of natural resources required for its chemical and enzymatic modifications for specific end uses $[19,23]$. Chitosan has been used in many fields such as food, medicine, cosmetics and wastewater treatment [24]. In addition, the efficient utilisation of marine biomass resources has become an environmental priority that leads to intensified research on chitosan production and its applications [25].

In this review, the applications of chitosan-based materials as adsorbents for the removal of pollutants from aqueous environments are reviewed. Although there are a number of review articles that describe the environmental applications of chitosan $[19,24,26,27]$, in this review we focus initially on the sources, properties and chemical modifications of chitosan and discuss the various factors that influence its properties as a material for the removal of pollutants. Next, we review the support materials utilised and combined with chitosan, including the emerging carbon and silicon supports, providing a more comprehensive account than previously published.

\section{Chitosan}

Chitin is the second most abundant natural polysaccharide (biopolymer) on Earth, following cellulose [26]. In 1811, the first chitin was extracted by Henri Bracon from mushrooms and was named initially as "fungine". In 1823, Odier [28] found the same material in the insect exoskeleton and called it chitin. Later, chitin was found in crab shells, confirming that it can be found in the crustacean exoskeleton. In 1859, Charles Roughet discovered that chitin could be transformed into a water-soluble form after chemical modification [19]. In 1894, this chemically modified chitin was called chitosan by Hoppe-Seyler $[29,30]$. Although chitin was discovered 30 years before cellulose, most of the research was focused on cellulose, due to the high investments made by the textile industries. Thus, chitin and chitosan remained restricted only to basic research during this period. Around 1970, interest in natural products increased and investigations directed at 
exploring the potential applications of chitosan began to attract considerable attention [13]. In 1977, the "1st International Conference on Chitin and Chitosan" was organised in Boston, USA, where the scientific and industrial communities leveraged the world's interest in these biopolymers [23].

\subsection{Source and Production}

Chitosan is derived from chitin, usually obtained from natural sources such as the residues of shrimp, crab and lobster, fungal mycelia and green algae [15,31,32]. This biopolymer can also be found in the exoskeletons of insects and fungal cell walls, as shown in Figure 1a. Chitin content in fungi varies between $19 \%$ and $42 \%$, compared to the exoskeleton, where chitin can reach up to $75 \%[29,33]$. Not all shellfish wastes are good sources of chitin. The blue crab (Callinectes) contains $14 \%$ of chitin, while oyster and clam shells have chitin content in the range of $4-6 \%[29,34]$. Chitin content can vary with the proportion of minerals, proteins, and carotenoids, depending on the species, reproductive cycle phase, nutritional status, age, and also the peeling conditions during the processing [13,17]. Chitosan can be obtained by deacetylation of chitin through enzymatic or alkaline methods (Figure $1 \mathrm{~b}$ ). However, the enzymatic method has been limited only to the laboratory scale, while the alkaline method has been more widely used on an industrial scale, due to its short processing time, simplicity, and low operational costs [29].

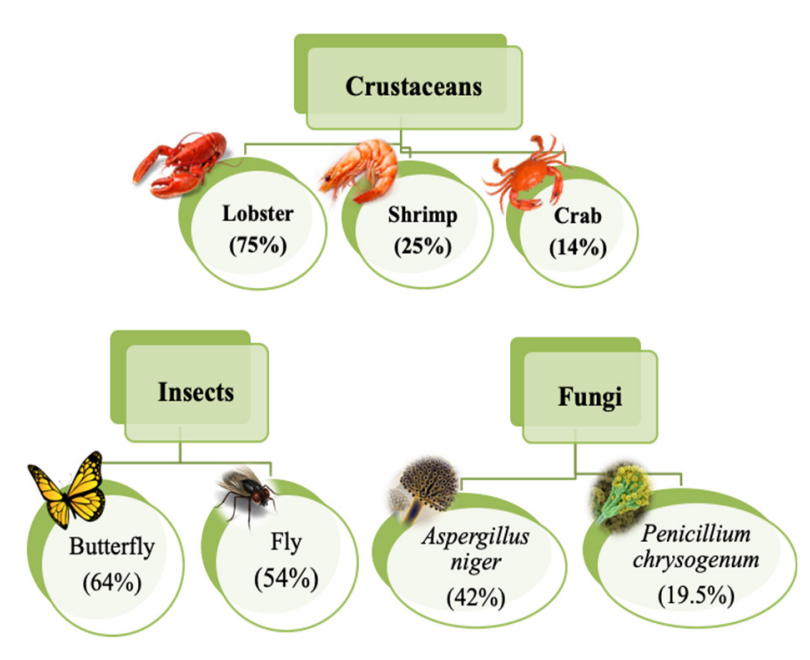

(a)

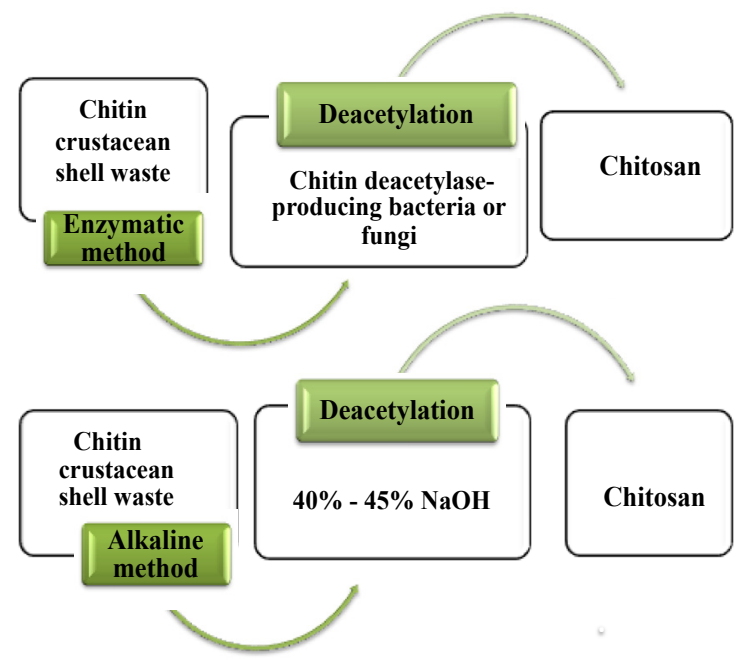

(b)

Figure 1. (a) Examples of chitin content from different sources, (b) Chitin deacetylation methods to produce chitosan.

\subsubsection{Enzymatic Methods}

The first step in the production of chitosan is the extraction of chitin from the seafood waste and this can be achieved using both biological and chemical approaches. The biological process involves the use of bacteria, that produce organic acids, and enzymes for the demineralisation and deproteinisation of crustacean shells [35]. In the demineralisation step, the lactic acid produced by bacteria reacts with the calcium carbonate component in the crustacean biomass waste resulting in the formation of calcium lactate, which can be precipitated and removed by washing, while proteases from the bacteria eliminate proteins [35]. Bacillus cereus A21 has shown high activity with both the demineralisation and deproteinisation steps from shrimp shell wastes, $91 \%$ and $80 \%$, respectively [36]. Likewise, the deproteinisation and demineralisation from natural crab shell wastes by Bacillus pumilusA1 were $94 \%$ and $80 \%$, respectively [37]. These results suggest that the chitin production process by the enzymatic method of the seafood wastes could be applicable and become a friendly environmental alternative. 
The deacetylation step that gives rise to the production of chitosan can be promoted by chitin deacetylase. This enzyme was first found in Mucorrouxii (Zygomycetes) in 1974, by Araki and Ito [38]. In 1984, Davis and Bartnicki-Garcia found evidence that changes in the culture medium during the fungi growth phase can directly influence the production of chitosan [39]. The reaction mechanism of the chitin deacetylase from Mucorrouxii is considered as a multipoint attack mode; specifically, the enzyme systematically hydrolyses acetyls from the non-reducing end of the binding site after it binds to a substrate chain, and then leaves the substrate and binds to another one [40]. Strains that produce a large amount of extracellular deacetylase with high activity are very valuable in the production of chitin deacetylase and the production of chitosan. Nevertheless, there are still some problems such as low enzyme activity and low yields of deacetylase-producing strains. Moreover, natural chitins are crystals, not a good substrate for deacetylase. Hence, many preparations still need to be carried out before the chitin deacetylase method can be used in the industrial production of chitosan [41].

Chitin deacetylase-producing bacteria, such as Serritia sp. and Bacillussp, may replace the current fungal strains. This microorganism culture method is another possibility to obtain chitosan, removing the acetyl groups by catalysing the substrate with the enzymes produced by these microorganisms. Moreover, bacteria grow faster than fungi in largescale fermentation processes. Recently, research has concentrated on the breeding of microorganism strains and optimisation of the culture medium. Chitosan formed by this method has shown good ion adsorption capacity [41], making it suitable for environmental applications.

\subsubsection{Alkaline Methods}

The traditional chemical methods to extract chitin from crustacean shell wastes involve three steps: demineralisation, deproteinisation and decolourisation. In the first step, crustacean shells are washed, dried, and grounded to smaller sizes [42]. In order to remove mineral constituents, mainly calcium carbonate, the powdered raw material is treated with dilute hydrochloric acid followed by the precipitation of calcium chloride. Alkali treatment is used for deproteinisation of the demineralised shells. Proteins are eliminated through solubilising with dilute aqueous sodium hydroxide and in the process, N-acetyl groups within the polymer backbone are hydrolysed. The recovery of protein may be obtained by lowering the $\mathrm{pH}$ to about 4.0. An additional decolourisation step can be incorporated when a colourless product is required. Acetone or organic solvent mixtures are used to remove the pigments such as carotenoids [15].

Chitosan is obtained by deacetylation of chitin in $40-45 \%$ sodium hydroxide, as shown in the sketch of Figure 2. The alkaline treatments hydrolyse the acetyl groups and transform the $\mathrm{N}$-acetyl-D-glucosamine units into D-glucosamine units with free $\mathrm{NH}_{2}$ groups [15]. Chitosan, with different degrees of deacetylation, is generated depending on the reaction temperature, time, and concentration of the alkaline solution [43]. An additional purification step can be performed to obtain high purity chitosan. For this, the deacetylated product is dissolved in acid, centrifuged or filtered, and the chitosan is precipitated through the addition of alkali generating pure chitosan (90-95\%) in paste form. These steps can be repeated to obtain higher purity chitosan (purity $>99.9 \%$ ) $[15,23]$. 


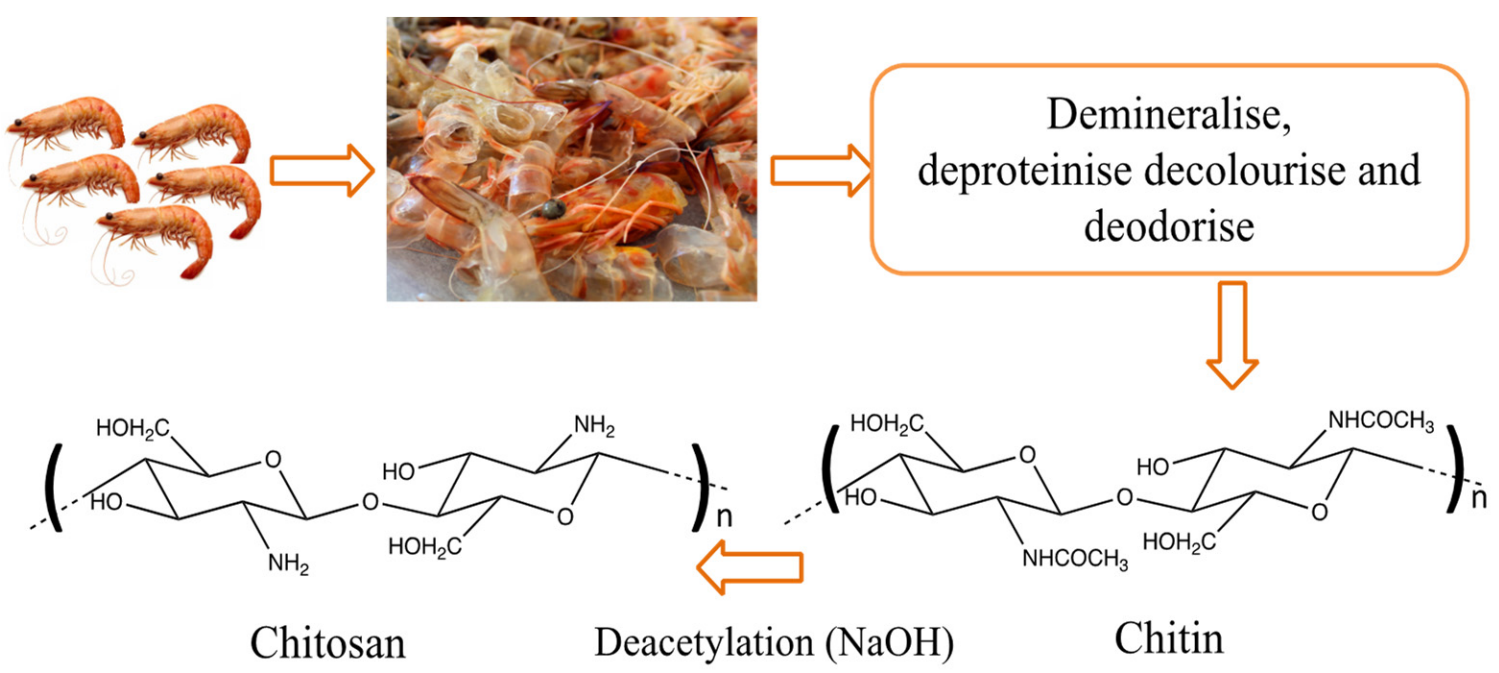

Figure 2. Process of obtaining chitosan by the deacetylation alkaline treatment of chitin from shrimp shell wastes.

The drying of chitosan is an important step in its production. In general, after drying, the desired product should contain a moisture content lower than 10\% (wet basis), to ensure good physicochemical and microbiological aspects during prolonged storage. Polymerisation and Maillard reactions are the main alterations that should be avoided during the drying operation [44]. Chitosan is composed mainly of carbohydrate monomer units that, at high temperatures, are capable of undergoing caramelisation of the polymer. Therefore, in this process, one of the key parameters is temperature [45,46]. Different techniques have been used to obtain good quality dried chitosan, such as spouted bed drying [47], spray drying [48], convective tray drying [49], oven drying and infrared drying [50], lyophilization [51] and low-pressure superheated steam drying [52]. All these techniques have shown that the most important factors are temperature and residence time, which must be controlled to obtain a high-quality product. For example, Dotto et al. [47] have shown that an increase in the temperature (from 90 to 100 and $110{ }^{\circ} \mathrm{C}$ ), using a spouted bed drying technique, causes an increase in powder darkening, an increase in molecular weight (from 147 to $25 \mathrm{kDa}$ ) and increased particle size (from 100 to $200 \mu \mathrm{m}$ ). Hence, the best powder quality was obtained at $90{ }^{\circ} \mathrm{C}$, which resulted in the final humidity content being within the commercial range $(10 \%)$.

\subsection{Structure and Properties}

Chitosan, a partially deacetylated product of chitin, is a biopolymer composed of $\beta-$ (1-4)-D-glucosamine, as shown in Figure 3. This biopolymer is a glycosaminoglycan and consists of two common sugars, $\beta-(1-4)-2$-acetamido-D-glucose and $\beta-(1-4)-2-a m i n o-$ D-glucose, glucosamine, and $N$-acetylglucosamin, respectively. The proportion of each depends on the alkaline treatment, and usually deviates from an equal contribution. In terms of structure, chitosan is analogous to cellulose, in which the hydroxyl (in cellulose) has been replaced by acetamido or amino groups (in chitosan) at carbon-2 [53]. Thus, unlike other polysaccharides abundant in carbon, oxygen, and hydrogen; chitin and chitosan contain additional nitrogen (6.89\%), making them interesting commercially [54]. 


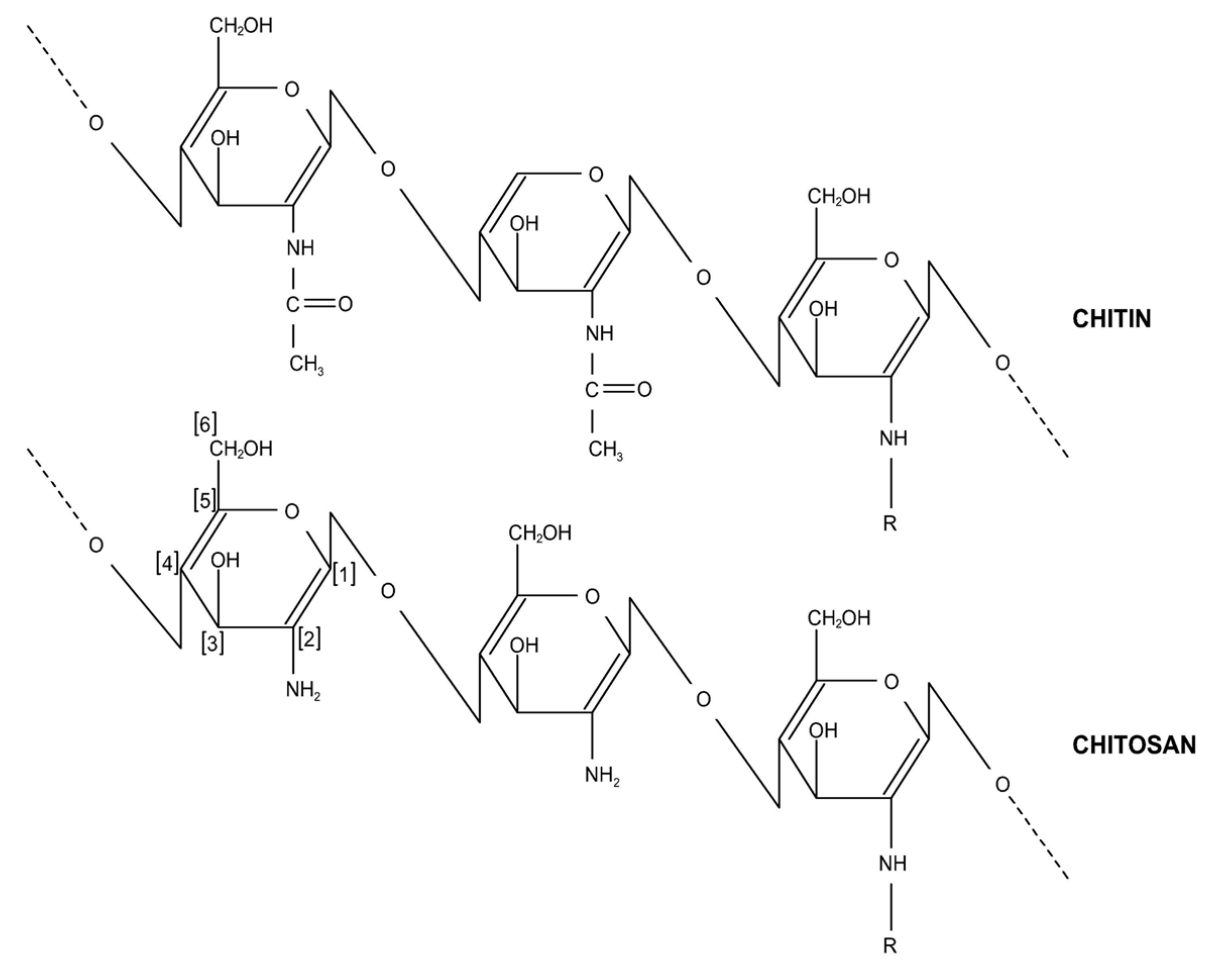

Figure 3. Chemical structure of chitin and chitosan.

The physicochemical properties of chitin and chitosan strongly depend on molecular chain orientation and regular packing. The abundance of hydroxyl groups and highly reactive amino groups in chitosan or its $\mathrm{N}$-acetyl counterpart with a strong tendency for intra- and inter-molecular hydrogen bonding, results in the formation of linear aggregates and rigid crystalline domains. However, chitosan is usually less crystalline than chitin, which presumably makes chitosan more accessible to reagents and, consequently, more soluble. Most of the aqueous acids dissolve chitosan whereas chitin is soluble in very few solvents. The protonation of amino groups by acids along the chitosan chain creates a multitude of cationic sites, which increases its solubility by increasing the polarity. This unique property expands the potential applications of chitosan, including its ability to adsorb different pollutants. Amine groups, for example, are strongly attracted to metal ions due to the lone pair of electrons on the nitrogen atoms $[55,56]$. The protonation of these amine groups may lead to the electrostatic attraction of anionic compounds, such as anionic dyes [57] and halogens [58]. Moreover, the existence of these free $-\mathrm{NH}_{2}$ and $-\mathrm{OH}$ active groups allows the adsorption of other pollutants, such as, phenol [59,60], antibiotics [61,62] and pesticides [63]. Hence, the chitosan adsorption capacity depends on its crystallinity, affinity to water, and deacetylation percentage [64].

The main properties of chitosan are summarised in Table 1. Some of the intrinsic properties of chitosan, such as its polycationic character in acid media, its ability to form hydrogen bonds, van der Walls and electrostatic interactions, make it an efficient adsorbent material. Other characteristics, such as the degree of deacetylation (DD), crystallinity, molecular weight (MW), solubility, surface area and particle size will all influence the properties of the final chitosan-based material and its adsorption potential [23]. Therefore, these properties and their optimisation are central in the formation of efficient adsorbent materials. 
Table 1. Main chitosan properties, according to the information reported in $[13,27]$.

\begin{tabular}{|c|c|}
\hline Physicochemical properties & $\begin{array}{l}\text { - } \text { Linear aminopolysaccharide with a high nitrogen } \\
\text { content } \\
\text { - } \quad \text { Ionic conductive } \\
\text { - } \quad \text { Cationic biopolymer with high charge density } \\
\text { - } \quad \text { Flocculating agent } \\
\text { - } \quad \text { Existence of reactive groups for chemical activation } \\
\text { - } \text { and cross-linking } \\
\text { - } \quad \text { pKa varies from } 6.5 \text { and } 6.7 \\
\text { - } \\
\text { Enable to form intermolecular hydrogen bonds }\end{array}$ \\
\hline Biological properties & $\begin{array}{ll}\text { - } & \text { Bioadhesivity } \\
\text { - } & \text { Non-toxic } \\
\text { - } & \text { Bioactivity } \\
\text { - } & \text { Adsorbable } \\
\text { - } & \text { Biodegradable } \\
\text { - } & \text { Antimicrobial activity } \\
\text { - } & \text { Antiacid, antiulcer and antitumoral properties } \\
\text { - } & \text { Hypolipidermic activity }\end{array}$ \\
\hline
\end{tabular}

\subsubsection{Deacetylation Degree}

The deacetylation degree (DD) of chitosan is one of the most important parameters as it defines the acetyl content in the biopolymer and it can be increased by repeating or prolonging the alkaline treatment step in the chitin deacetylation process [15]. It can be easily determined using several analytical tools, including UV spectrophotometry [65], X-ray diffraction [66], FTIR-spectroscopy [67,68] and titration methods [69-71]. Increases in DD lead to an increase in the number of free amino groups on the chitosan polymeric chain. These amino groups are responsible for differences in the physicochemical properties and structure of chitosan, due to intra- and inter-molecular hydrogen bonds. As a consequence, the chitosan solubility and polycationic character are increased, expanding the applications of chitosan [72].

The control and manipulation of the physicochemical properties of chitosan, such as the mechanical properties, crystallinity, swelling and thermal degradation, have been shown to correlate with the distribution of the acetyl groups along the main chain $[73,74]$. With an increase in the DD, the charge density along the chain increases and the chitosan chain becomes more flexible, tending to form a random coil with more inter- and intramolecular hydrogen bonds within the chain. In Table 2, the influence of DD on the physicochemical properties is shown, where it is seen that the DD \% has a significant impact. 
Table 2. Influence of deacetylation degree (DD) on physicochemical properties of chitosan in different forms.

\begin{tabular}{|c|c|c|c|c|}
\hline Form & DD (\%) & Properties & Results & Ref. \\
\hline Films & $82,80-85,100$ & $\begin{array}{l}\text { Crystallinity, tensile strength, \% } \\
\text { elongation, swelling index }\end{array}$ & $\begin{array}{c}\text { Crystallinity and tensile strength increased, while \% elongation and swelling index } \\
\text { decreased with increase in DD (highest MW) }\end{array}$ & [75] \\
\hline Powder & $76-92$ & Thermal degradation & Thermal stability decreased with increase in DD & [76] \\
\hline Microspheres & $48,62,75$ & Swelling index & Swelling index increased with increase in DD & [78] \\
\hline Membranes & $75,87,96$ & $\begin{array}{l}\text { Crystallinity, swelling index, tensile } \\
\text { strength, \% elongation }\end{array}$ & $\begin{array}{c}87 \% \text { DD presented lower crystallinity and mechanical properties, but higher } \\
\text { swelling index than } 75 \% \text { or } 96 \% \text { DD }\end{array}$ & [79] \\
\hline Nanofibers & $59,76,85$ & Thermal degradation & Thermal stability decreased with increase in DD & [80] \\
\hline Films & $15-70$ & Tensile strength, \% elongation & Tensile strength, and \% elongation increased with increase in DD & [81] \\
\hline Sponge & $58,73,82,88,91$ & Swelling index, tensile strength & Swelling index increased and tensile strength decreased with increase in DD & [82] \\
\hline Films & $72-85$ & $\begin{array}{l}\text { Crystallinity, tensile strength, } \% \\
\text { elongation, degradation rate }\end{array}$ & $\begin{array}{l}\text { Crystallinity increased and tensile strength decreased with increase in DD, \% } \\
\text { elongation decreased when the DD was increased from } 72 \% \text { to } 75 \% \text { and decreased } \\
\text { when it increased from } 75 \% \text { to } 85 \% \text {. No difference in degradation rates }\end{array}$ & [83] \\
\hline Beads & $83,94,96$ & Tensile strength, thermal degradation & Tensile strength, thermal stability increased with increased in DD & [84] \\
\hline
\end{tabular}


In most cases, an increase in DD was shown to result in an increase in tensile strength and crystallinity and a decrease in the percentage of elongation of the materials. This effect of increasing tensile strength with increasing DD is usually attributed to an increase in crystallinity of the chitosan. Chitosan chains with higher DD have fewer acetyl side groups leading to a more efficient and regular packing of the polymer chains, which in turn, promotes crystallinity in the chitosan $[77,85,86]$. On the other hand, chitosan with lower DD presents more acetyl side groups that prevent regular packing of the chains due to steric hindrances leading to a reduced crystalline or an amorphous structure $[77,86]$. Despite the improved tensile strength and stiffness of the chitosan which is observed on increasing the crystallinity this also leads to an increase in the brittleness and a decrease in the percentage of elongation [86]. For example, Zhuang et al. [86] evaluated chitosan films with different DD $(81.0 \%, 88.1 \%$ and $95.2 \%)$. They reported that the tensile strengths of chitosan films increased from 28.86 to $32.96 \mathrm{MPa}$ and the elongation decreased from $54.31 \%$ to $41.66 \%$ as DD increased from $81.0 \%$ to $95.2 \%$. In applications where film-formation properties of chitosan are important, chitosan with improved tensile strength is an advantage [81,87]. Liu et al. [88] developed composite films of gelatin and chitosan of different MW and $\mathrm{DD}$, and evaluated the interactions between the two polymers in order to improve the films produced. It was verified that the tensile strengths of gelatine films were improved, especially when using chitosan of higher DD and MW. On the other hand, Moura et al. [89] reported a decrease in tensile strength and in elongation of chitosan films with increasing DD, while Nunthanide et al. [75] found both an increase and decrease in tensile strength and elongation, depending on the molecular weight, on increasing DD. These studies which account for the role of MW in the observed results are interesting and highlight the role of both MW and DD.

DD also influences the swelling and thermal degradation characteristics of chitosan $[77,78,90,91]$. These studies have shown that chitosan with higher DD exhibits faster thermal degradation rates and reduced swelling, as compared to lower DD chitosan. These characteristics may also depend on crystallinity. Chitosan with higher DD and crystallinity are expected to have a close-packed microstructure, which limits water permeation and thus reduced swelling [77]. Moreover, a decrease in the N-acetyl content results in a decrease in the thermal stability as the $\mathrm{N}$-acetyl domains are more thermally stable than the deacetylated ones [92]. Khoulenjani et al. [90], in using chitosan with different DDs (56\%, 64\% and 74\%), showed that the swelling index decreased from $216 \%$ to $115 \%$ with an increase in DD from $56 \%$ to $74 \%$. Nunthanide et al. [75] also reported that the films become more brittle with a lower swelling index with an increase in DD. Wanjun et al. [93] verified that an increase in DD resulted in a decrease in the thermal stability of chitosan due to the decreased acetyl content. This relationship between thermal effects and the DD of chitosan has also been confirmed by Kittur et al. [76]. In another study, Tavares et al. [84] demonstrated that the DD of chitosan had a positive influence on the thermal degradation behaviour. They prepared genipin-crosslinked chitosan beads and evaluated the effect of the chitosan DD $(83 \%, 94 \%$ and $96 \%)$ on their characteristics. It was verified that the chemical interactions between chitosan and genipin result in a material more thermally stable, especially when a higher chitosan DD (96\%) was used. This behaviour was attributed to the decrease in the hydrophilic groups available to form hydrogen bonds with water molecules, resulting in a material more thermally stable.

However, the highly hydrophilic character of chitosan with high DD might be a disadvantage for its surface modification and hence limit the development of chitosanbased materials. Iamsamai et al. [94] have shown that the DD of chitosan plays a critical role in the dispersion of multiwall carbon nanotubes (MWCNTs) and their stability. They confirmed that the chitosan surface coverage on the MWCNTs was twice as high when modifying the surface of the nanotubes with the $61 \%$ DD than when using the $93 \%$ DD chitosan; suggesting that the dispersion of MWCNTs with chitosan might be improved when using chitosan having a lower DD level. 
In addition to the above properties, DD also affects the adsorption properties of chitosan-based materials, since it is linked directly to its cationic properties. Piccin et al. [95] studied the adsorption of FD\&C Red 40 dye by chitosan powder with different deacetylation degrees. It was shown that an increase in the DD from $42 \%$ to $84 \%$ caused an increase in the adsorption capacity from 266 to $373 \mathrm{mg} \mathrm{g}^{-1}$. Habiba et al. [96] prepared a chitosan/polyvinyl alcohol/ $\mathrm{TiO}_{2}$ composite with different $\mathrm{DD}$ for methyl orange adsorption. They have shown that the adsorption capacity was higher for the composite containing chitosan with higher DD. Furthermore, the composite containing chitosan with higher DD was more reusable and stable with good adsorption capacity even after 15 regenerations. Józwiaket al. [97] have developed chitosan adsorbents with different forms (flakes and hydrogel granules) and different DD (75\%, 85\% and 90\%) to remove Reactive Black 5 (RB5) from aqueous solutions. The highest adsorption capacity $\left(1559.7 \mathrm{mg} \mathrm{g}^{-1}\right)$ was obtained for the chitosan-hydrogel granules formed with $90 \% \mathrm{DD}$. Chitosan hydrogel granules reached up to $224 \%$ higher adsorption capacity $\left(q_{D D 75 \%}=1307.5 \mathrm{mg} \mathrm{g}^{-1}\right)$ than chitosan in the form of flakes ( $\mathrm{qDD}_{\mathrm{D}} \%=403.4 \mathrm{mg} \mathrm{g}^{-1}$ ), which indicated that the chitosan form is also important to the adsorption operation. Besides, the DD of chitosan had a particularly large impact on the RB5 adsorption effectiveness of chitosan in the form of flakes. The adsorption on the flakes with a $90 \%$ DD was $1049.6 \mathrm{mg} \mathrm{g}^{-1}$ and was higher by $260 \%$ than on the flakes with $75 \%$ DD. All the authors of these studies concluded that the DD had influenced the physicochemical properties as well as the interactions of chitosan with the pollutants in the adsorption process. Therefore, DD is a major factor in matching chitosan to other materials to develop potential adsorbent materials [98].

\subsubsection{Molecular Weight}

The molecular weight (MW) of chitosan is a characteristic associated with the number of monomeric units per polymer molecule (n). The deacetylation process brings about a change in MW and depending on the source and preparation procedure, the average MW of chitosan may range from 50 to $2000 \mathrm{kDa}$ [99]. The MW of chitosan can be measured by light scattering, high-performance liquid chromatography (HPLC) and viscosimetric methods [23]. Chitosan can be classified as low molecular weight (LMW), medium molecular weight (MMW) and high molecular weight (HMW) [99]. Generally, the MW of chitosan can be modified by using depolymerisation techniques where the high MW chitosan is converted to a lower MW. These MW modifications are important as they can preserve the integral structure of chitosan $[99,100]$.

The control, evaluation and modifications of this characteristic are fundamental since MW affects many of the physicochemical properties, including solubility, viscosity, crystallinity, tensile strength, adsorption and elasticity. Consequently, MW has a significant effect on the applications of chitosan. Zhou et al. [73] prepared hydrogels with different MW of chitosan and verified that the viscosity of the hydrogels increased with MW, increasing from 88 to $1360 \mathrm{kDa}$ at $37^{\circ} \mathrm{C}$. Moreover, the increase of MW was favourable for sol-to-gel transition and high molecular chitosan was optimal for hydrogel preparation. In Table 3, the various molecular weights employed in chitosan-based materials are summarised. In all cases, the MW is a key factor that influences the tensile strength (TS) and elongation-at-break (EB) properties, as well as the different physical forms of chitosan.

Zhong et al. [101] studied the effect of MW on the properties of chitosan films and found that the conductivity, viscosity, surface tension, and crystallinity of the chitosan film were raised with increasing MW due to an increase in the proportion of amine-groups and degrees of chitosan chain entanglements. Moura et al. [89] verified that the tensile strength, elongation-at-break and water barrier properties of chitosan films were improved with an increase in MW. On the other hand, Ziani et al. [102] showed that the low MW films exhibited greater tensile strengths and percentage of elongation compared to the high MW films despite the high DD of the low MW chitosan. In this study, they verified that the MW had more influence on the mechanical properties than DD. These characteristics were attributed to the number of hetero-monomers, which form stronger films than the 
character of the acetylated or deacetylated monomers. In general, according to Tables 2 and 3, several studies have demonstrated that DD and MW can be used to manipulate the physical-mechanical and the thermal degradation properties of chitosan materials. However, these studies also highlight that there is a significant and complex interaction between DD and MW and this interaction can lead to conflicting results, e.g., tensile strengths have been shown to increase and decrease with an increase in DD, according to the MW, and increasing MW can both increase and decrease the percentage of elongation, depending on DD. It is also noted that the type or mode of fabrication of the chitosan (e.g., films, gels, membranes, etc.) may be further influenced by the DD and MW properties.

Table 3. Tensile strength (TS) and elongation-at-break (EB) properties of chitosan-materials with different molecular weight (MW) chitosan.

\begin{tabular}{|c|c|c|c|c|}
\hline Material & Chitosan MW (kDa) & TS (MPa) & EB (\%) & Ref. \\
\hline \multirow{3}{*}{ Chitosan film } & 6.55 & $8.67 \pm 1.72$ & $32.53 \pm 4.78$ & \multirow[t]{3}{*}{ [101] } \\
\hline & 12.93 & $12.05 \pm 2.24$ & $35.52 \pm 6.32$ & \\
\hline & 47.70 & $11.51 \pm 2.25$ & $25.74 \pm 3.69$ & \\
\hline Chitosan coated & 25.00 & $9.70 \pm 1.50$ & $6.7 \pm 1.3$ & \multirow[t]{2}{*}{ [103] } \\
\hline \multirow[t]{2}{*}{ cellulose paper } & 2100 & $13.40 \pm 1.50$ & $6.9 \pm 0.5$ & \\
\hline & 101.0 & $22.30 \pm 0.2$ & $8.7 \pm 0.2$ & \multirow[t]{3}{*}{ [89] } \\
\hline \multirow{2}{*}{ Chitosan film } & 153.6 & $29.50 \pm 0.1$ & $11.4 \pm 0.2$ & \\
\hline & 201.7 & $39.80 \pm 0.1$ & $15.7 \pm 0.2$ & \\
\hline \multirow{3}{*}{$\begin{array}{l}\text { Chitosan-starch } \\
\text { composite film }\end{array}$} & LMW & $5.77 \pm 0.62$ & $9.04 \pm 1.42$ & \multirow[t]{3}{*}[104]{} \\
\hline & MMW & $20.90 \pm 3.52$ & $4.67 \pm 0.58$ & \\
\hline & HMW & $22.30 \pm 2.21$ & $9.09 \pm 0.42$ & \\
\hline
\end{tabular}

\subsubsection{Solubility}

The solubility of chitosan is a fundamental property that is particularly important in the fabrication of chitosan-based materials $[17,26,105]$. The main factors that affect this property are DD and MW. It is known that due to the high degree of acetylation, chitin is hydrophobic making it insoluble in water and most organic solvents, decreasing its applications [13]. On the other hand, with higher DD levels, more amino groups in the molecular chain become protonated to give higher degrees of solubility [106,107]. However, an increase in the MW brings about an increase in the intra- and inter-molecular hydrogen bonds within the chains, giving rise to entanglement of the chains and a reduction in solubility [108].Chitosan is soluble in weak acids but insoluble above a $\mathrm{pH}$ of 7 . The $\mathrm{pH}$ has a significant influence on the charged state and properties of chitosan due to the presence of the amino groups [74]. At low $\mathrm{pH}$, the amino groups of chitosan are protonated and become positively charged which leads to a soluble cationic polyelectrolyte. However, as the $\mathrm{pH}$ increases to above 6 , the amino groups of chitosan are deprotonated, the biopolymer loses its charge, and this gives an insoluble structure. The soluble-insoluble transition occurs at about a $\mathrm{pH}$ of 6.5 (pKa of the amino group). This characteristic makes chitosan a cationic polyelectrolyte $(\mathrm{pKa} \approx 6.5)$, one of the few found in nature [19,27].

In addition to the properties mentioned previously, solubility depends also on the type of acid used [13]. Formic acid is one of the best solvents when aqueous solutions of chitosan are required and the formic acid concentrations can range from $0.2-100 \%$ [14]. Acetic acid (1\%) has been the most used solvent for the solubilisation of chitosan [13]. However, acetic acid solutions with high concentrations and at elevated temperatures can give rise to the depolymerisation of chitosan [109]. Rinaudo et al. [109,110] observed that for acetic and hydrochloric acid, the chitosan solubility was entirely related to the $\mathrm{pH}$ and to the ionic strength, while Kurita et al. [111] verified that it was dependent on chain flexibility, degree of ionisation, crystallinity, solvation of the chain, and the presence of acetyl-glucosamine blocks. Shamov et al. [112] have observed that chitosan solubility is also influenced by interactions between the hydrocarbon chains of the carboxylic acids. There are many other factors that have vital effects on chitosan solubility. These factors can 
include alkali concentration, temperature, time of deacetylation, prior treatments applied to chitin isolation, particle size, etc. [113]. In addition, these studies also highlight that solubility in acidic solution imparts the chitosan with excellent gel-forming properties and can expand the potential applications of chitosan-composite materials.

\subsubsection{Surface Area and Particle Size}

Chitosan surface area and particle size are important characteristics which are related to the porosity, pore volume and pore size distribution of the chitosan. Surface area and particle size are fundamental for adsorption applications, since accessible sites and a porous structure are required [114,115]. It is known that chitosan powders or flakes are non-porous materials which present a low surface area (lower than $10 \mathrm{~m}^{2} \mathrm{~g}^{-1}$ ) [23]. Thus, chemical and physical modifications of chitosan have been performed to increase the surface area and improve potential applications [17,27,58,59,116,117]. Phongying et al. [118] obtained chitosan directly from chitin and prepared chitosan nanoscaffolds in order to improve the surface area, particle size and pore volume. They verified that the surface area of their chitosan scaffolds $\left(55.75 \mathrm{~m}^{2} \mathrm{~g}^{-1}\right)$ was approximately seven times higher than the commercial chitosan flakes $\left(7.70 \mathrm{~m}^{2} \mathrm{~g}^{-1}\right)$. Moreover, the pore volume and pore size of the chitosan nanoscaffolds were higher. Esquerdo et al. [119] developed chitosan scaffolds and verified that the new material had a specific surface area, porosity and pore volume of $1135 \mathrm{~m}^{2} \mathrm{~g}^{-1}, 92.2 \%$ and $0.0079 \mathrm{~m}^{3} \mathrm{~kg}^{-1}$, respectively. These values are higher that other chitosan-based materials, such as chitosan powders (surface area of $4.2 \mathrm{~m}^{2} \mathrm{~g}^{-1}$ and pore volume of $9.5 \times 10^{-6} \mathrm{~m}^{3} \mathrm{~kg}^{-1}$ ) [120], chitosan flakes (surface area range of $4-6 \mathrm{~m}^{2} \mathrm{~g}^{-1}$ ), chitosan beads (surface area range of 30-40 $\mathrm{m}^{2} \mathrm{~g}^{-1}$ ) [121], chitosan hydrogel beads (porosity of $85 \%$ ) [122], and chitosan-graphene mesostructures (surface area of $603.2 \mathrm{~m}^{2} \mathrm{~g}^{-1}$ ) [123]. These studies confirm that modification of chitosan leads to an improvement in the surface area and, consequently, in the porosity and pore volume.

Moreover, the particle size of the adsorbents has a significant effect on the final solute concentration, and hence on the overall performance of the adsorption process. Larger particle sizes reduce the uptake due to the lower specific surface area. Thus, an increase in surface area of adsorbent results in new active sites formed, thus allowing more binding of solute molecules [124]. Piccin et al. [120] investigated the effects of particle size, surface area and pore volume of chitosan on the adsorption of FD\&C Red 40. The particle sizes used were $0.10,0.18$ and $0.26 \mathrm{~mm}$, with surface areas of $4.2,3.4$ and $1.6 \mathrm{~m}^{2} \mathrm{~g}^{-1}$, respectively. The results showed that an increase in the surface area and a decrease in particle size doubled the adsorption capacity. Dotto et al. [57] evaluated chitin and chitosan as adsorbents for tartrazine dye. They verified that chitosan showed better adsorbent properties than chitin due to its higher deacetylation degree and higher surface area, pore volume and pore size. These characteristics are particularly important for adsorption applications because it provides access to large pollutant molecules, enabling them to reach the internal adsorption sites.

\section{Chitosan Supports}

Although chitosan is an effective adsorbent for a variety of pollutants (as illustrated in Section 2), it nevertheless suffers from poor mechanical properties and thermal stability combined with a relatively low surface area. Therefore, it is not surprising that it has been modified with a variety of other additives to form composites or hybrids. These additives include cellulose [125,126], starch [127], other biopolymers such as alginate [128], gelatin [129], clays, such as bentonite [130], zeolites [131], metal organic frameworks (MOFs) [132], conducting polymers, such as polypyrrole [133] and other polymeric systems comprising methacrylamide [134],polyacrylamide [135], polyurethane [136], poly(vinyl alcohol) [137] and lignosulfonate [138]. These additives are interesting because they can form interpenetrated polymers with chitosan. 


\subsection{Chitosan Combined with Carbon-Based Materials}

In more recent times, there has been considerable interest in combining chitosan (CS) with carbon-based materials as many carbon-based materials have very good adsorption qualities and these materials can also be employed to enhance the surface area of the adsorbents. Shown in Figure 4 is a summary of the number of papers published in 2019 and 2020 that have employed chitosan combined with various carbon-based materials as adsorbents. It is clearly evident from this analysis that it is graphene and especially graphene oxide (GO) that is dominating the carbon-based materials, with a somewhat lower number of papers describing the use of activated carbon. In the following sections, these CS/carbon-based materials are introduced, highlighting their properties and abilities to facilitate adsorption.

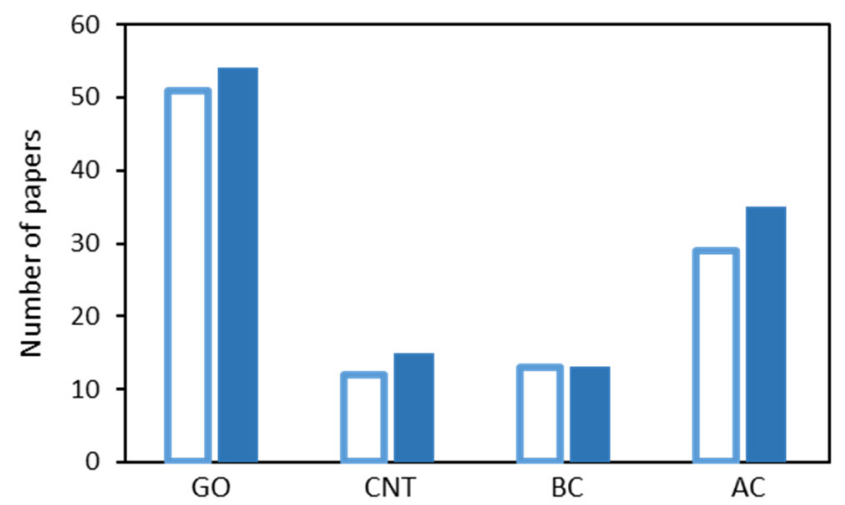

Figure 4. Number of papers published in 2019 (open) and 2020 (solid) focussed on various CS/carbonbased materials, where the carbon materials are graphene oxide (GO), carbon nanotubes (CNT), biochar (BC) and activated carbon (AC). All data taken from Scopus.

\subsubsection{Chitosan/Graphene Composites}

Since its discovery, graphene has been used in a wide variety of applications, ranging from sensors [139], batteries [140], electro-Fenton [141] to electronics [142]. It has also been recognised as an adsorbent material, as it possesses a large surface area and there is considerable evidence to show that $\pi-\pi$ interactions occur between the aromatic rings of various organic pollutants and the basal planes of graphene [143]. These $\pi-\pi$ interactions occur between aromatic pollutants and pristine graphene, but fortunately graphene oxide, which is considerably easier to synthesise and is more cost effective, is an especially promising adsorbent [144]. GO contains a number of oxygen containing functional groups, such as epoxides $(\mathrm{C}-\mathrm{O}-\mathrm{C})$, hydroxyl $(-\mathrm{OH})$, carboxylic $(-\mathrm{COOH})$ and carbonyl groups $(>\mathrm{C}=\mathrm{O})$ [145], while other oxygen containing groups, such as ketones and quinones, have also been detected [146]. These functional groups can facilitate the binding of positively charged molecules through electrostatic interactions [147]. Indeed, numerous studies have demonstrated the excellent ability of GO to adsorb various planar aromatic molecules, such as dyes, through a combination of $\pi-\pi$ stacking, electrostatic interaction and hydrogen bonding $[148,149]$.

Graphene oxide (GO) is normally synthesised by oxidising graphite using the wellknown modified Hummers method [150]. The interlayer spacing increases as the graphite is oxidised to give GO sheets that can be exfoliated through a relatively simple liquid-phase exfoliation and/or ultrasonication. The GO sheets are stable in colloidal solutions and are easily combined with chitosan to give CS/GO composites. Typically, the chitosan is dissolved in acetic acid and the GO is added to form a homogeneous mixture. The CS/GO hydrogel can be easily formed, by a combination of violent shaking and sonication [144], adding $\mathrm{NaOH}$ [151], freeze drying [152], or by employing solvothermal reactions [153]. Chitosan is a positively charged polysaccharide at near neutral $\mathrm{pH}$ due to protonation of the amino groups and therefore it attracts the negatively charged GO sheets. These electrostatic interactions combined with hydrogen bonding facilitates the formation of 
the CS/GO hydrogel to give stable composites with excellent thermal and mechanical properties [154], as illustrated in the schematic provided in Figure 5. Indeed, it has been shown by Fan et al. [155] using FTIR measurements, that the -NH groups on the chitosan chains react with the $-\mathrm{COOH}$ groups of $\mathrm{GO}$ to form a linking - NHCO- group. Using these approaches, CS/GO composites have been formed as beads [156], membranes [157,158] and columns $[144,159]$ and employed successfully as adsorbents for the removal of pollutants from aqueous media.

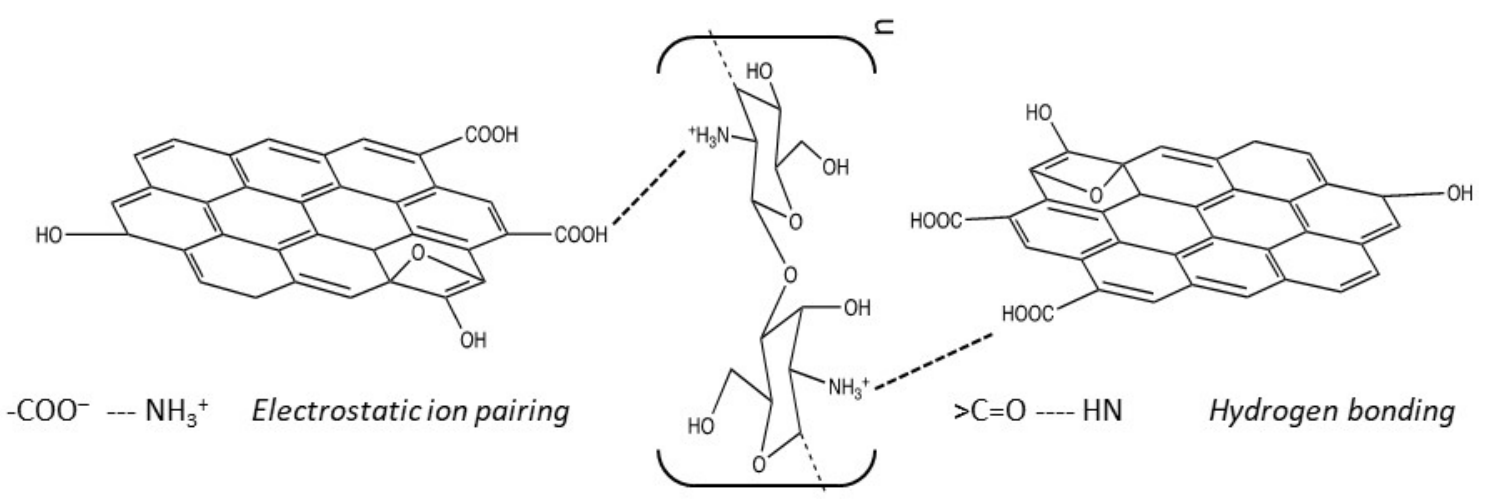

Figure 5. Schematic representation of the interactions between chitosan and GO.

Several studies have been reported using CS/GO composites and these hydrogels have been employed to adsorb and remove various dyes from water [160], heavy metal ions [161], phenolic compounds [162] and pharmaceutical and personal care products [163]. In more recent years, other components have been added in an attempt to further enhance the adsorption capacity of the CS/GO composites, while three-dimensional GO and graphene based aerogels have also been developed and these are now described in turn.

\section{Magnetic Chitosan/GO}

Magnetic chitosan has emerged as an exciting new material in environmental applications and recently there has been much interest in the applications of magnetic CS/GO [164,165]. The introduction of magnetism facilitates the separation of the adsorbent from the aqueous medium through a simple magnetic process [166]. It is normally difficult to separate chitosan-based adsorbents, and indeed other adsorbents, from aqueous environments through conventional filtration and sedimentation techniques, as these adsorbents can block filters and are often lost, contributing to secondary pollution. The $\mathrm{Fe}_{3} \mathrm{O}_{4}$, a ferromagnetic black iron oxide, is the most widely employed, as it possesses good compatibility, low toxicity and also has high magnetic properties [167]. Furthermore, it contains both $\mathrm{Fe}(\mathrm{II})$ and $\mathrm{Fe}(\mathrm{III})$, and with the presence of $\mathrm{Fe}(\mathrm{II})$, which has the potential to act as an electron donor, oxidation of the pollutants can be achieved. $\mathrm{Fe}_{3} \mathrm{O}_{4}$ can also be formed as rods, spheres, wires and nanoparticles and these can be combined with CS/GO. There has also been a report where $\mathrm{FeO}(\mathrm{OH})$ was utilised with CS/GO [168], while $\gamma-\mathrm{Fe}_{2} \mathrm{O}_{3}$ has been combined with chitosan and employed as a magnetic adsorbent [169].

Magnetic CS/GO can be easily formed through both in-situ [170] and ex-situ methods [171] and variations of these two approaches. The $\mathrm{GO} / \mathrm{Fe}_{3} \mathrm{O}_{4}$ can be initially formed before being combined with chitosan [172], or the $\mathrm{CS} / \mathrm{Fe}_{3} \mathrm{O}_{4}$ can be firstly formed [173]. For example, Singh et al. [165] used the reactions between the carboxyl and epoxy groups on GO and the amine groups on chitosan to form amide and hydroxyl functionalised groups that facilitated the conversion of the iron ions to the iron oxide, enabling the in-situ preparation of the magnetic CS/GO. Alternatively, the $\mathrm{Fe}_{3} \mathrm{O}_{4}$ nanoparticles can be initially synthesised using simple methods, such as co-precipitation using ferric and ferrous salts, as illustrated in the schematic provided in Figure 6a. The $\mathrm{Fe}_{3} \mathrm{O}_{4}$ nanoparticles are then combined with the CS/GO hydrogel [174]. Using these approaches, Tran et al. [175] showed that a large number of the $\mathrm{Fe}_{3} \mathrm{O}_{4}$ nanoparticles were immobilised onto the GO 
sheets, Figure 6b, while Rebekah et al. [164] also concluded that the $\mathrm{Fe}_{3} \mathrm{O}_{4}$ nanoparticles became attached to the edges and basal planes of GO.

(a)

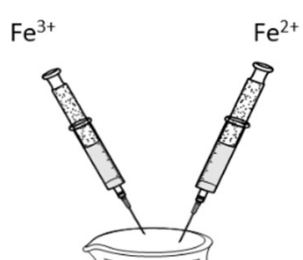

$\mathrm{Fe}^{2+}$

Base
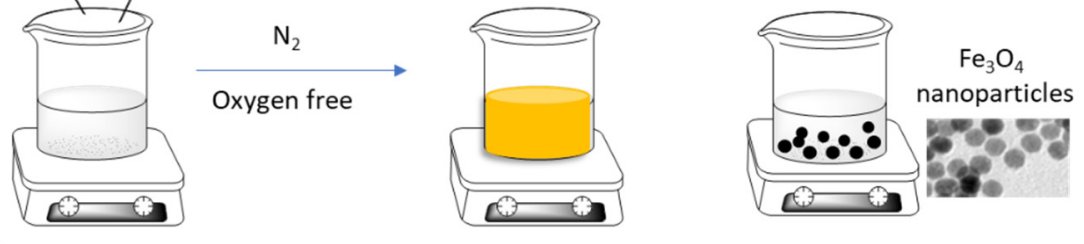

(b)
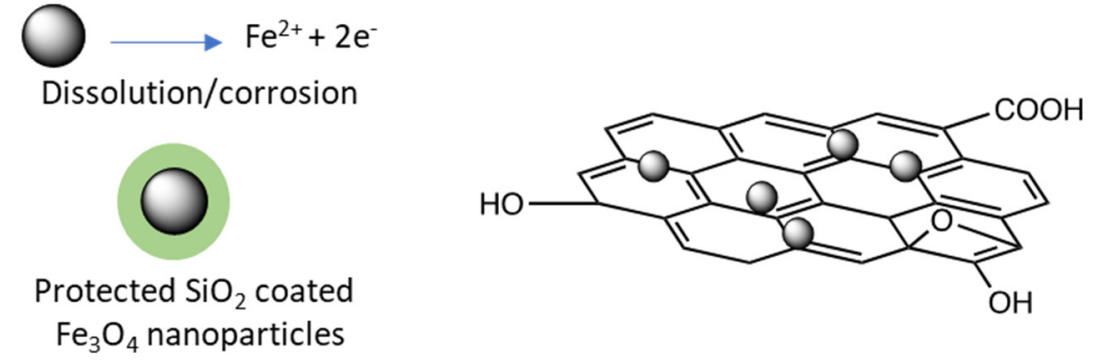

Figure 6. (a) Schematic representation of the co-precipitation method used to prepare $\mathrm{Fe}_{3} \mathrm{O}_{4}(\mathbf{b}) \mathrm{SiO}_{2}$ coated $\mathrm{Fe}_{3} \mathrm{O}_{4}$ nanoparticles deposited and dispersed on GO.

The dispersion and aggregation, size dispersion and shape of the $\mathrm{Fe}_{3} \mathrm{O}_{4}$ nanoparticles within the hydrogels are all important characteristics in terms of their performance as adsorbents. In general, the $\mathrm{Fe}_{3} \mathrm{O}_{4}$ nanoparticles appear aggregated, due to their magnetic nature [173]. Some authors have estimated the particle sizes or have observed some isolated particles among the clusters. Spherical $\mathrm{Fe}_{3} \mathrm{O}_{4}$ clustered particles were observed by Gul et al. [167] with some isolated particles of approximately $90 \mathrm{~nm}$. Shafaati et al. [176] have prepared spherical $\mathrm{Fe}_{3} \mathrm{O}_{4}$ particles with an average size of $45 \mathrm{~nm}$ with evidence of some agglomeration, but when they were combined with chitosan an increase in the particle size was observed, indicating more extensive agglomeration during the reaction with chitosan or as the authors suggested, the chitosan polymer chains may provide links between the neighbouring $\mathrm{Fe}_{3} \mathrm{O}_{4}$ particles. Again, Jiang et al. [177] have shown that the $\mathrm{Fe}_{3} \mathrm{O}_{4}$ particles can become severely aggregated, but when the $\mathrm{Fe}_{3} \mathrm{O}_{4}$ particles were coated with silica the aggregation was markedly reduced. TEM micrographs indicated that the GO sheets were decorated with the silica coated $\mathrm{Fe}_{3} \mathrm{O}_{4}$ particles with the more wrinkled GO sheets providing more adsorption sites for the particles. A similar finding, highlighting the role of silica in reducing aggregation of the $\mathrm{Fe}_{3} \mathrm{O}_{4}$ particles, was reported by Tang et al. [178]. This reduction in the aggregation was attributed to a decrease in the dipole-dipole interactions between the silica modified $\mathrm{Fe}_{3} \mathrm{O}_{4}$ nanoparticles. Furthermore, the inert silica coating layers can protect the magnetic cores as the $\mathrm{Fe}_{3} \mathrm{O}_{4}$ particles are susceptible to dissolution and corrosion in acidic solutions, which lead to the loss of magnetism [179], as illustrated in Figure 6b.

\section{Chitosan/rGO}

While GO is the main form of graphene employed with chitosan, there is also evidence to show that reduced $\mathrm{GO}$, designated as $\mathrm{rGO}$, can be employed to give $\mathrm{CS} / \mathrm{rGO}$ hydrogel adsorbent materials. The rGO is formed through the reduction of GO and this can be achieved using various thermal approaches, where the $\mathrm{GO}$ is heated to high temperatures to transform the oxygen-containing groups to gaseous $\mathrm{CO}$ or $\mathrm{CO}_{2}$ [180], reducing agents, such as borohydride or ascorbic acid [181], or through the electrochemical reduction of GO [182-184]. However, it is very difficult to completely reduce $\mathrm{GO}$ and maintain it in the fully reduced form 
and therefore rGO will always contain some oxygen-containing functional groups. The rGO is considerably more conducting compared to GO, and therefore it can be easily decorated with various metals or metal oxide particles or single atoms. Indeed, Pradeep and co-workers [185] employed the conducting nature and properties of rGO to form well dispersed and uncapped silver, gold, platinum, palladium and manganese oxide decorated rGO, which was then supported within a chitosan hydrogel. The redox reaction between the metal ion precursors and rGO leads to the progressive oxidation of rGO back to GO, providing the metal decorated graphene sheets with functional groups, facilitating its incorporation within chitosan.

$\mathrm{CS} / \mathrm{rGO}$ has also been combined with $\mathrm{Fe}_{3} \mathrm{O}_{4}$ to give magnetic CS/rGO adsorbents and employed to give the effective adsorption of an antibiotic [186] and dyes [187]. While the conducting rGO can be beneficial in depositing well dispersed metal/metal oxide particles through reduction, there is evidence to show that CS/GO composites have a higher adsorption capacity when compared with the reduced GO counterparts. For example, $\mathrm{Gu}$ et al. [188] compared the performance of chitosan combined with GO and rGO in adsorbing and removing a dye from aqueous solutions and found that while adsorption was evident with both systems, the CS/GO was the more efficient adsorbent. This appears to be related to the presence of the functional groups providing a combination of $\pi-\pi$ stacking, electrostatic interaction and hydrogen bonding with the pollutants $[148,149]$.

\section{Chitosan with 3D Graphene, Graphene Aerogels, Foams and Sponges}

Although GO sheets can be well dispersed within chitosan, restacking of these sheets can occur over time to give GO aggregates and this, in turn, will reduce the surface area of the adsorbent, reducing its adsorption capacity. Consequently, there has been increasing interest in using three-dimensional (3D) GO or rGO hierarchical macrostructures for environmental applications $[189,190]$. The 3D GO structures can be fabricated as foams, sponges and as porous or macro-porous aerogels [191] and are based on the bending and wrinkling of the GO sheets to give a low mass density and very high specific surface areas [192]. These 3D materials have the potential to act as scaffolds with very good mechanical strength and a high specific surface area, facilitating adsorption. Moreover, they are easily recovered from the liquid phase following adsorption. However, 3D GO and rGO structures without any other additives can have relatively poor stability in water, but this stability can be enhanced considerably by combining the 3D GO network with biopolymers such as chitosan. Indeed, it was shown by Ma et al. [193], in studying the adsorption and removal of methylene blue, that the GO foam was susceptible to collapse, but its macroscopic morphology could be maintained over three repeated uses when combined with chitin. Similarly, 3D GO combined with high molecular weight chitosan was successfully applied in five repeated cycles of adsorption followed by regeneration, achieving a $90 \%$ adsorption capacity [152]. Very good stability and recyclability was also achieved with layered chitosan/GO sponges, with a regeneration efficiency greater than $80 \%$ over five cycles [194]. A number of CS/aerogel composites have been formed and these have been employed successfully in the removal of $\mathrm{Cu}$ (II) [195], tetracycline [196], azo dyes [197], anionic and cationic dyes [198], hexavalent chromium [199] and 4-nonylphenol [151].

\section{Chitosan/GO with Other Additives}

Other additives have been combined with CS/GO adsorbents and these have included $\beta$-cyclodextrins exploiting the hydrophobic properties of the $\beta$-cyclodextrin to enhance the adsorption of dyes. These $\beta$-cyclodextrin modified CS/GO composite materials have been fabricated and employed to adsorb methylene blue [200]. In this case the authors clearly showed that the extent of adsorption was enhanced on going from GO to $\mathrm{CS} / \mathrm{GO}$ to $\mathrm{CS} / \mathrm{GO} / \beta$-cyclodextrin, illustrating the beneficial effects of incorporating the $\beta$-cyclodextrin. Yan et al. [201] employed a similar CS/GO/ $\beta$-cyclodextrin composite to adsorb $\mathrm{Mn}(\mathrm{II})$, while $\mathrm{Li}$ et al. [202] found that the added $\beta$-cyclodextrin improved the adsorption of $\mathrm{Cr}(\mathrm{VI})$. Similar findings were reported in studying the adsorption of hydroquinone [203] and dye molecules [204]. 
Polypyrrole, a well-known conducting polymer, has also been combined with CS/GO by polymerising the corresponding pyrrole monomer within the CS/GO dispersion. This gives ternary hydrogel composites with a conducting polymer that has the ability to bind anionic and cationic species as dopants and these materials have been shown to give efficient adsorbents $[205,206]$. Moreover these hybrids can be further decorated with magnetic nanoparticles, enabling the removal of the adsorbent from water following the adsorption process [207]. Other polymeric systems that have been combined with CS/GO include polyacrylamide [208] and polyacrylate [209]. These high molecular weight polymers can improve the swelling and adsorption behaviour of the CS/GO hydrogels.

Although chitosan has a number of binding sites for metal ions, some of these are consumed in the crosslinking with the GO sheets. Consequently, additives that have additional binding sites have been added with the aim of enhancing the adsorption capacity. Particularly interesting additives include polydopamine, a mussel adhesive, that is easily formed through the oxidation and polymerisation of dopamine in slightly alkaline solutions [210]. It is a promising adsorbent material [211]. Polydopamine has a high density of amine and catechol groups and the combination of chitosan and polydopamine gives more binding groups and has been used to adsorb $\mathrm{Cr}(\mathrm{VI})$ [212] and $\mathrm{Cu}(\mathrm{II}), \mathrm{Pb}$ (II) and $\mathrm{Cd}(\mathrm{II})$ [213]. Other interesting materials are layered double hydroxides (LDHs) that have the general formula $\left[\mathrm{M}^{2+}{ }_{1-\mathrm{x}} \mathrm{M}^{3+}{ }_{\mathrm{x}}(\mathrm{OH})_{2}\right]^{\mathrm{x}}\left[\left(\mathrm{A}^{\mathrm{n}-}\right)_{\mathrm{x} / \mathrm{n}} \mathrm{mH}_{2} \mathrm{O}\right]$ where $\mathrm{M}^{2+}$ and $\mathrm{M}^{3+}$ are the divalent and trivalent cations, respectively, such as $\mathrm{Fe}^{2+}$ and $\mathrm{Al}^{3+}$, while $\mathrm{A}^{\mathrm{n}-1}$ represents the intercalating anions. These layered materials have very good adsorption properties for metal ions and have been used extensively for the removal of heavy metal ions [214]. It is not surprising that LDHs have recently been combined with chitosan and GO to give efficient adsorbents with enhanced adsorption performances $[215,216]$. Recently, metal-organic frameworks (MOFs) have also been combined with CS/GO $[217,218]$ to give good adsorption properties. MOFs have received considerable interest in environmental science and chemistry as these materials have high porosity and high specific surface areas, with tunable pore structures. Indeed they have been used for heavy metal adsorption and are attracting applications in wastewater treatment [219]. However, MOFs, which are typically powders, are difficult to separate from aqueous environments and this is limiting their environmental applications. The CS/GO hydrogel provides a matrix for encapsulating these powdered materials and as detailed earlier the GO sheets can be easily decorated with magnetic iron to introduce magnetic separation.

A number of other additives has been combined with CS/GO, such as kaolin as a filler to enhance the mechanical strength of the hydrogel composite [220], lignosulfonate for additional binding sites [221,222], triethylenetetramine providing amine groups to enhance adsorption [223], hydroxyapatite to enhance strength and adsorption capacity [224] and silica as it contains a number of silanol groups ( $\mathrm{Si}-\mathrm{OH})$ [225] and it can be furthermore employed to aid the dispersion of $\mathrm{GO}$ within chitosan to give effective adsorbents [226]. Moreover, other biopolymers have been combined with chitosan to form blends which are then combined with GO to give high performing adsorbents. These comprise CS/GO/gelatin [227], CS/GO/alginate [228], CS/GO/heparin [229] and CS/GO/cellulose blends [230].

\subsubsection{Chitosan/Carbon Nanotubes}

Carbon nanotubes (CNTs), like GO sheets, have high surface areas and excellent stability. Therefore, there has been considerable interest in combining these carbon-based materials with chitosan to give adsorbent materials. CNTs are now readily synthesised as single-walled (SWCNT) and multi-walled nanotubes (MWCNT), distinguished by the number or graphitic layers folded over to form the tubes, with very high aspect ratios. They can be well dispersed within chitosan minimising their agglomeration. For good dispersion, the CNTs are normally treated in nitric acid to generate - $\mathrm{COOH}$ groups [231] and these groups can also bind with the chitosan. More recently, the CNTs have been functionalised with valine and starch to aid their dispersion within chitosan and enhance their affinity 
for the adsorption of heavy metal ions [232]. In addition, they have been coated with polydopamine thin films to aid dispersion and minimise aggregation within chitosan [233]. Similar to that employed in the formation of CS/GO, the CS/CNTs are formed by initially dissolving the chitosan in acetic acid, then the CNTs are added, dispersed and normally a crosslinking agent, such as glutaraldehyde [215], is used. These CS/CNT composites have been employed as adsorbents and used in the removal of $\mathrm{Cr}(\mathrm{VI})$ [234], $\mathrm{V}(\mathrm{V}), \mathrm{Cr}(\mathrm{VI}), \mathrm{Cu}(\mathrm{II})$, $\mathrm{As}(\mathrm{V})$ and $\mathrm{Ag}(\mathrm{I})$ from biological and environmental samples [235], $\mathrm{Cu}(\mathrm{II})$ [236], U(VI) [237], $\mathrm{Pb}$ (II) [238], phosphate [239], phenol [60], fluoride [58], diazinon [240], food dyes [241] and dyes [242].

Magnetic separation has also been developed and this provides a convenient method to remove the CS/CNT adsorbents from the aquatic environment. This is especially important for CNTs as there is considerable concern over the environmental and ecological risks associate with the release of CNTs into the environment $[243,244]$. For example, Zhou et al. [245] decorated CNTs with $-\mathrm{NH}_{2}$ functionalised super paramagnetic $\mathrm{CoFe}_{2} \mathrm{O}_{4}$ nanoparticles and combined these magnetic CNTs with chitosan and employed the resulting composites for the removal of $\mathrm{Pb}(\mathrm{II})$ and tetrabromobisphenol A. Magnetic $\mathrm{Fe}_{3} \mathrm{O}_{4}$ nanoparticles have also been used to form magnetic CS/CNTs composites and employed to remove $\mathrm{Pb}$ (II) [246].

Multicomponent and multifunctional CS/CNTs have also been formed. For example, CS/CNT has been further modified with poly(acrylic acid) and poly(4-aminodiphenylamine). The resulting adsorbent enabled the removal of $\mathrm{Cr}(\mathrm{VI})$ through adsorption and reduction to the $\mathrm{Cr}$ (III) species. The partially oxidised poly(4-aminodiphenylamine) was transformed in the presence of $\mathrm{Cr}(\mathrm{VI})$ into its fully oxidised form with the corresponding reduction of $\mathrm{Cr}(\mathrm{VI})$ to $\mathrm{Cr}$ (III) [247]. Alsabagh et al. [248] have fabricated a multifunctional nanocomposite comprising chitosan, well dispersed silver and copper nanoparticles and CNTs for the adsorption of $\mathrm{Cu}(\mathrm{II}), \mathrm{Cd}(\mathrm{II})$ and $\mathrm{Pb}(\mathrm{II})$. Other components have been added to CS/CNT and these include a prussian blue analogue [249], while a cellulose acetate (CA) and chitosan solution were used as an electrospinning solution and employed to form multicomponent electrospun CA/CS/CNTs $/ \mathrm{Fe}_{3} \mathrm{O}_{4} / \mathrm{TiO}_{2}$ nanofibers [250].

$\mathrm{CS} / \mathrm{CNTs}$ have also been formulated to give selective adsorption. While many adsorbents can give relatively high adsorption capacity, it is more challenging to obtain selective adsorption. One avenue that can be employed is imprinting technology. This has been used successfully with ion imprinted polymers, whereby the polymer is formed with a template molecule through a copolymerisation process. The template molecule is then removed leaving behind cavities in the polymer matrix with an affinity for that template, facilitating its rebinding. Li et al. [251] have used this approach to form CS/CNTs composites for the selective capture of $\mathrm{Gd}(\mathrm{III})$ by imprinting the chitosan with the $\mathrm{Gd}(\mathrm{III})$.

\subsubsection{Chitosan/Biochar}

Biochar (BC) is a porous carbon rich material which is obtained through the pyrolysis of organic matter, in the presence of a limited concentration of oxygen. It has attracted much attention in environmental applications as it has a porous structure [252,253]. Moreover, it is a cost-effective material as it is fabricated from wastes, mainly agricultural and forestry waste materials. However, the adsorption capacity of biochar is limited and the density of the functional groups on its surface depend on the pyrolytic temperature with a general loss in these functional groups as the pyrolytic temperature is increased [253]. Accordingly, much attention has been paid to the modification of the biochar production process and modification of the surface through oxidation and/or functionalisation, to give more effective adsorbents $[254,255]$. Treatment of the $\mathrm{BC}$ with $\mathrm{H}_{2} \mathrm{O}_{2}$ is an interesting modification that gives rise to an increase in the concentration of the oxygen-containing functional groups and aids the removal of heavy metal ions from water [254].

Chitosan has been coated onto biochar surfaces [256] and employed as a dispersing and stabilising reagent to form CS/BC composites [257,258]. The BC powders are difficult to retrieve from aqueous solutions, but when the $B C$ is incorporated within the chitosan 
hydrogel, it is more readily separated from the solution phase. Separation can be further facilitated by forming magnetic CS/BC hydrogels $[259,260]$. In addition, by using the chitosan solution phase, it is possible to add a number of other additives or reagents in addition to the $\mathrm{BC}$, giving the composite more functional properties. For example, while $\mathrm{CS} / \mathrm{BC}$ composites have a number of functional groups, such as amine and hydroxyl groups, other additives that increase the number of functional groups can be introduced within the hydrogel matrix. Using this approach, pyromellitic dianhydride (PMDA) has been employed as it can react with the amine groups of chitosan to give additional amides and carboxyl groups and this facilitates electrostatic interactions and complexation with heavy metal ions [261]. Indeed, it was found that the CS/PMDA modified BC exhibited selective adsorption for $\mathrm{Cu}(\mathrm{II})$ and this was attributed to the $\mathrm{N}$-containing functional groups and carbonyl groups. Moreover, poly(acrylic acid), with carboxylate groups, was grafted to the chitosan modified BC to give not only additional functional groups, but also enhance chemical stability with stronger intermolecular forces [262]. Supramolecules, such as cyclodextrins, which have hydrophobic cavities and hydrophilic exteriors, and can form inclusion complexes with a wide range of organic molecules, have also been combined with CS/BC to give higher performing adsorbents [263]. These CS/BC composites have been employed as adsorbents in a number of studies to remove heavy metal ions from water [264], including $\mathrm{Cr}(\mathrm{VI})$ [265]. In addition, they have been utilised in the removal of phosphates [266], nitrates and phosphates [267], fluorides [268], benzoates [269] and various antibiotic and pharmaceutical molecules, such as diclofenac, ibuprofen and naproxen [270], ciprofloxacin [271,272] and ofloxacin [273].

\subsubsection{Chitosan/Activated Carbon}

Activated carbon (AC) is well-known as an adsorbent material. It has been used in a number of environmental applications [274]. However, its relatively high cost is limiting its more widespread applications. One of the more commonly used starting materials in the synthesis of AC is coal [275], but given the depleted amounts of coal now available, this gives rise to an increase in the price of coal-based AC. Consequently, there is a recent focus on developing more environmentally acceptable synthesis and fabrication methods, using starting materials such as mandarin peel [276] and coconut shell [274]. Another avenue being exploited is the fabrication of multifunctional adsorbent materials that contain relatively small amounts of AC. Chitosan, with its high density of functional groups and good dispersion properties, is an ideal companion material. Indeed, there is evidence to suggest that this combination is effective as an adsorbent material. On comparing the maximum adsorption capacities of AC, chitosan and CS / AC for Cd(II), Hydari et al. [277] observed values of 10.3, 10.0, and $52.63 \mathrm{mg} \mathrm{g}^{-1}$ for AC, chitosan and CS/AC, respectively. Likewise, Auta and Hameed [278] observed synergistic effects between AC and chitosan in the removal of cationic and anionic dyes, while Fatombi et al. [279] also concluded that the best performance was achieved with a CS/AC composite.

$\mathrm{CS} / \mathrm{AC}$ composites have been formed using commercially available activated carbon, coconut shell charcoal/carbon [280,281], renewable waste tea [278], sapotaceae seed shells [282] Typhalatifolia leaves [283] and olive stones as the carbon source [284]. These composites can be formed through a surface modification process, where the surface of the AC is modified by chitosan [285]. Babel et al. [280] concluded that surface modification of coconut shell charcoal with chitosan significantly improved the adsorption of $\mathrm{Cr}(\mathrm{VI})$. They also found that the pre-treatment of the $\mathrm{AC}$ with acids gave rise to enhanced adsorption. Amuda et al. [281] arrived at a similar conclusion, and showed that chitosan coated acid treated coconut shell carbon was very effective in the removal of $\mathrm{Zn}$ (II). Alternatively, the chitosan can be dissolved in acid and then the AC can be added in the form of a powder to generate CS / AC [286,287]. Crosslinking agents, such as glutaraldehyde [288], genipin [289] or epichlorohydrin [290], can be added to generate the composite hydrogels. With this latter approach, the ratio of activated carbon to chitosan can be easily varied [291], while other additives can be introduced. For example, a CS/AC was formed with $\mathrm{SiO}_{2} / \mathrm{Fe}_{3} \mathrm{O}_{4}$ 
to give magnetic CS/AC [288], while CS/AC was combined with an anionic surfactant, sodium dodecyl sulphate (SDS), to adsorb a cationic dye [292]. In addition, chitosan has been blended with polyvinyl alcohol [293,294], and polyethylene glycol [295] and then combined with activated carbon, while CS/CA has also been combined with alginate to form CS/CA/alginate adsorbent beads [289].

Activated carbon fibres, regarded as the third generation of carbonaceous adsorbents, have also been employed with chitosan. These have been utilised as membranes [296] and have been decorated with iron oxides and modified with chitosan to remove arsenic, phenol and humic acid from water, with high adsorption capacity for As(V) [297]. Magnetic activated carbon nanofibers based on chitosan and cellulose acetate have also been fabricated for the adsorption of $\mathrm{Cr}(\mathrm{VI}), \mathrm{Ni}(\mathrm{II})$ and phenol from aqueous solutions [298]. In addition, a number of magnetic CS/AC composites has been formed with the majority involving $\mathrm{Fe}_{3} \mathrm{O}_{4}$ [299,300], while others have employed $\mathrm{CoFe}_{2} \mathrm{O}_{4}$ [301] and barium ferrite [302].

These CS/AC composites have been evaluated for the removal of phenols [303], parabens [304], dyes [305], food dyes [306], anti-inflammatory drugs [307], acetaminophen [308], organic molecules, such as aniline [309], and various heavy metal ions [289]. Generally, there is good agreement that the combination of chitosan and AC gives rise to enhanced adsorption, when compared to the individual chitosan and AC counterparts.

\subsection{Chitosan Combined with Inorganic Adsorbent Materials}

While chitosan has been combined with various carbon based materials, as illustrated in Section 3.1, there is growing interest in the use of inorganic components, such as activated alumina [310], mesoporous alumina [311], silica and ordered mesoporous silica-based materials, as the chitosan support materials [312,313]. Silica has very good physical, mechanical and thermal stability and can be easily functionalised due to its hydroxyl groups. In particular, mesoporous silica is a fascinating material, which first gained prominence in the 1990s with a regular mesostructure, with uniform pore distribution and tunable pore sizes, very high specific surface areas, combined with thermal and mechanical stability [314]. It is attracting considerable interest as an adsorbent material [315]. These materials can be formed by a simple sol-gel synthesis route comprising hydrolysis, condensation and polycondensation reactions using various templates or surfactant molecules [316]. In particular, the template-assisted mesoporous silica synthesis using surfactants is gaining considerable attention. Typically, liquid silicon alkoxide precursors, such as tetramethyoxysilane or tetraethoxysilane are used. The successive polymerisation, gelation, drying and aging steps can be tailored to control the microstructure of the final materials. The surfactant-silica assembly occurs simultaneously with condensation of the inorganic species to produce the mesoporous silica composite.

CS/silica composites have been formed using a variety of methods which can be broadly grouped into two main approaches, comprising silica supported chitosan, where the chitosan is coated or adsorbed onto the silica support, and secondly a CS/silica hybrid that is fabricated using the sol-gel methodology. Several reports have focussed on $\mathrm{SiO}_{2}$ as a bead, particle, nanoparticle or powder, where the $\mathrm{SiO}_{2}$ particles are added to the chitosan solution phase to give a chitosan coated particle [317]. The $\mathrm{SiO}_{2}$ particles can also be functionalised with amine and carboxylic groups to give more efficient binding with the chitosan [318]. Silica layers have also been added to previously formed chitosan-based beads to give organic-inorganic (CS/silica) layered structures, with greater stability [319] and sol-gel synthesis has been employed to immobilise chitosan onto silica particles [320]. Sol-gel synthesis is more commonly used to form a CS/silica hybrid layer on silica bead/particle supports [321,322]. For example, Xu et al. [323] covalently linked chitosan with an epoxide containing siloxane through the sol-gel process to give a hybrid chitosan layer on silica particles. The CS/silica hybrid has been further modified with EDTA (ethylenediaminetetraacetic acid), which is very well known to form stable chelates with a number of metal ions [324], to give adsorbents for heavy metal ions [325]. While the sol-gel synthesis is very versatile, Blachnio et al. [326], on comparing three CS/silica 
composites formed by the adsorption of chitosan on silica gel and fumed silica and by the sol-gel process, concluded that the adsorbed chitosan had a higher adsorption capacity for dye molecules, although the CS/silica fabricated using the sol-gel synthesis had a high surface area of $600 \mathrm{~m}^{2} \mathrm{~g}^{-1}$.

There has been considerable interest in combining mesoporous silica with chitosan to combine the good adsorption properties of chitosan with the large surface area and adjustable pore size of silica. Likewise, magnetic mesoporous silica, which has a magnetic $\mathrm{Fe}_{3} \mathrm{O}_{4}$ core surrounded by the mesoporous silica is attracting a lot of attention in environmental applications [327]. These magnetic materials are environmentally acceptable with no toxicity, are biocompatible, have high surface area, very good stability and the outer mesoporous silica can be functionalised and modified by chitosan to add functional groups. The cross-linking method can be employed to decorate the mesoporous silica with the chitosan. Cross-linking agents, such as glutaraldehyde [328], formaldehyde [329] and epoxides [327], can be used, while in a recent study, He et al. [330] used thiol-ene click chemistry to achieve binding between chitosan and magnetic mesoporous silica. The surface areas, pore sizes and volumes of a number of these materials are summarised in Table 4. In general, the surface area, pore size and volume of the mesoporous silica are reduced as higher amounts of chitosan are added and partially fill the pores. However, these chitosan and mesoporous silica composites possess good surface areas with a high density of functional groups and with the potential to give magnetic separation.

Table 4. Surface area, pore diameter and pore volume of CS/mesoporous silica composites and hybrids.

\begin{tabular}{|c|c|c|c|c|}
\hline System & $\begin{array}{c}\text { Surface } \\
\text { Area } / \mathrm{m}^{2} \mathrm{~g}^{-1}\end{array}$ & $\begin{array}{l}\text { Pore Size } \\
\text { /nm }\end{array}$ & $\begin{array}{l}\text { Pore Volume/ } \\
\mathrm{cm}^{3} \mathrm{~g}^{-1}\end{array}$ & Ref \\
\hline CS & 130.2 & 3.98 & 0.482 & [331] \\
\hline CS/silica (electrospun) & 272.3 & 3.52 & 0.431 & \\
\hline SBA-15 & 809.4 & 6.6 & 1.10 & [332] \\
\hline SBA-15 (10\% CS) & 653.9 & 6.6 & 0.90 & \\
\hline SBA-15 (20\% CS) & 461.9 & 6.7 & 0.80 & \\
\hline CS & 150 & - & 0.753 & [312] \\
\hline CS/silica (43\% CS) & 342 & - & 1.092 & \\
\hline Silica & 739 & - & 3.645 & \\
\hline SBA-15 & 876 & 7.8 & 1.30 & [333] \\
\hline SBA-15/CS $/ \mathrm{Fe}_{2} \mathrm{O}_{3}$ & 446 & 6.7 & 0.90 & \\
\hline CS/silica $(81.3 \% \mathrm{Si})$ & 357.3 & 8.18 & 0.730 & [325] \\
\hline CS/silica $(74.4 \% \mathrm{Si})$ & 309.7 & 6.19 & 0.479 & \\
\hline CS/silica $(59.9 \% \mathrm{Si})$ & 268.1 & 6.08 & 0.407 & \\
\hline
\end{tabular}

\section{Adsorption and Removal of Pollutants}

The removal of pollutants from aquatic environments through adsorption is one of the more popular approaches in environmental applications. The aim in these technologies is to remove the maximum amount of pollutant and therefore adsorption isotherms have been used extensively to develop an understanding of the adsorption equilibria. In this section, these adsorption models are briefly introduced, followed by adsorption kinetics and finally a comparison of the performance of the various chitosan composites is made.

\subsection{Adsorption Models and Adsorption Kinetics}

Adsorption isotherms are frequently employed in the study of adsorption, facilitating a quantitative comparison of different adsorbent materials. In addition, they are often used to optimise the use of adsorbents, by observing the adsorption capacity as a function of the experimental conditions. Several different isotherm models have been employed to analyse experimental adsorption data and these include the Langmuir, Freundlich, Temkin, Frumkin, Redlich-Peterson (R-P), Halsey, Henderson and Dubinin-Radushkevich isotherms. However, the two most frequently used models with chitosan and chitosan- 
based composite materials are the Langmuir $[223,334]$ and to a lesser extent the Freundlich isotherms [335]. The Langmuir adsorption model is described in Equation (1) and the linear form commonly employed in fitting data in Equation (2). Here $q_{e}$ is the equilibrium concentration of the adsorbate, $q_{\mathrm{m}}$ is the monolayer adsorption capacity, $C_{e}$ is the concentration of the adsorbate in the aqueous phase and $K$ is a constant. In this model all sites are considered as energetically equivalent, to give monolayer adsorption with no interactions between adjacent adsorbates. In this analysis, the adsorbent has a finite capacity for the adsorbate and a saturation point is reached where no further adsorption occurs. The BiLangmuir model can also be applied with chitosan-based composites [317] and, in this case, the relationship is given in Equation (3), where $q_{m 1}$ and $q_{m 2}$ represent the maximum adsorption capacities of two different adsorption sites and $K_{L 1}$ and $K_{L 2}$ correspond to these two sites. The Freundlich model assumes multilayer adsorption on a heterogeneous surface and can be described by Equations (4) and (5), where $q_{e}$ represents the amount of adsorbent adsorbed at the surface, $C_{e}$ is the equilibrium concentration, and $n$ and $K_{F}$ are the Freundlich constant and Freundlich exponent, respectively. The Freundlich constant, $K_{F}$, provides a measure of the adsorption capacity and the magnitude of $n$ is related to the extent of adsorption with $n>1$, indicating favourable adsorption. An adsorption plot, using simulated data, is illustrated in Figure 7, where a schematic of monolayer and multilayer adsorption is also shown. In this example, the experimental data are more consistent with the Freundlich isotherm.

$$
\begin{gathered}
q_{e}=\frac{q_{m} K_{L} C_{e}}{1+K_{L} C_{e}} \\
\frac{C_{e}}{q_{e}}=\frac{1}{K_{L} q_{m}}+\frac{C_{e}}{q_{m}} \\
q_{e}=\frac{q_{m 1} K_{L 1} C_{e}}{1+K_{L 1} C_{e}}+\frac{q_{m 2} K_{L 2} C_{e}}{1+K_{L 2} C_{e}} \\
q_{e}=K_{F} C_{e}^{1 / n} \\
\log q_{e}=\log K_{F}+\frac{1}{n} \log C_{e}
\end{gathered}
$$

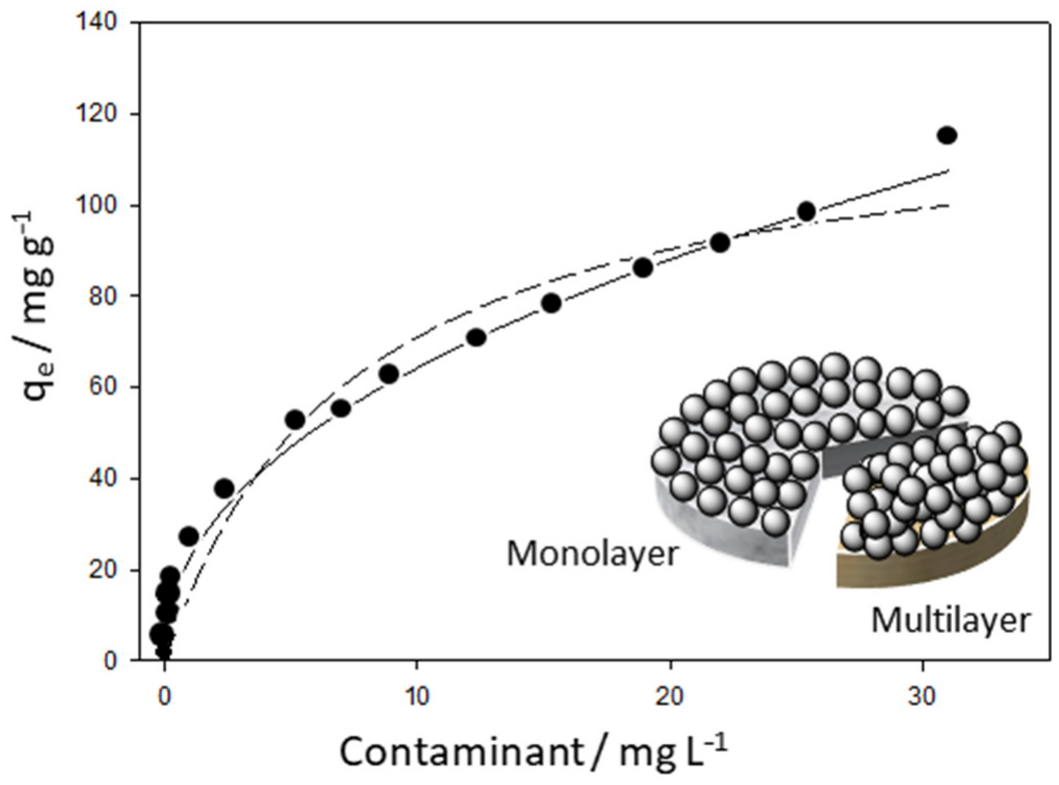

Figure 7. Schematic of an adsorption plot showing experimental data (symbols), with the Freundlich isotherm and - - - Langmuir isotherm fitting and the inset shows monolayer and multilayer adsorption processes. 
The kinetics of the adsorption process are important as these studies provide information on the rate of adsorption which is relevant in terms of the contact time required to remove the maximum amount of adsorbate. The Lagergren rate equation is one of the most widely used adsorption rate equations for the adsorption of adsorbates from a solution phase and this has been used with various chitosan composites [336]. The pseudo-first order (PFO) and pseudo second-order models (PSO) are described in Equations (6) and (7) where $q_{t}$ and $q_{e}$ represent the mass of the adsorbing molecule per unit mass of adsorbent at time $t$ and at equilibrium, while $k_{1}$ and $k_{2}$ correspond to the first- and second-order rate constants and $t$ is the time. Other kinetic models have been employed in the study of chitosan composite materials and these include a double-exponential kinetic model [337], and a generalised fractal kinetic model (Brouers-Sotolongo model) [338]. Generally, the adsorption kinetics are controlled by the (i) rate of diffusion of the adsorbate from the bulk solution to the adsorbent-solution boundary, (ii) diffusion form the boundary layer to the adsorbent surface, (iii) diffusion of the adsorbate within the adsorbent material, i.e., intraparticle diffusion and (iv) the rate of the adsorption step. Normally, the diffusion process in the bulk solution can be eliminated through agitation, while the adsorption is fast and the rate-determining step is typically intraparticle diffusion [200].

$$
\begin{gathered}
\ln \left(q_{e}-q_{t}\right)=\ln q_{e}-k_{1} t \\
\frac{t}{q_{t}}=\frac{1}{q_{t}}+\frac{1}{k_{2} q_{e}^{2}}
\end{gathered}
$$

\subsection{A Comparison of the Chitosan Supported Composites in the Adsorption of Pollutants}

The performance of the chitosan composites in the removal of heavy metal ions is summarised and illustrated in Tables 5-7, where the chitosan is combined with GO, CNTs, $\mathrm{BC}, \mathrm{AC}$ and silica as support materials.

The Langmuir isotherm is based on the assumption that the surface of the absorbent is homogenous, and every adsorption site is equal. Although these chitosan-composites have various functional groups, which in turn, give rise to different affinities with the adsorbates, the Langmuir model and to a lesser extent, the Freundlich model, correlate well with most of the experimental studies. It is also evident in Tables 5-7, that many of the $3 \mathrm{D}$ or porous supports give higher adsorption capacity values, highlighting the influence of the more porous materials, while the magnetic chitosan materials, (MSC), with $\mathrm{Fe}_{3} \mathrm{O}_{4}$ particles/nanoparticles, also perform well. It is difficult to make a direct comparison between the carbon-based materials and silica-based supports, as the adsorption capacity depends on the nature of the chitosan. However, some of the highest adsorption capacities are seen when chitosan is combined with GO.

It can be seen from these tables that a large variety of heavy metal ions have been adsorbed and removed. This is not surprising as these ions are toxic and pose a significant threat to both human beings and aquatic life. As illustrated, the adsorption capacity varies considerably from relatively low values of $9.4 \mathrm{mg} \mathrm{g}^{-1}$ to much higher values in the vicinity of $957 \mathrm{mg} \mathrm{g}^{-1}$. These variations appear to be somewhat related to the nature of the heavy metal ions, with relatively high adsorption values for $\mathrm{Pb}(\mathrm{II})$ and lower values for $\mathrm{Cr}(\mathrm{VI})$. However, the nature and properties of the chitosan, including its DD levels, MW, porosity, particle size, solubility (Section 2), crosslinking agents and the ratio of chitosan to the carbon-based or silica supports are also important elements that will influence the extent of adsorption. 
Table 5. Adsorption performance of CS/GO composites in the removal of heavy metal ions.

\begin{tabular}{|c|c|c|c|c|c|c|}
\hline Adsorbent & Adsorbate & $\mathrm{pH}$ & Ads. Cap./mg g ${ }^{-1}$ & Kinetic Model & Isotherm Model & Ref \\
\hline \multirow[t]{3}{*}{ CS/GO-SH } & $\mathrm{Cd}(\mathrm{II})$ & 5.0 & 177 & PSO & Freundlich & [339] \\
\hline & $\mathrm{Pb}(\mathrm{II})$ & 5.0 & 447 & $\mathrm{PSO}$ & Freundlich & \\
\hline & $\mathrm{Cu}(\mathrm{II})$ & 5.0 & 425 & PSO & Freundlich & \\
\hline $\mathrm{CS} / \mathrm{GO}$ & $\mathrm{Cu}(\mathrm{II})$ & 6.0 & 254 & $\mathrm{PSO}$ & Langmuir & [195] \\
\hline CS/GO aerogel & $\mathrm{Cu}(\mathrm{II})$ & 6.0 & 407 & PSO & Langmuir & \\
\hline \multirow[t]{3}{*}{ CS/GOnano-fibrous } & $\mathrm{Pb}(\mathrm{II})$ & 6.0 & 461 & Double-exp & $\mathrm{R}-\mathrm{P}$ & [337] \\
\hline & $\mathrm{Cu}(\mathrm{II})$ & 6.0 & 423 & Double-exp & $\mathrm{R}-\mathrm{P}$ & \\
\hline & $\mathrm{Cr}(\mathrm{VI})$ & 3.0 & 310 & Double-exp & $\mathrm{R}-\mathrm{P}$ & \\
\hline \multirow{3}{*}{ MCS/GO with EDTA } & $\mathrm{Pb}(\mathrm{II})$ & 5.0 & 206 & PSO & Langmuir & [336] \\
\hline & $\mathrm{Cu}(\mathrm{II})$ & 5.5 & 207 & $\mathrm{PSO}$ & Langmuir & \\
\hline & As (III) & 8.0 & 43 & $\mathrm{PSO}$ & Freundlich & \\
\hline MCS/GO & $\mathrm{Cu}(\mathrm{II})$ & 7.0 & 217 & PSO & Langmuir & [340] \\
\hline MCS/GO & As(III) & 7.3 & 2.3 & PSO & Langmuir & [341] \\
\hline $\mathrm{CS} / \mathrm{GO} / \mathrm{MOF}$ & $\mathrm{Cr}(\mathrm{VI})$ & 3.0 & 144 & PSO & Langmuir & [217] \\
\hline MCS/GO & $\mathrm{Cr}(\mathrm{VI})$ & 2.0 & 270 & PSO & Langmuir & [342] \\
\hline MSC/GO with IL & $\mathrm{Pb}(\mathrm{II})$ & 5.0 & 85 & PSO & Langmuir & [343] \\
\hline \multirow[t]{3}{*}{ MSC/GO gel beads } & $\mathrm{Cd}(\mathrm{II})$ & 6.0 & 86 & PSO & Langmuir & [228] \\
\hline & $\mathrm{Pb}(\mathrm{II})$ & 5.0 & 189 & $\mathrm{PSO}$ & Langmuir & \\
\hline & $\mathrm{Cu}(\mathrm{II})$ & 5.0 & 55 & PSO & Langmuir & \\
\hline MSC/3D-GO & $\mathrm{Pb}(\mathrm{II})$ & 8.5 & 957 & - & - & [344] \\
\hline CS-GO/CMC aerogel & $\mathrm{Cr}(\mathrm{VI})$ & - & 127 & - & Langmuir & [230] \\
\hline $\mathrm{MCS} / \mathrm{GO}$ & $\mathrm{Cr}(\mathrm{VI})$ & 2.0 & 100 & PSO & Freundlich & [345] \\
\hline CS/GO & $\mathrm{U}(\mathrm{VI})$ & 6.0 & 78 & PSO & Freundlich & [346] \\
\hline MCS/3D graphene & $\mathrm{Pb}(\mathrm{II})$ & 8.5 & 947 & - & - & [344] \\
\hline CS/GO-PVA & $\mathrm{Cd}(\mathrm{II})$ & 8.0 & 172 & $\mathrm{PSO}$ & Langmuir & \\
\hline CS/GO-PVA & $\mathrm{Ni}(\mathrm{II})$ & 8.0 & 71 & PSO & Langmuir & [347] \\
\hline MCS/GO-EDTA & $\mathrm{Pb}$ (II) & 8.3 & 666 & $\mathrm{PFO}$ & Langmuir & [172] \\
\hline CS/GO gel & $\mathrm{Pb}(\mathrm{II})$ & 6.0 & 470 & PSO & Langmuir & [348] \\
\hline CS/GO-silica & $\mathrm{Pb}$ (II) & 6.0 & 256 & $\mathrm{PSO}$ & Langmuir & [225] \\
\hline
\end{tabular}

In terms of the experimental conditions employed in these studies, it is well documented that the $\mathrm{pH}$ plays a significant role in the adsorption process. It is well known that the $-\mathrm{NH}_{2}$ and $-\mathrm{OH}$ groups on the chitosan chains have a strong association with metal cations and this facilitates the adsorption of various heavy metal ions at slightly acidic or near neutral pH values. This is clearly evident in Tables 5-7, where several of the studies are performed in slightly acidic solutions. As the chitosan becomes protonated, with the formation of $\mathrm{NH}_{3}{ }^{+}$at lower $\mathrm{pH}$ values, this protonated group repels the cationic heavy metal ions. Moreover, the chitosan becomes less stable and more soluble in highly acidic environments. Indeed, the $\mathrm{pH}$ of zero charge $\left(\mathrm{pH}_{\mathrm{pzc}}\right)$ has been determined as 6.0 for CS/GO composites, indicating that the surface of CS/GO is positively charged for $\mathrm{pH}$ values $<6.0$ but for $\mathrm{pH}$ values $>6.0$, the surface adopts a negative charge [365]. However, the speciation of the metal ions is also important, and this is illustrated in Figure 8 , where the Pourbaix diagrams for various heavy metals, designated as $\mathrm{M}$, and $\mathrm{Cr}$ are shown. In general, for heavy metals, such as $\mathrm{Cu}(\mathrm{II})$, the adsorption capacity increases gradually as the $\mathrm{pH}$ increases from about 2 to 7 and then it decreases rapidly as the $\mathrm{pH}$ is further increased. The rapid decrease at higher $\mathrm{pH}$ values is due to the formation of insoluble hydroxide species. While higher concentrations of the metal cations are present in the solution phase at low $\mathrm{pH}$ values, the adsorption capacity is poor, which can be attributed to the protonation of chitosan. As the $\mathrm{pH}$ is increased, the- $\mathrm{NH}_{2}$ chelating groups become available and at these conditions the concentrations of the metal cations is still sufficiently high to facilitate chelation with the chitosan. The nature of the $-\mathrm{COOH}$ functional groups on GO and the other carbon-based materials is also $\mathrm{pH}$ dependent with the generation of $-\mathrm{COO}^{-}$at higher $\mathrm{pH}$ values and again this anionic group will bind with metal cations. Therefore, the maximum adsorption is seen at $\mathrm{pH}$ values from about 5 to 7 , as illustrated in Tables $5-7$, for a number of heavy metal ions. The Pourbaix diagram of $\mathrm{Cr}$ is somewhat 
different with the generation of the anionic dichromate $\left(\mathrm{Cr}_{2} \mathrm{O}_{7}{ }^{2-}\right)$ and chromate $\left(\mathrm{HCrO}_{4}{ }^{-}\right)$ ions at the lower more acidic $\mathrm{pH}$ values and the insoluble oxide phases at higher $\mathrm{pH}$ values. In this case, the $\mathrm{HCrO}_{4}{ }^{-}$ions can be adsorbed at the chitosan through electrostatic interactions with the protonated chitosan, to give more favourable adsorption at $\mathrm{pH}$ values between approximately 2.0 and 4.0 .

Table 6. Adsorption performance of CS/CNT, CS/BC and CS/AC composites in the removal heavy metal ions.

\begin{tabular}{|c|c|c|c|c|c|c|}
\hline Adsorbent & Adsorbate & $\mathrm{pH}$ & $\begin{array}{c}\text { Ads. Cap./ } \\
\text { mg g }^{-1}\end{array}$ & Kinetic Model & Isotherm Model & Ref \\
\hline $\begin{array}{l}\mathrm{CS} / \mathrm{CNT} / \\
\mathrm{CoFe}_{2} \mathrm{O}_{4}\end{array}$ & $\mathrm{~Pb}(\mathrm{II})$ & 6.0 & 140 & PSO & Langmuir & [245] \\
\hline $\mathrm{MCS} / \mathrm{CNT}$ & $\mathrm{Pb}(\mathrm{II})$ & 5.0 & 101 & $\mathrm{PSO}$ & Sips & [246] \\
\hline $\mathrm{CS} / \mathrm{CNT} / \mathrm{PDA}$ & $\mathrm{Cu}(\mathrm{II})$ & 7.0 & 112 & PSO & Langmuir & [233] \\
\hline CS/CNT & $\mathrm{Cu}(\mathrm{II})$ & 7.0 & 115 & PSO & Langmuir & [349] \\
\hline $\begin{array}{l}\mathrm{CS} / \mathrm{CNT} \\
\text { at } 293 \mathrm{~K}\end{array}$ & $\mathrm{Cr}(\mathrm{VI})$ & 2.0 & 142 & $\mathrm{PSO}$ & Langmuir & [350] \\
\hline at $303 \mathrm{~K}$ & $\mathrm{Cr}(\mathrm{VI})$ & 2.0 & 151 & PSO & Langmuir & \\
\hline at $313 \mathrm{~K}$ & $\mathrm{Cr}(\mathrm{VI})$ & 2.0 & 164 & PSO & Langmuir & \\
\hline \multirow[t]{2}{*}{ CS/CNT/PB } & $\mathrm{Cs}(\mathrm{I})$ & 6.0 & 219 & PSO & Freundlich & [249] \\
\hline & $\mathrm{Sr}(\mathrm{II})$ & 6.0 & 205 & PSO & Freundlich & \\
\hline $\mathrm{CS} / \mathrm{CNT}$ & U(VI) & 4.0 & 126 & PSO & Langmuir & [351] \\
\hline \multirow[t]{2}{*}{$\mathrm{MCS} / \mathrm{CNT}$} & $\mathrm{Cr}(\mathrm{III})$ & 4.0 & 66 & PSO & Langmuir & [352] \\
\hline & $\mathrm{Cr}(\mathrm{VI})$ & 4.0 & 449 & PSO & Langmuir & \\
\hline \multirow[t]{3}{*}{$\begin{array}{l}\text { CS/BC/ } \\
\text { PMDA }\end{array}$} & $\mathrm{Cu}(\mathrm{II})$ & 5.0 & 96 & PSO & Langmuir & [261] \\
\hline & $\mathrm{Pb}(\mathrm{II})$ & 5.0 & 13 & PSO & Langmuir & \\
\hline & $\mathrm{Cd}(\mathrm{II})$ & 5.0 & 38 & PSO & Langmuir & \\
\hline $\mathrm{CS} / \mathrm{BC} / \beta-\mathrm{CD}$ & $\mathrm{Cr}(\mathrm{VI})$ & 2.0 & 206 & PSO & Freundlich & [263] \\
\hline \multirow[t]{2}{*}{$\mathrm{MCS} / \mathrm{BC}$} & $\mathrm{Cr}(\mathrm{VI})$ & 3.0 & 30 & PSO & Freundlich & [353] \\
\hline & $\mathrm{Cu}(\mathrm{II})$ & 5.8 & 54 & PSO & Freundlich & \\
\hline \multirow[t]{2}{*}{$\mathrm{CS} / \mathrm{BC}$} & $\mathrm{Hg}$ (II) & 3.0 & 594 & PSO & Langmuir & [258] \\
\hline & $\mathrm{Pb}(\mathrm{II})$ & 5.0 & 210 & PSO & Langmuir & \\
\hline \multirow[t]{3}{*}{$\mathrm{CS} / \mathrm{BC} / \mathrm{PAA}$} & $\mathrm{Mn}(\mathrm{II})$ & $3-7$ & 139 & PSO & Langmuir & [262] \\
\hline & $\mathrm{Co}(\mathrm{II})$ & $3-7$ & 135 & $\mathrm{PSO}$ & Langmuir & \\
\hline & $\mathrm{Pb}(\mathrm{II})$ & $3-7$ & 476 & PSO & Langmuir & \\
\hline \multirow[t]{3}{*}{ CS/BC/Clay } & $\mathrm{Cu}(\mathrm{II})$ & 5.0 & 121 & Elovich & Freundlich & [354] \\
\hline & $\mathrm{Pb}(\mathrm{II})$ & 5.0 & 336 & PSO & Temkin & \\
\hline & $\mathrm{Zn}(\mathrm{II})$ & 5.0 & 134 & Elovich & Freundlich & \\
\hline $\mathrm{CS} / \mathrm{AC}$ & $\mathrm{Zn}(\mathrm{II})$ & 6.0 & 60 & - & Langmuir & [281] \\
\hline $\mathrm{CS} / \mathrm{AC}$ & $\mathrm{Cr}(\mathrm{VI})$ & 5.0 & 84 & PSO & Langmuir & [282] \\
\hline \multirow[t]{2}{*}{$\mathrm{CS} / \mathrm{AC}$} & $\mathrm{Pb}(\mathrm{II})$ & 5.0 & 125 & PFO & Freundlich & [287] \\
\hline & $\mathrm{Cd}(\mathrm{II})$ & 5.0 & 69 & PFO & Freundlich & \\
\hline \multirow[t]{2}{*}{$\mathrm{CS} / \mathrm{PEO} / \mathrm{AC}$} & $\mathrm{Fe}(\mathrm{III})$ & 3.0 & 217 & - & Langmuir/ & [355] \\
\hline & $\mathrm{Cu}(\mathrm{II})$ & 5.0 & 195 & - & Freundlich & \\
\hline $\mathrm{CS} / \mathrm{AC}$ & $\mathrm{Hg}(\mathrm{II})$ & 7.0 & 576 & - & Langmuir & [289] \\
\hline $\mathrm{CS} / \mathrm{AC} / \mathrm{PVA}$ & $\mathrm{Cr}(\mathrm{VI})$ & 2.0 & 109 & PSO & Langmuir & [293] \\
\hline
\end{tabular}

Abbreviations: PMDA: pyromellitic dianhydride; PAA: poly(acrylic acid); PVA: poly(vinyl alcohol); PEO: poly(ethylene oxide); PB: Prussian blue. 
Table 7. Adsorption performance of CS/silica composites in the removal heavy metal ions from water.

\begin{tabular}{|c|c|c|c|c|c|c|}
\hline Adsorbent & Adsorbate & $\mathrm{pH}$ & $\begin{array}{l}\text { Ads. Capacity } \\
\qquad / \mathrm{mg} \mathrm{g}^{-1}\end{array}$ & Kinetic Model & Isotherm Model & Ref \\
\hline CS/Silica & $\mathrm{V}(\mathrm{V})$ & 6.5 & 16 & - & - & [329] \\
\hline \multirow{4}{*}{ Mesoporous } & $\mathrm{Cu}(\mathrm{II})$ & 6.5 & 21 & - & - & \\
\hline & $\mathrm{Pb}(\mathrm{II})$ & 6.5 & 22 & - & - & \\
\hline & $\mathrm{Cd}(\mathrm{II})$ & 6.5 & 12 & - & - & \\
\hline & $\mathrm{Hg}$ (II) & 6.5 & 13 & - & - & \\
\hline \multirow{3}{*}{$\begin{array}{c}\text { MCS/Silica/ } \\
\text { PAM }\end{array}$} & $\mathrm{Cu}(\mathrm{II})$ & 5.0 & 43 & PSO & Langmuir & [356] \\
\hline & $\mathrm{Pb}(\mathrm{II})$ & 5.0 & 63 & PSO & Langmuir & \\
\hline & $\mathrm{Hg}(\mathrm{II})$ & 5.0 & 263 & PSO & Langmuir & \\
\hline CS/SBA-15 & $\mathrm{Pb}(\mathrm{II})$ & 5.0 & 57 & PSO & Langmuir & [357] \\
\hline \multirow{2}{*}{ MCS/SBA-15 } & $\mathrm{Cu}(\mathrm{II})$ & 6.0 & 107 & PSO & Langmuir & [333] \\
\hline & $\mathrm{Zn}(\mathrm{II})$ & 6.0 & 100 & PSO & Langmuir & \\
\hline MCS/SBA-15 & $\mathrm{Zn}(\mathrm{II})$ & 6.0 & 107 & PSO & Langmuir & [358] \\
\hline \multirow[t]{2}{*}{ CS/Silica } & $\mathrm{Hg}(\mathrm{II})$ & 6.0 & 204 & & Langmuir & [359] \\
\hline & $\mathrm{As}(\mathrm{V})$ & 6.0 & 198 & & Freundlich & \\
\hline CS/KCC-1 & $\mathrm{Pb}(\mathrm{II})$ & 9.0 & 168 & PSO & Langmuir & [360] \\
\hline MSC/Silica & $\mathrm{Cu}(\mathrm{II})$ & 5.0 & 73 & PSO & Langmuir & [361] \\
\hline SC/Silica & $\mathrm{Cr}(\mathrm{VI})$ & 3.0 & 9 & PSO & Langmuir & [362] \\
\hline MSC/Silica & $\mathrm{Cu}(\mathrm{II})$ & 6.0 & 350 & - & Freundlich & [363] \\
\hline MSC/Silica aerogel & $\mathrm{Cd}(\mathrm{II})$ & 8.0 & 71 & PSO & Langmuir & [364] \\
\hline CS/GO/Silica & $\mathrm{Pb}(\mathrm{II})$ & 6.0 & 256 & PSO & Langmuir & [225] \\
\hline MCS/Silica & $\mathrm{Cr}(\mathrm{III})$ & 4.0 & 39 & PSO & Bi-langmuir & [317] \\
\hline
\end{tabular}

Abbreviations: polyacrylamide (PAM).

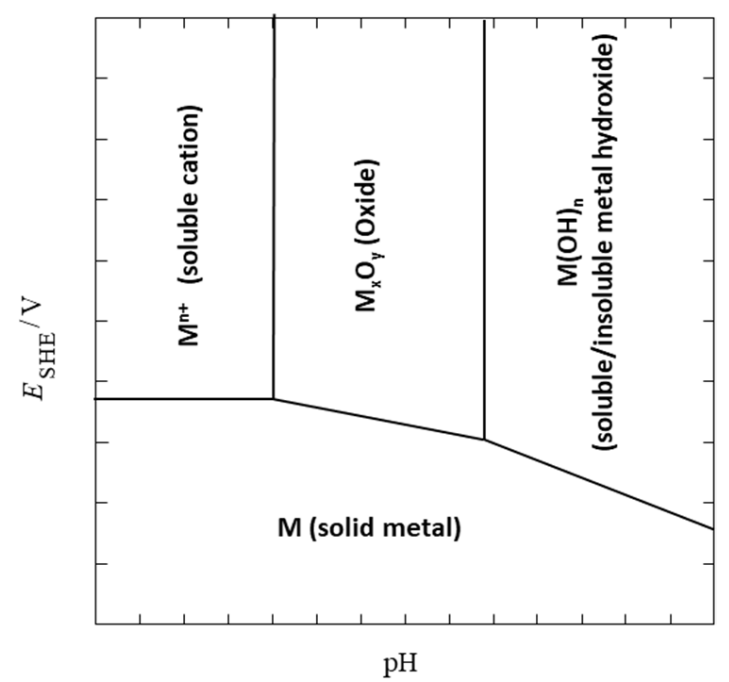

(a)

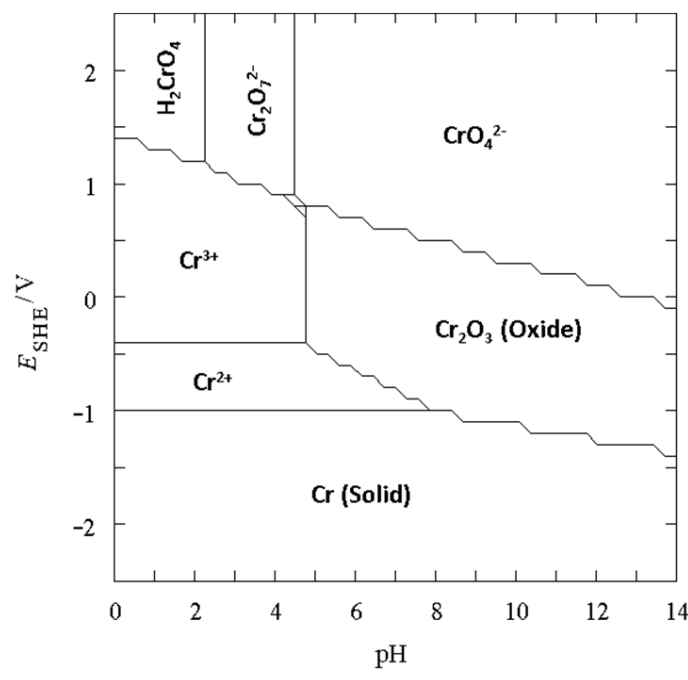

(b)

Figure 8. Pourbaix diagrams illustrating the speciation of (a) heavy metals, $\mathrm{M}$, and (b) $\mathrm{Cr}$ in aqueous solutions.

Other conditions that can alter the adsorption capacity of the heavy metal ions are temperature and ionic strength. Generally, the adsorption capacity increases with higher temperatures [195], as $\Delta G$ becomes more negative, implying that the adsorption process becomes more favourable at higher temperatures, with $\Delta G^{\circ}<0, \Delta H^{\circ}>0$ and $\Delta S^{\circ}>0$ for several adsorbents, however, adsorption can also be exothermic [337]. There have been relatively few studies devoted to the selectivity of the adsorption process at these chitosan composites. This is especially important in terms of the potential applications of the adsorbents, as the water samples or industrial effluents are likely to contain other cations and anions, such as $\mathrm{Cl}^{-}, \mathrm{NO}_{3}{ }^{-}, \mathrm{SO}_{4}{ }^{2-}, \mathrm{Mg}^{2+}$ and $\mathrm{Na}^{+}$. For example, it was found 
that an increase in the ionic strength inhibited the adsorption of Cu(II) at CS/GO [195]. One approach that can be employed to enhance the binding of a particular heavy metal ion is templating [251]. This is generally successful provided the target metal ion is reasonably different to the size of the co-existing ions.

The adsorption capacity of the various supported chitosan composites in the removal of dye molecules and other organic molecules, including antibiotics, is summarised in Table 8. Various cationic and anionic dyes have been employed as model compounds and very impressive adsorption capacities have been obtained in a number of studies. In particular, the adsorption of methylene blue (MB), a cationic dye molecule, is very high at CS/GO composites reaching values $>1000 \mathrm{mg} \mathrm{g}^{-1}$ in a number of studies, as illustrated in Table 8 . This good adsorption is attributed mainly to the $\pi-\pi$ interactions between the MB and GO layers. The electrostatic interactions between the $-\mathrm{COO}^{-}$groups on $\mathrm{GO}$ and the cationic $\mathrm{MB}$ can also facilitate adsorption, provided the solution $\mathrm{pH}$ is not acidic giving rise to the formation of the unionised-COOH groups. Therefore, it is the GO that is largely responsible for the adsorption of cationic dyes [144]. On the other hand, the chitosan plays a more significant role in the adsorption of anionic dye molecules. Although $\pi-\pi$ interactions will exist between GO and the anionic dyes, the electrostatic repulsion between the $-\mathrm{COO}^{-}$groups and the anionic dye will inhibit its adsorption at higher $\mathrm{pH}$ values, where the $\mathrm{COOH}$ groups are ionised. The electrostatic interactions between the cationic centres in the chitosan chains and the anionic dyes will have a significant effect at low $\mathrm{pH}$ values, while a combination of electrostatic forces, van der Waals interactions and hydrogen bonding are likely to occur at higher $\mathrm{pH}$ values [366]. This explains the good adsorption of anionic dyes observed at near neutral $\mathrm{pH}$ values in Table 8. The concentrations of the dye molecules can also influence the adsorption process. Many of these dye molecules can form dimers and aggregates and this becomes more relevant as the concentrations of the dye molecules increase, with aggregates forming in solution and at the surface. Indeed, the impressive adsorption of rhodamine B [367] and its adsorption kinetics were questioned as the aggregation of rhodamine B in water was not taken into account in the original study [368].

Various antibiotics have also been adsorbed at the chitosan-based composites, as shown in Table 8. Again, many of these molecules have benzene rings which facilitate their adsorption onto the carbon surface through $\pi-\pi$ electron donor-acceptor interactions. Furthermore, many of these organic molecules have $-\mathrm{OH},>\mathrm{C}=\mathrm{O}$ and $-\mathrm{NH}_{2}$ groups which can be involved in hydrogen bonding with the oxygen groups on the carbon surfaces in the chitosan composites [369]. Hydrophobic interactions may also be relevant [370]. These organic molecules tend to be hydrophobic making hydrophobic interaction between the antibiotics and the carbon surfaces possible. However, high numbers of oxygen-containing groups, such as $-\mathrm{OH}$ and $-\mathrm{COOH}$ on the carbon surfaces tend to make the surface more hydrophilic.

The CS/ silica composites are only emerging as potential adsorbents and compared with the chitosan-carbon based systems, there are much fewer reports focused on the removal of dyes and organic molecules with these adsorbents. This may be due in part to the silanol groups, which are hydrophilic, and easily form hydrogen bonds with water, thus limiting the adsorption process. However, the mesoporous silica surfaces can be functionalised, and this provides the opportunity to design more hydrophobic surfaces that can be tailored to adsorb organic molecules. Indeed, there is clear evidence in Table 8 that the CS/ silica composites can be employed in the removal of dyes. 
Table 8. Adsorption performance of chitosan composites in the removal pharmaceuticals, organics and drug molecules from water.

\begin{tabular}{|c|c|c|c|c|c|c|}
\hline Adsorbent & Adsorbate & $\mathrm{pH}$ & Ads. Capacity & Kinetic Model & Isotherm Model & Ref \\
\hline $\mathrm{CS} / \mathrm{GO}$ & MB & 5.3 & 95 & PSO & Langmuir & [155] \\
\hline $\begin{array}{c}\mathrm{MCS} / \mathrm{GO} \\
\beta-\mathrm{CD}\end{array}$ & $\mathrm{MB}$ & - & 84 & PSO & Langmuir & [204] \\
\hline $\mathrm{MCS} / \mathrm{GO}$ & Acid orange & 3.0 & 42 & PSO & Langmuir & [372] \\
\hline MCS/GO & MO & 4.0 & 398 & PSO & Langmuir & [373] \\
\hline \multirow[t]{2}{*}{$\mathrm{CS} / \mathrm{GO}$ aerogel } & $\mathrm{MO}$ & 4.0 & 686 & PSO & - & [197] \\
\hline & Amido black & 4.0 & 573 & PSO & - & \\
\hline $\mathrm{CS} / \mathrm{GO}$ aerogel & Metanil yellow & 6.8 & 430 & PSO & Langmuir & {$[365]$} \\
\hline \multirow[t]{2}{*}{ CS/GO aerogels } & Indigo carmine & 6.8 & 534 & - & Langmuir & [198] \\
\hline & $\mathrm{MB}$ & 7.0 & 168 & - & Langmuir & \\
\hline CS/GO/Ligno-sulfonate aerogel & MB & 7.0 & 1023 & PSO & Langmuir & [221] \\
\hline $\begin{array}{l}\text { CS/GO/ } \\
\text { Cellulose }\end{array}$ & $\mathrm{MB}$ & 6.0 & 3190 & PSO & Langmuir & [230] \\
\hline MCS/GOCS-EDTA & Rhodamine B & 7.5 & 1085 & PSO & Langmuir & [367] \\
\hline CS/GO aerogel & Congo red & 7.0 & 384 & PSO & Langmuir & [374] \\
\hline MCS/GO & MB & 8.5 & 2478 & PFO & Sips & [170] \\
\hline MCS/CNT & Acid red & 3.0 & 809 & PSO & $\begin{array}{l}\mathrm{R}-\mathrm{P} . \\
\text { Freundlich }\end{array}$ & [376] \\
\hline \multirow{2}{*}{$\mathrm{MSC} / \mathrm{CNT} / \mathrm{SiO}_{2}$} & DB 71 & 6.8 & 61 & PSO & Langmuir & [377] \\
\hline & RB 19 & 2.0 & 97 & PSO & Langmuir & \\
\hline \multirow[t]{3}{*}{$\mathrm{CS} / \mathrm{CNT}$} & DB 71 & 6.2 & 29 & PSO & Langmuir & [378] \\
\hline & FdR17 & 3.0 & 1508 & Avrami & Langmuir & [241] \\
\hline & FdB1 & 3.0 & 1480 & Avrami & Langmuir & \\
\hline $\mathrm{CS} / \mathrm{CNT} / \mathrm{GO}$ & Rhodamine B & - & 9.6 & PSO & - & [215] \\
\hline $\mathrm{CS} / \mathrm{CNT}$ & Phenol & 6.5 & 404 & PSO & Dubinin-Radushkevic & {$[60]$} \\
\hline $\mathrm{CS} / \mathrm{AC}$ & Crystal violet & 9.0 & $12.5(323 \mathrm{~K})$ & PSO & Langmuir and Freundlich & {$[283]$} \\
\hline $\mathrm{CS} / \mathrm{AC}$ & FBL2 & 3.0 & 155 & Avrami & - & [286] \\
\hline $\mathrm{CS} / \mathrm{AC}$ & FR17 & 3.0 & 133 & Avrami & - & \\
\hline $\mathrm{CS} / \mathrm{AC} / \mathrm{PVA}$ & MB & 6.0 & 468 & $\mathrm{PFO}$ & Langmuir and Freundlich & [294] \\
\hline
\end{tabular}


Table 8. Cont.

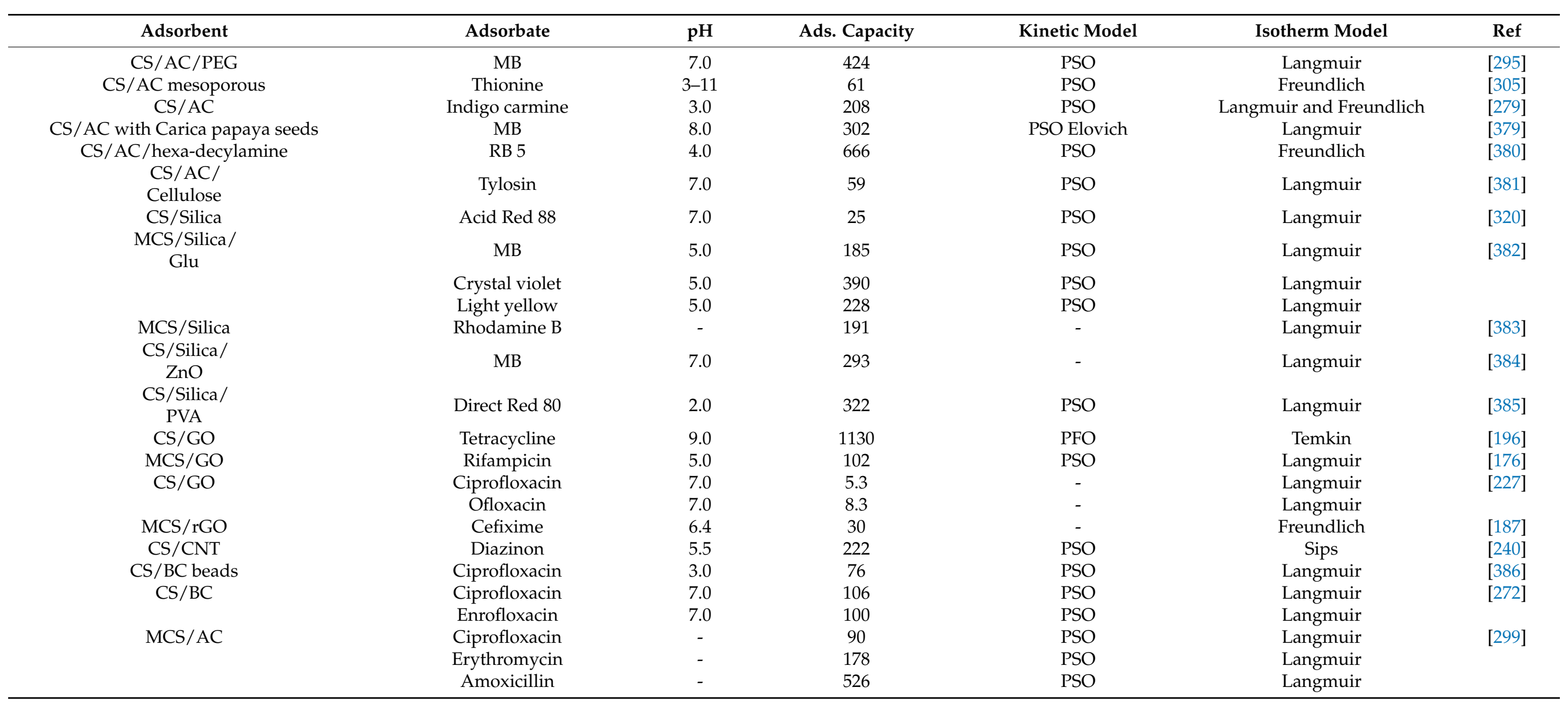




\section{Conclusions and Future Perspectives}

It is clear from the reports reviewed and the growing number of publications, where chitosan and chitosan-based materials are employed as adsorbents, that these materials are emerging as interesting candidates in the formulation of adsorbents for environmental applications. Chitosan can be easily combined with different support materials, and while earlier studies were devoted to blending chitosan with other polymeric materials, many of the more recent reports are focused on combing chitosan with carbon-based materials with GO, and to a lesser extent activated carbon, attracting considerable attention. Likewise, there is increasing attention being focussed on merging chitosan and mesoporous silica. The CS/GO composites have shown impressive adsorption capacity with both dyes and heavy metal ions.

However, this research field is still in its infancy and a number of challenges exist and must be addressed before these chitosan-carbon based or chitosan-silica based materials can be employed as adsorbents for the removal of a variety of pollutants. One of the more challenging aspects, that has direct implications in terms of costs, is the regeneration of the adsorbents. Ideally, adsorbents should have the capacity to be regenerated and used multiple times. Regeneration is normally achieved using $\mathrm{NaOH}$ or acid treatments, where, for example, heavy metal ions are released from the chitosan. However, these treatments lead to a progressive hydrolysis of the polysaccharide on the chitosan. Consequently, the adsorption capacity decreases with each adsorption-regeneration cycle. New regeneration processes are required to give more longer lasting and cost-effective chitosan-based adsorbents. Other challenges are the introduction of selectivity in the adsorption process. Real water samples contain a number of ions that will compete with the removal of heavy metal ions, consuming the adsorption sites and reducing the uptake of the targeted pollutants. Furthermore, the removal of neutral pollutant molecules using these chitosan-based materials is more difficult to achieve, although the addition of GO provides two dimensional sheets that facilitate the adsorption of aromatic ring structures. In addition, the adsorbents need to be removed from the aquatic environment or employed in a continuous flow system. While the development of magnetic chitosan-based materials provides the opportunity to remove the adsorbents using magnetic separation, these magnetic materials are only emerging and it is not entirely clear if they can be sufficiently anchored within the chitosan composites to prevent their leaching over longer terms. However, the development of silica coated and protected magnetic iron-containing particles is promising. There are added concerns over the environmental impact of GO and CNTs, which if leached from the chitosan composites, can enter the aquatic system and have adverse effects on the aquatic ecosystem. Therefore, the CS-carbon and CS-silica composites must be stable and not prone to leaching of GO flakes, CNTs, or the magnetic iron oxide particles. Consequently, studies that monitor the leaching of the various carbon, silica and iron species from the chitosan composites are needed from an environmental perspective.

Fundamental studies on kinetics and intraparticle diffusion require further study. Most of the kinetic models employed are relatively simple pseudo-second order models while the impermeable nature of the GO sheets, CNTs, carbon and silica particles on the internal diffusion of the pollutants are not well developed. While the physical and chemical properties of chitosan can be tailored by varying its molecular weight, DD levels, particle sizes, etc, the complex relationships between some of these parameters and how they control the adsorption process and capacity are difficult to establish.

Nevertheless, these chitosan-based materials, and especially the emerging chitosancarbon and chitosan-silica based composites, have a promising future as adsorbent materials. While chitosan is currently unable to compete with activated carbon in commercial and industrial settings, it is nevertheless an attractive and viable material as it is derived from chitin, which can be found in abundance and extracted from seafood wastes. With further developments aimed at strengthening the mechanical properties of chitosan, the development of recovery protocols, scale-up of production using green solvents and implementation of nonthermal technologies, industrial exploitation can become a reality. 
Moreover, there has been a recent explosion in the development of new two-dimensional materials. Some of these 2D layered materials, for example MXenes, $\mathrm{MoS}_{2}$ and $\mathrm{MoSe}_{2}$, are potential adsorbents and could be easily combined with chitosan to generate a new family of high-performance materials.

Author Contributions: Conceptualization, D.C.d.S.A. and C.B.B.; writing-original draft preparation, D.C.d.S.A., B.H., L.A.d.A.P., T.R.S.C.J. and C.B.B.; writing-review and editing, D.C.d.S.A., B.H., L.A.d.A.P., T.R.S.C.J. and C.B.B.; supervision, L.A.d.A.P., T.R.S.C.J. and C.B.B. All authors have read and agreed to the published version of the manuscript.

Funding: This research was funded by Coordenação de Aperfeiçoamento de Pessoal de Nível Superior (CAPES) / Brazil, grant number 001 and by Conselho Nacional de Desenvolvimento Científico e Tecnológico $(\mathrm{CNPq})$ /Brazil. This research also was funded by Secretaria de Desenvolvimento, Ciência e Tecnologia/RS/Brazil, grant numbers DCIT 70/2015 and DCIT 77/2016.

Conflicts of Interest: The authors declare no conflict of interest.

\section{References}

1. Brindha, K.; Schneider, M. Impact of urbanization on groundwater quality. In GIS and Geostatistical Techniques for Groundwater Science; Elsevier Inc.: Amsterdam, The Netherlands, 2019; pp. 179-196. ISBN 9780128154137.

2. Tran, N.H.; Reinhard, M.; Gin, K.Y.H. Occurrence and fate of emerging contaminants in municipal wastewater treatment plants from different geographical regions-a review. Water Res. 2018, 133, 182-207. [CrossRef] [PubMed]

3. Brindha, K.; Paul, R.; Walter, J.; Tan, M.L.; Singh, M.K. Trace metals contamination in groundwater and implications on human health: Comprehensive assessment using hydrogeochemical and geostatistical methods. Environ. Geochem. Health 2020, 42, 3819-3839. [CrossRef] [PubMed]

4. $\quad$ Burant, A.; Selbig, W.; Furlong, E.T.; Higgins, C.P. Trace organic contaminants in urban runoff: Associations with urban land-use. Environ. Pollut. 2018, 242, 2068-2077. [CrossRef] [PubMed]

5. Pai, S.M.; Kini, S.; Selvaraj, R.; Pugazhendhi, A. A review on the synthesis of hydroxyapatite, its composites and adsorptive removal of pollutants from wastewater. J. Water Process Eng. 2020, 38, 101574. [CrossRef]

6. Soylak, M.; Ozalp, O.; Furkan, U. Magnetic nanomaterials for the removal, separation and preconcentration of organic and inorganic pollutants at trace levels and their practical applications: A review. Trends Environ. Anal. Chem. 2020, 106192. [CrossRef]

7. Reyes-Contreras, C.; Matamoros, V.; Ruiz, I.; Soto, M.; Bayona, J.M. Evaluation of PPCPs removal in a combined anaerobic digester-constructed wetland pilot plant treating urban wastewater. Chemosphere 2011, 84, 1200-1207. [CrossRef] [PubMed]

8. Zhang, Y.; Li, J.L.; Cai, T.; Cheng, Z.L.; Li, X.; Chung, T.S. Sulfonated hyperbranched polyglycerol grafted membranes with antifouling properties for sustainable osmotic power generation using municipal wastewater. J. Memb. Sci. 2018, 563, 521-530. [CrossRef]

9. Zhou, G.J.; Ying, G.G.; Liu, S.; Zhou, L.J.; Chen, Z.F.; Peng, F.Q. Simultaneous removal of inorganic and organic compounds in wastewater by freshwater green microalgae. Environ. Sci. Process. Impacts 2014, 16, 2018-2027. [CrossRef] [PubMed]

10. Zhang, N.; Ishag, A.; Li, Y.; Wang, H.; Guo, H.; Mei, P.; Meng, Q.; Sun, Y. Recent investigations and progress in environmental remediation by using covalent organic framework-based adsorption method: A review. J. Clean. Prod. 2020, 277, 123360. [CrossRef]

11. Wan Ngah, W.S.; Teong, L.C.; Hanafiah, M.A.K.M. Adsorption of dyes and heavy metal ions by chitosan composites: A review. Carbohydr. Polym. 2011, 83, 1446-1456. [CrossRef]

12. Crini, G.; Badot, P.M. Application of chitosan, a natural aminopolysaccharide, for dye removal from aqueous solutions by adsorption processes using batch studies: A review of recent literature. Prog. Polym. Sci. 2008, 33, 399-447. [CrossRef]

13. Rinaudo, M. Chitin and chitosan: Properties and applications. Prog. Polym. Sci. 2006, 31, 603. [CrossRef]

14. Yi, H.; Wu, L.Q.; Bentley, W.E.; Ghodssi, R.; Rubloff, G.W.; Culver, J.N.; Payne, G.F. Biofabrication with chitosan. Biomacromolecules 2005, 6, 2881-2894. [CrossRef]

15. Weska, R.F.; Moura, J.M.; Batista, L.M.; Rizzi, J.; Pinto, L.A.A. Optimization of deacetylation in the production of chitosan from shrimp wastes: Use of response surface methodology. J. Food Eng. 2007, 80, 749-753. [CrossRef]

16. FAO. Fishery and Aquaculture Statistics; FAO: Rome, Italy, 2018.

17. Gonçalves, J.O.; Esquerdo, V.M.; Cadaval, T.R.S.; Pinto, L.A.A. Chitosan-based hydrogels. In Sustainable Agriculture Reviews 36; Springer: Aix-en-Provence, France, 2019; pp. 49-123. ISBN 9783540228608.

18. Varun, T.K.; Senani, S.; Jayapal, N.; Chikkerur, J.; Roy, S.; Tekulapally, V.B. Extraction of chitosan and its oligomers from shrimp shell waste, their characterization and antimicrobial effect. Vet. World 2017, 10, 170-175. [CrossRef] [PubMed]

19. Bakshi, P.S.; Selvakumar, D.; Kadirvelu, K.; Kumar, N.S. Chitosan as an environment friendly biomaterial-A review on recent modifications and applications. Int. J. Biol. Macromol. 2020, 150, 1072-1083. [CrossRef] [PubMed]

20. Maity, J.; Ray, S.K. Chitosan based nano composite adsorbent-synthesis, characterization and application for adsorption of binary mixtures of $\mathrm{Pb}(\mathrm{II})$ and Cd(II) from water. Carbohydr. Polym. 2017, 182, 159-171. [CrossRef] [PubMed] 
21. Qu, B.; Luo, Y. Chitosan-based hydrogel beads: Preparations, modifications and applications in food and agriculture sectors-A review. Int. J. Biol. Macromol. 2020, 152, 437-448. [CrossRef]

22. Shokrgozar, M.A.; Mottaghitalab, F.; Mottaghitalab, V.; Farokhi, M. Fabrication of porous chitosan/poly (vinyl alcohol) reinforced single-walled carbon nanotube nanocomposites for neural tissue engineering. J. Biomed. Nanotechnol. 2011, 7, 276-284. [CrossRef]

23. Dotto, G.L.; Pinto, L.A.A. General considerations about chitosan. In Frontiers in Biomaterials; Bentham Science: Sharjah, UAE, 2017; pp. 3-33.

24. Kumar, D.; Gihar, S.; Shrivash, M.K.; Kumar, P.; Kundu, P.P. A review on the synthesis of graft copolymers of chitosan and their potential applications. Int. J. Biol. Macromol. 2020, 163, 2097-2112. [CrossRef]

25. Muñoz, I.; Rodríguez, C.; Gillet, D.; Moerschbacher, B.M. Life cycle assessment of chitosan production in India and Europe. Int. J. Life Cycle Assess. 2018, 23, 1151-1160. [CrossRef]

26. Pakdel, P.M.; Peighambardoust, S.J. Review on recent progress in chitosan-based hydrogels for wastewater treatment application. Carbohydr. Polym. 2018, 201, 264-279. [CrossRef] [PubMed]

27. Jiménez-Gómez, C.P.; Cecilia, J.A. Chitosan: A Natural biopolymer with a wide and varied range of applications. Molecules 2020, 25, 3981. [CrossRef] [PubMed]

28. Odier, A. Mémoir sur la composition chimique des parties cornées des insectes. Mémoirs la Soc. d'Histoire Nat. 1823, 1, 29-42.

29. Hamed, I.; Özogul, F.; Regenstein, J.M. Industrial applications of crustacean by-products (chitin, chitosan, and chitooligosaccharides): A review. Trends Food Sci. Technol. 2016, 48, 40-50. [CrossRef]

30. Hoppe-Seyler, F. Ueber chitin un cellulose. Berichte der Dtsch. Chem. Gesellschaft 1894, 27, 3329-3331. [CrossRef]

31. Muslim, S.; Al, I.M.S.; Naseer, A.; Ali, M.; Kadham, B.; Ahmad, M.; Saadoon, S.; Hammood, N.; Nsayef, S. Chitosan extracted from Aspergillus flavus shows synergistic effect, eases quorum sensing mediated virulence factors and biofilm against nosocomial pathogen Pseudomonas aeruginosa. Int. J. Biol. Macromol. 2018, 107, 52-58. [CrossRef]

32. Berger, L.R.R.; Stamford, T.C.M.; De Oliveira, K.; Árabe, R.; Pessoa, A.D.M.P.; De Lima, M.A.B.; Pintado, M.M.E.; Câmara, M.P.S.; Franco, L.D.O.; Magnani, M.; et al. Chitosan produced from Mucorales fungi using agroindustrial by-products and its efficacy to inhibit Colletotrichum species. Int. J. Biol. Macromol. 2018, 108, 635-641. [CrossRef]

33. Campana-Filho, S.P.; Signini, R. Efeito de aditivos na desacetilação de quitina. Polímeros: Ciência e Tecnologia 2001, 11, 169-173. [CrossRef]

34. Kaur, S.; Dhillon, G.S. Recent trends in biological extraction of chitin from marine shell wastes: A review. Crit. Rev. Biotechnol. 2015, 35, 44-61. [CrossRef]

35. Arbia, W.; Arbia, L.; Adour, L.; Amrane, A. Chitin extraction from crustacean shells using biological methods-A review. Food Technol. Biotechnol. 2013, 51, 12-25.

36. Ghorbel-bellaaj, O.; Younes, I.; Maâlej, H.; Hajji, S.; Nasri, M. Chitin extraction from shrimp shell waste using Bacillus bacteria. Int. J. Biol. Macromol. 2012, 51, 1196-1201. [CrossRef] [PubMed]

37. Hajji, S.; Ghorbel-bellaaj, O.; Younes, I.; Jellouli, K.; Nasri, M. Chitin extraction from crab shells by Bacillus bacteria. Biological activities of fermented crab supernatants. Int. J. Biol. Macromol. 2015, 79, 167-173. [CrossRef] [PubMed]

38. Araki, Y.; Ito, E. A pathway of chitosan formation in Mucor rouxii. Biochem. Biophys. Res. Commun. 1974, 56, 669-675. [CrossRef]

39. Davis, L.L.; Bartnicki-Garcia, S. Chitosan synthesis by the tandem action of chitin synthetase and chitin deacetylase from mucor rouxifi. Biochemistry 1984, 1065-1073. [CrossRef]

40. Tsigos, I.; Zydowicz, N.; Martinou, A.; Domard, A.; Bouriotis, V. Mode of action of chitin deacetylase from Mucor rouxii on N -acetylchitooligosaccharides. Eur. J. Biochem. 1999, 705, 698-705. [CrossRef]

41. Teng, D. From chitin to chitosan. In Chitosan-Based Hydrogels: Functions and Applications; Taylor \& Francis: Boca Raton, FL, USA, 2012; pp. 5-8.

42. Yuan, Y.; Chen, L.; Shi, W.; Wang, Z.; Zhang, H. Insight into physicochemical, rheological, and antibacterial properties of chitosan extracted from antarctic krill: A comparative study. Molecules 2020, 25, 4074. [CrossRef]

43. De Moura, C.M.; De Moura, J.M.; Soares, N.M.; Antonio, L.; Pinto, D.A. Evaluation of molar weight and deacetylation degree of chitosan during chitin deacetylation reaction: Used to produce biofilm. Chem. Eng. Process. Process Intensif. 2011, 50, 351-355. [CrossRef]

44. García-Bermejo, A.B.; Cardelle-Cobas, A.; Ruiz-Matute, A.I.; Montañés, F.; Olano, A.; Corzo, N. Effect of drying methods on the reactivity of chitosan towards Maillard reaction. Food Hydrocoll. 2012, 29, 27-34. [CrossRef]

45. Dotto, G.L.; de Souza, V.C.; de Moura, J.M.; de Moura, C.M.; de Almeida Pinto, L.A. Influence of drying techniques on the characteristics of chitosan and the quality of biopolymer films. Dry. Technol. 2011, 29, 1784-1791. [CrossRef]

46. Thakhiew, W.; Devahastin, S.; Soponronnarit, S. Physical and mechanical properties of chitosan films as affected by drying methods and addition of antimicrobial agent. J. Food Eng. 2013, 119, 140-149. [CrossRef]

47. Dotto, G.L.; Souza, V.C.; Pinto, L.A.A. Drying of chitosan in a spouted bed: The influences of temperature and equipment geometry in powder quality. LWT Food Sci. Technol. 2011, 44, 1786-1792. [CrossRef]

48. Estevinho, B.N.; Rocha, F.; Santos, L.; Alves, A. Microencapsulation with chitosan by spray drying for industry applications-A review. Trends Food Sci. Technol. 2013, 31, 138-155. [CrossRef]

49. Batista, L.M.; da Rosa, C.A.; Pinto, L.A.A. Diffusive model with variable effective diffusivity considering shrinkage in thin layer drying of chitosan. J. Food Eng. 2007, 81, 127-132. [CrossRef] 
50. Srinivasa, P.C.; Ramesh, M.N.; Kumar, K.R.; Tharanathan, R.N. Properties of chitosan films prepared under different drying conditions. J. Food Eng. 2004, 63, 79-85. [CrossRef]

51. Kim, M.Y.; Lee, J. Chitosan fibrous 3D networks prepared by freeze drying. Carbohydr. Polym. 2011, 84, 1329-1336. [CrossRef]

52. Mayachiew, P.; Devahastin, S. Effects of drying methods and conditions on release characteristics of edible chitosan films enriched with Indian gooseberry extract. Food Chem. 2010, 118, 594-601. [CrossRef]

53. Ibrahim, M.; Osman, O.; Mahmoud, A.A. Spectroscopic analyses of cellulose and chitosan: FTIR and modeling approach. J. Comput. Theor. Nanosci. 2011, 8, 117-123. [CrossRef]

54. Xia, W.; Liu, P.; Zhang, J.; Chen, J. Biological activities of chitosan and chitooligosaccharides. Food Hydrocoll. 2011, 25, 170-179. [CrossRef]

55. Gerhardt, R.; Farias, B.S.; Moura, J.M.; De Almeida, L.S.; Adriano, R.; Dias, D.; Cadaval, T.R.S.; Pinto, L.A.A. Development of chitosan/Spirulina sp. blend films as biosorbents for $\mathrm{Cr}^{6+}$ and $\mathrm{Pb}^{2+}$ removal. Int. J. Biol. Macromol. 2020, 155, 142-152. [CrossRef]

56. Yang, Z.; Chai, Y.; Zeng, L.; Gao, Z.; Zhang, J.; Ji, H. Efficient removal of copper ion from wastewater using a stable chitosan gel material. Molecules 2019, 24, 4205. [CrossRef] [PubMed]

57. Dotto, G.L.; Vieira, M.L.G.; Pinto, L.A.A. Kinetics and mechanism of tartrazine adsorption onto chitin and chitosan. Ind. Eng. Chem. Res. 2012, 51, 6862-6868. [CrossRef]

58. Affonso, L.N.; Marques, J.L.; Lima, V.V.C.; Gonçalves, J.O.; Barbosa, S.C.; Primel, E.G.; Burgo, T.A.L.; Dotto, G.L.; Pinto, L.A.A.; Cadaval, T.R.S. Removal of fluoride from fertilizer industry effluent using carbon nanotubes stabilized in chitosan sponge. $J$. Hazard. Mater. 2020, 388, 122042. [CrossRef] [PubMed]

59. Alves, D.C.S.; Coseglio, B.B.; Pinto, L.A.A.; Cadaval, T.R.S. Development of Spirulina/chitosan foam adsorbent for phenol adsorption. J. Mol. Liq. 2020, 309, 113256. [CrossRef]

60. Alves, D.C.S.; Gonçalves, J.O.; Coseglio, B.B.; Burgo, T.A.L.; Dotto, G.L.; Pinto, L.A.A.; Cadaval, T.R.S. Adsorption of phenol onto chitosan hydrogel scaffold modified with carbon nanotubes. J. Environ. Chem. Eng. 2019, 7, 103460. [CrossRef]

61. Soares, S.F.; Fernandes, T.; Trindade, T.; Daniel-da-silva, A.L. Trimethyl chitosan/siloxane-hybrid coated $\mathrm{Fe}_{3} \mathrm{O}_{4}$ nanoparticles for the uptake of sulfamethoxazole from water. Molecules 2019, 24, 1958. [CrossRef]

62. Phasuphan, W.; Praphairaksit, N.; Imyim, A. Removal of ibuprofen, diclofenac, and naproxen from water using chitosan-modified waste tire crumb rubber Warintorn. J. Mol. Liq. 2019, 111554. [CrossRef]

63. Sanchez, L.M.; Ollier, R.P.; Pereira, A.E.S.; Fraceto, L.F.; Alvarez, V.A. Pesticide Removal from Industrial Effluents Using Biopolymeric Materials; Elsevier Inc.: Amsterdam, The Netherlands, 2020; ISBN 9780128181348.

64. Gonçalves, J.O.; Duarte, D.A.; Dotto, G.L.; Pinto, L.A.A. Use of chitosan with different deacetylation degrees for the adsorption of food dyes in a binary system. Clean-Soil Air Water 2013, 9, 767-774. [CrossRef]

65. Liu, D.; Wei, Y.; Yao, P.; Jiang, L. Determination of the degree of acetylation of chitosan by UV spectrophotometry using dual standards. Carbohydr. Res. 2006, 341, 782-785. [CrossRef]

66. Kumirska, J.; Czerwicka, M.; Kaczyński, Z.; Bychowska, A.; Brzozowski, K.; Thöming, J.; Stepnowski, P. Application of spectroscopic methods for structural analysis of chitin and chitosan. Mar. Drugs 2010, 8, 1567-1636. [CrossRef]

67. Duarte, M.L.; Ferreira, M.C.; Marvão, M.R.; Rocha, J. An optimised method to determine the degree of acetylation of chitin and chitosan by FTIR spectroscopy. Int. J. Biol. Macromol. 2002, 31, 1-8. [CrossRef]

68. Beil, S.; Schamberger, A.; Naumann, W.; MacHill, S.; Van Pée, K.H. Determination of the degree of N-acetylation (DA) of chitin and chitosan in the presence of water by first derivative ATR FTIR spectroscopy. Carbohydr. Polym. 2012, 87, 117-122. [CrossRef]

69. Wang, C.; Yuan, F.; Jin, L.; Du, X.; Cai, H. Evaluation of the deacetylation degree of chitosan with two-abrupt-change coulometric titration. Electroanalysis 2016, 28, 401-406. [CrossRef]

70. Zhang, Y.; Zhang, X.; Ding, R.; Zhang, J.; Liu, J. Determination of the degree of deacetylation of chitosan by potentiometric titration preceded by enzymatic pretreatment. Carbohydr. Polym. 2011, 83, 813-817. [CrossRef]

71. Kong, X. Simultaneous determination of degree of deacetylation, degree of substitution and distribution fraction of -COONa in carboxymethyl chitosan by potentiometric titration. Carbohydr. Polym. 2012, 88, 336-341. [CrossRef]

72. Gupta, V.K.S. Application of low-cost adsorbents for dye removal-A review. J. Environ. Manag. 2009, 90, 2313-2342. [CrossRef]

73. Zhou, H.Y.; Guang, X.; Kong, M.; Sheng, C.; Su, D.; Kennedy, J.F. Effect of molecular weight and degree of chitosan deacetylation on the preparation and characteristics of chitosan thermosensitive hydrogel as a delivery system. Carbohydrate 2008, 73, 265-273. [CrossRef]

74. Pillai, C.K.S.; Paul, W.; Sharma, C.P. Chitin and chitosan polymers: Chemistry, solubility and fiber formation. Prog. Polym. Sci. 2009, 34, 641-678. [CrossRef]

75. Nunthanid, J.; Puttipipatkhachorn, S.; Yamamoto, K.; Peck, G.E. Physical properties and molecular behavior of chitosan films. Drug Dev. Ind. Pharm. 2001, 27, 143-157. [CrossRef]

76. Kittur, F.S.; Harish Prashanth, K.V.; Udaya Sankar, K.; Tharanathan, R.N. Characterization of chitin, chitosan and their carboxymethyl derivatives by differential scanning calorimetry. Carbohydr. Polym. 2002, 49, 185-193. [CrossRef]

77. Wenling, C.; Duohui, J.; Jiamou, L.; Yandao, G.; Nanming, Z.; Xiufang, Z. Effects of the degree of deacetylation on the physicochemical properties and schwann cell affinity of chitosan films. J. Biomater. Appl. 2005, 20, 157-177. [CrossRef] [PubMed]

78. Gupta, K.C.; Jabrail, F.H. Effects of degree of deacetylation and cross-linking on physical characteristics, swelling and release behavior of chitosan microspheres. Carbohydr. Polym. 2006, 66, 43-54. [CrossRef] 
79. Trung, T.S.; Thein-han, W.W.; Qui, N.T.; Ng, C.-H.; Stevens, W.F. Functional characteristics of shrimp chitosan and its membranes as affected by the degree of deacetylation. Bioresour. Technol. 2006, 97, 659-663. [CrossRef] [PubMed]

80. Nam, Y.S.; Park, W.H.; Ihm, D.; Hudson, S.M. Effect of the degree of deacetylation on the thermal decomposition of chitin and chitosan nanofibers. Carbohydr. Polym. 2010, 80, 291-295. [CrossRef]

81. Potivas, T.; Laokuldilok, T. Deacetylation of chitin and the properties of chitosan films with various deacetylation degrees. Food Appl. Biosci. 2014, 13, 559-568. [CrossRef]

82. Sukul, M.; Sahariah, P.; Reseland, J.E.; Lauzon, L.; Borges, J.; Másson, M.; Mano, J.F.; Haugen, H.J.; Reseland, J.E. In vitro biological response of human osteoblasts in 3D chitosan sponges with controlled degree of deacetylation and molecular weight. Carbohydr. Polym. 2020, 117434. [CrossRef]

83. Foster, L.J.R.; Ho, S.; Hook, J.; Basuki, M.; Marçal, H. Chitosan as a biomaterial: Influence of degree of deacetylation on its physiochemical, material and biological properties. PLoS ONE 2015, 10, e0135153. [CrossRef]

84. Tavares, L.; Emanuel, E.; Flores, E.; Rodrigues, R.C.; Hertz, P.F. Effect of deacetylation degree of chitosan on rheological properties and physical chemical characteristics of genipin-crosslinked chitosan beads. Food Hydrocoll. 2020, 106. [CrossRef]

85. Li, J.; Revol, J.F.; Marchessault, R.H. Effect of degree of deacetylation of chitin on the properties of chitin crystallites. J. Appl. Polym. Sci. 1997, 65, 373-380. [CrossRef]

86. Zhuang, C.; Zhong, Y.; Zhao, Y. Effect of deacetylation degree on properties of chitosan films using electrostatic spraying technique. Food Control 2019, 97, 25-31. [CrossRef]

87. Sivashankari, P.R.; Prabaharan, M. Deacetylation modification techniques of chitin and chitosan. In Chitosan Based Biomaterials: Fundamentals; Elsevier: Amsterdam, The Netherlands, 2017; Volume 1, pp. 117-133. ISBN 9780081002308.

88. Liu, Z.; Ge, X.; Lu, Y.; Dong, S.; Zhao, Y.; Zeng, M. Effects of chitosan molecular weight and degree of deacetylation on the properties of gelatine-based films. Food Hydrocoll. 2012, 26, 311-317. [CrossRef]

89. Moura, J.M.; Farias, B.S.; Rodrigues, D.A.S. Preparation of chitosan with different characteristics and its application for biofilms production. J. Polym. Environ. 2015, 23, 470-477. [CrossRef]

90. Bagheri-Khoulenjani, S.; Taghizadeh, S.M.; Mirzadeh, H. An investigation on the short-term biodegradability of chitosan with various molecular weights and degrees of deacetylation. Carbohydr. Polym. 2009, 78, 773-778. [CrossRef]

91. Barbosa, H.F.G.; Francisco, D.S.; Ferreira, A.P.G.; Cavalheiro, É.T.G. A new look towards the thermal decomposition of chitins and chitosans with different degrees of deacetylation by coupled TG-FTIR. Carbohydr. Polym. 2019, 225, 115232. [CrossRef] [PubMed]

92. Gámiz-gonzález, M.A.; Correia, D.M.; Lanceros-mendez, S.; Sencadas, V. Kinetic study of thermal degradation of chitosan as a function of deacetylation degree. Carbohydr. Polym. 2017, 167, 52-58. [CrossRef]

93. Wanjun, T.; Cunxin, W.; Donghua, C. Kinetic studies on the pyrolysis of chitin and chitosan. Polym. Degrad. Stab. 2005, 87, 389-394. [CrossRef]

94. Iamsamai, C.; Hannongbua, S.; Ruktanonchai, U. The effect of the degree of deacetylation of chitosan on its dispersion of carbon nanotubes. Carbon 2010, 48, 25-30. [CrossRef]

95. Piccin, J.S.; Vieira, M.L.G.; Gonçalves, J.O.; Dotto, G.L.; Pinto, L.A.A. Adsorption of FD \& C Red No. 40 by chitosan: Isotherms analysis. J. Food Eng. 2009, 95, 16-20. [CrossRef]

96. Habiba, U.; Chin, T.; Siddique, T.A.; Salleh, A.; Chin, B.; Afifi, A.M. Effect of degree of deacetylation of chitosan on adsorption capacity and reusability of chitosan/polyvinyl alcohol/ $\mathrm{TiO}_{2}$ nano composite. Int. J. Biol. Macromol. 2017, 104, 1133-1142. [CrossRef]

97. Józwiak, T.; Filipkowska, U.; Szymczyk, P.; Zysk, M. Effect of the form and deacetylation degree of chitosan sorbents on sorption effectiveness of Reactive Black 5 from aqueous solutions. Int. J. Biol. Macromol. 2017, 95, 1169-1178. [CrossRef]

98. Cadaval, T.R.S.; Camara, A.S.; Dotto, G.L.; Pinto, L.A. de A. Adsorption of Cr(VI) by chitosan with different deacetylation degrees. Desalin. Water Treat. 2013, 51, 7690-7699. [CrossRef]

99. Tsai, M.; Chen, R.H. Modifying the molecular weight of chitosan. In Chitosan Based Biomaterials: Fundamentals; Elsevier: Duxford, UK, 2017; Volume 1, pp. 135-158. ISBN 9780081002308.

100. De Farias, B.S.; Grundmann, D.D.R.; Rizzi, F.Z.; Martins, N.S.S.; Cadaval, T.R.S.A.; Pinto, L.A.D.A. Production of low molecular weight chitosan by acid and oxidative pathways: Effect on physicochemical properties. Food Res. Int. 2019, 123, 88-94. [CrossRef] [PubMed]

101. Zhong, Y.; Zhuang, C.; Gu, W.; Zhao, Y. Effect of molecular weight on the properties of chitosan films prepared using electrostatic spraying technique. Carbohydr. Polym. 2019, 212, 197-205. [CrossRef] [PubMed]

102. Ziani, K.; Oses, J.; Coma, V.; Mate, J.I. Effect of the presence of glycerol and Tween 20 on the chemical and physical properties of films based on chitosan with different degree of deacetylation. Food Sci. Technol. 2008, 41, 2159-2165. [CrossRef]

103. Tanpichai, S.; Witayakran, S.; Wootthikanokkhan, J.; Srimarut, Y. Mechanical and antibacterial properties of the chitosan coated cellulose paper for packaging applications: Effects of molecular weight types and concentrations of chitosan. Int. J. Biol. Macromol. 2020, 155, 1510-1519. [CrossRef]

104. Bof, M.J.; Bordadgaray, V.C.; Locaso, D.E.; García, M.A. Chitosan molecular weight effect on starch-composite film properties. Food Hydrocoll. 2015, 51, 281-294. [CrossRef]

105. Akpan, E.I.; Gbenebor, O.P.; Adeosun, S.O.; Cletus, O. Solubility, degree of acetylation, and distribution of acetyl groups in chitosan. In Handbook of Chitin and Chitosan; Elsevier: Amsterdam, The Netherlands, 2020; pp. 131-164. ISBN 9780128179703. 
106. Kubota, N.; Eguchi, Y. Facile preparation of water-soluble N-acetylated chitosan and molecular weight dependence of its water-solubility. Polym. J. 1997, 29, 123-127. [CrossRef]

107. Bajaj, M.; Winter, J.; Gallert, C. Effect of deproteination and deacetylation conditions on viscosity of chitin and chitosan extracted from Crangon crangon shrimp waste. Biochem. Eng. J. 2011, 56, 51-62. [CrossRef]

108. Chang, S.H.; Lin, H.T.V.; Wu, G.J.; Tsai, G.J. pH Effects on solubility, zeta potential, and correlation between antibacterial activity and molecular weight of chitosan. Carbohydr. Polym. 2015, 134, 74-81. [CrossRef]

109. Rinaudo, M.; Pavlov, G.; Desbrieres, J. Influence of acetic acid concentration on the solubilization of chitosan. Int. J. Polym. 1999, 40, 7029-7032. [CrossRef]

110. Rinaudo, M.; Pavlov, G.; Desbrières, J. Solubilization of chitosan in strong acid medium. Int. J. Polym. Anal. Charact. 1999, 5, 267-276. [CrossRef]

111. Kurita, K.; Kamiya, M.; Nishimura, S.I. Solubilization of a rigid polysaccharide: Controlled partial N-Acetylation of chitosan to develop solubility. Carbohydr. Polym. 1991, 16, 83-92. [CrossRef]

112. Shamov, M.V.; Bratskaya, S.Y.; Avramenko, V.A. Interaction of carboxylic acids with chitosan: Effect of pK and hydrocarbon chain length. J. Colloid Interface Sci. 2002, 249, 316-321. [CrossRef] [PubMed]

113. Lu, S.; Song, X.; Cao, D.; Chen, Y.; Yao, K. Preparation of water-soluble chitosan. J. Appl. Polym. Sci. 2004, 91, 3497-3503. [CrossRef]

114. Vieira, M.L.G.; Pinheiro, C.P.; Silva, K.A.; Lutke, S.F.; Cadaval, T.R.S.A.; Dotto, G.; de Pinto, L.A.A. Chitosan and cyanoguanidinecrosslinked chitosan coated glass beads and its application in fixed bed adsorption. Chem. Eng. Commun. 2019, 206, 1474-1486. [CrossRef]

115. Jayasuriya, A.C. Production of micro- and nanoscale chitosan particles for biomedical applications. In Chitosan Based Biomaterials: Fundamentals; Elsevier: Duxford, UK, 2017; Volume 1, pp. 185-209. ISBN 9780081002308.

116. Santos, J.C.C.; Mansur, A.A.P.; Mansur, H.S. One-step biofunctionalization of quantum dots with chitosan and n-palmitoyl chitosan for potential biomedical applications. Molecules 2013, 18, 6550-6572. [CrossRef]

117. Gonçalves, J.O.; Dotto, G.L.; Pinto, L.A.A. Cyanoguanidine-crosslinked chitosan to adsorption of food dyes in the aqueous binary system. J. Mol. Liq. 2015, 211, 425-430. [CrossRef]

118. Phongying, S.; Aiba, S.; Chirachanchai, S. Direct chitosan nanoscaffold formation via chitin whiskers. Polymer 2007, 48, 393-400. [CrossRef]

119. Esquerdo, V.; Jr, T.R.S.C.; Dotto, G.L.; Pinto, L.A. Chitosan scaffold as an alternative adsorbent for the removal of hazardous food dyes from aqueous solutions. J. Colloid Interface Sci. 2014, 424, 7-15. [CrossRef]

120. Piccin, J.S.; Dotto, G.L.; Vieira, M.L.G.; Pinto, L.A.A. Kinetics and mechanism of the food dye FD \& C Red 40 adsorption onto chitosan. J. Chem. Eng. Data 2011, 56, 3759-3765.

121. Wu, F.C.; Tseng, R.L.; Juang, R.S. Comparative adsorption of metal and dye on flake- and bead-types of chitosans prepared from fishery wastes. J. Hazard. Mater. 2000, 73, 63-75. [CrossRef]

122. Chatterjee, S.; Lee, D.S.; Lee, M.W.; Woo, S.H. Enhanced adsorption of congo red from aqueous solutions by chitosan hydrogel beads impregnated with cetyl trimethyl ammonium bromide. Bioresour. Technol. 2009, 100, 2803-2809. [CrossRef] [PubMed]

123. Cheng, J.S.; Du, J.; Zhu, W. Facile synthesis of three-dimensional chitosan-graphene mesostructures for reactive black 5 removal. Carbohydr. Polym. 2012, 88, 61-67. [CrossRef]

124. Karimi, S.; Tavakkoli Yaraki, M.; Karri, R.R. A comprehensive review of the adsorption mechanisms and factors influencing the adsorption process from the perspective of bioethanol dehydration. Renew. Sustain. Energy Rev. 2019, 107, 535-553. [CrossRef]

125. Wittmar, A.S.M.; Böhler, H.; Kayali, A.L.; Ulbricht, M. One-step preparation of porous cellulose/chitosan macro-spheres from ionic liquid-based solutions. Cellulose 2020, 27, 5689-5705. [CrossRef]

126. Li, N.; Bai, R. Copper adsorption on chitosan-cellulose hydrogel beads: Behaviors and mechanisms. Sep. Purif. Technol. 2005, 42, 237-247. [CrossRef]

127. Chen, L.; Hao, H.; Zhang, W.; Shao, Z. Adsorption mechanism of copper ions in aqueous solution by chitosan-carboxymethyl starch composites. J. Appl. Polym. Sci. 2020, 137. [CrossRef]

128. Zhao, X.; Wang, X.; Lou, T. Preparation of fibrous chitosan/sodium alginate composite foams for the adsorption of cationic and anionic dyes. J. Hazard. Mater. 2021, 403, 124054. [CrossRef]

129. Preethi, J.; Karthikeyan, P.; Vigneshwaran, S.; Meenakshi, S. Facile synthesis of $\mathrm{Zr}^{4+}$ incorporated chitosan/gelatin composite for the sequestration of Chromium(VI) and fluoride from water. Chemosphere 2021, 262, 128317. [CrossRef]

130. Da Silva, J.C.S.; França, D.B.; Rodrigues, F.; Oliveira, D.M.; Trigueiro, P.; Silva Filho, E.C.; Fonseca, M.G. What happens when chitosan meets bentonite under microwave-assisted conditions? Clay-based hybrid nanocomposites for dye adsorption. Colloids Surf. A Physicochem. Eng. Asp. 2021, 609, 125584. [CrossRef]

131. Lin, J.; Zhan, Y. Adsorption of humic acid from aqueous solution onto unmodified and surfactant-modified chitosan/zeolite composites. Chem. Eng. J. 2012, 200, 202-213. [CrossRef]

132. Zhao, R.; Ma, T.; Zhao, S.; Rong, H.; Tian, Y.; Zhu, G. Uniform and stable immobilization of metal-organic frameworks into chitosan matrix for enhanced tetracycline removal from water. Chem. Eng. J. 2020, 382. [CrossRef]

133. Karthik, R.; Meenakshi, S. Removal of hexavalent chromium ions from aqueous solution using chitosan/polypyrrole composite. Desalin. Water Treat. 2015, 56, 1587-1600. [CrossRef] 
134. Kundakci, S. Synthesis of Methacrylamide/chitosan polymeric cryogels and swelling/dye sorption properties. Polym. Sci. Ser. A 2020, 62, 481-493. [CrossRef]

135. Da Silva, R.C.; de Aguiar, S.B.; da Cunha, P.L.R.; de Paula, R.C.M.; Feitosa, J.P.A. Effect of microwave on the synthesis of polyacrylamide-g-chitosan gel for azo dye removal. React. Funct. Polym. 2020, 148. [CrossRef]

136. Da Rosa Schio, R.; da Rosa, B.C.; Gonçalves, J.O.; Pinto, L.A.A.; Mallmann, E.S.; Dotto, G.L. Synthesis of a bio-based polyurethane/chitosan composite foam using ricinoleic acid for the adsorption of Food Red 17 dye. Int. J. Biol. Macromol. 2019, 121, 373-380. [CrossRef]

137. Zhu, H.-Y.; Fu, Y.-Q.; Jiang, R.; Yao, J.; Xiao, L.; Zeng, G.-M. Novel magnetic chitosan/poly(vinyl alcohol) hydrogel beads: Preparation, characterization and application for adsorption of dye from aqueous solution. Bioresour. Technol. 2012, 105, 24-30. [CrossRef]

138. Gu, F.; Geng, J.; Li, M.; Chang, J.; Cui, Y. Synthesis of chitosan-lignosulfonate composite as an adsorbent for dyes and metal ions removal from wastewater. ACS Omega 2019, 4, 21421-21430. [CrossRef]

139. Lee, C.W.; Suh, J.M.; Jang, H.W. Chemical sensors based on two-dimensional (2D) materials for selective detection of ions and molecules in liquid. Front. Chem. 2019, 7. [CrossRef]

140. Chang, Y.-M.; Lin, H.-W.; Li, L.-J.; Chen, H.-Y. Two-dimensional materials as anodes for sodium-ion batteries. Mater. Today Adv. 2020, 6. [CrossRef]

141. Yu, T.; Breslin, C.B. Graphene-modified composites and electrodes and their potential applications in the electro-fenton process. Materials 2020, 13, 2254. [CrossRef] [PubMed]

142. Li, D.; Lai, W.-Y.; Zhang, Y.-Z.; Huang, W. Printable transparent conductive films for flexible electronics. Adv. Mater. 2018, 30. [CrossRef] [PubMed]

143. Rochefort, A.; Wuest, J.D. Interaction of substituted aromatic compounds with graphene. Langmuir 2009, 25, 210-215. [CrossRef] [PubMed]

144. Chen, Y.; Chen, L.; Bai, H.; Li, L. Graphene oxide-chitosan composite hydrogels as broad-spectrum adsorbents for water purification. J. Mater. Chem. A 2013, 1, 1992-2001. [CrossRef]

145. Liu, Z.; Rios-Carvajal, T.; Ceccato, M.; Hassenkam, T. Nanoscale chemical mapping of oxygen functional groups on graphene oxide using atomic force microscopy-coupled infrared spectroscopy. J. Colloid Interface Sci. 2019, 556, 458-465. [CrossRef]

146. Aliyev, E.; Filiz, V.; Khan, M.M.; Lee, Y.J.; Abetz, C.; Abetz, V. Structural characterization of graphene oxide: Surface functional groups and fractionated oxidative debris. Nanomaterials 2019, 9, 1180. [CrossRef]

147. Şinoforoğlu, M.; Gür, B.; Arik, M.; Onganer, Y.; Meral, K. Graphene oxide sheets as a template for dye assembly: Graphene oxide sheets induce H-aggregates of pyronin (Y) dye. RSC Adv. 2013, 3, 11832-11838. [CrossRef]

148. Ramesha, G.K.; Vijaya Kumara, A.; Muralidhara, H.B.; Sampath, S. Graphene and graphene oxide as effective adsorbents toward anionic and cationic dyes. J. Colloid Interface Sci. 2011, 361, 270-277. [CrossRef]

149. Chowdhury, S.; Balasubramanian, R. Recent advances in the use of graphene-family nanoadsorbents for removal of toxic pollutants from wastewater. Adv. Colloid Interface Sci. 2014, 204, 35-56. [CrossRef]

150. Eda, G.; Chhowalla, M. Chemically derived graphene oxide: Towards large-area thin-film electronics and optoelectronics. Adv. Mater. 2010, 22, 2392-2415. [CrossRef]

151. Javadi, E.; Baghdadi, M.; Taghavi, L.; Ahmad Panahi, H. Removal of 4-nonylphenol from surface water and municipal wastewater effluent using three-dimensional graphene oxide-chitosan aerogel beads. Int. J. Environ. Res. 2020, 14, 513-526. [CrossRef]

152. Lai, K.C.; Lee, L.Y.; Hiew, B.Y.Z.; Yang, T.C.-K.; Pan, G.-T.; Thangalazhy-Gopakumar, S.; Gan, S. Utilisation of eco-friendly and low cost 3D graphene-based composite for treatment of aqueous Reactive Black 5 dye: Characterisation, adsorption mechanism and recyclability studies. J. Taiwan Inst. Chem. Eng. 2020, 114, 57-66. [CrossRef]

153. Zhang, M.; Ma, G.; Zhang, L.; Chen, H.; Zhu, L.; Wang, C.; Liu, X. Chitosan-reduced graphene oxide composites with 3D structures as effective reverse dispersed solid phase extraction adsorbents for pesticides analysis. Analyst 2019, 144, 5164-5171. [CrossRef] [PubMed]

154. Yang, X.; Tu, Y.; Li, L.; Shang, S.; Tao, X.-M. Well-dispersed chitosan/graphene oxide nanocomposites. ACS Appl. Mater. Interfaces 2010, 2, 1707-1713. [CrossRef] [PubMed]

155. Fan, L.; Luo, C.; Li, X.; Lu, F.; Qiu, H.; Sun, M. Fabrication of novel magnetic chitosan grafted with graphene oxide to enhance adsorption properties for methyl blue. J. Hazard. Mater. 2012, 215-216, 272-279. [CrossRef]

156. Li, K.; Zhao, B.; Yu, Q.; Xu, J.; Li, X.; Wei, D.; Qian, L.; Liu, G.; Wang, W. Porous graphene oxide/chitosan beads with honeycombbiomimetic microchannels as hydrophilic adsorbent for the selective capture of glycopeptides. Microchim. Acta 2020, 187, 324. [CrossRef]

157. Zhang, J.; Chen, N.; Su, P.; Li, M.; Feng, C. Fluoride removal from aqueous solution by zirconium-chitosan/graphene oxide membrane. React. Funct. Polym. 2017, 114, 127-135. [CrossRef]

158. Li, C.; Ashraf, M.A. Preparation of a new graphite oxide/chitosan composite membrane and its application in environmental protection engineering. Funct. Mater. 2019, 26, 441-445. [CrossRef]

159. Vo, T.S.; Vo, T.T.B.C.; Suk, J.W.; Kim, K. Recycling performance of graphene oxide-chitosan hybrid hydrogels for removal of cationic and anionic dyes. Nano Converg. 2020, 7, 4. [CrossRef]

160. Du, Q.; Li, Y.; Li, J.; Zhang, Z.; Qiao, B.; Sui, K.; Wang, D.; Wang, C.; Li, H.; Xia, Y. Preparation of graphene oxide/chitosan pellets and their adsorption properties for Congo Red. Int. J. Nanosci. 2019, 18, 1850030. [CrossRef] 
161. Liu, L.; Li, C.; Bao, C.; Jia, Q.; Xiao, P.; Liu, X.; Zhang, Q. Preparation and characterization of chitosan/graphene oxide composites for the adsorption of $\mathrm{Au}(\mathrm{III})$ and Pd(II). Talanta 2012, 93, 350-357. [CrossRef] [PubMed]

162. Mohseni Kafshgari, M.; Tahermansouri, H. Development of a graphene oxide/chitosan nanocomposite for the removal of picric acid from aqueous solutions: Study of sorption parameters. Colloids Surf. B Biointerfaces 2017, 160, 671-681. [CrossRef] [PubMed]

163. Delhiraja, K.; Vellingiri, K.; Boukhvalov, D.W.; Philip, L. Development of highly water stable graphene oxide-based composites for the removal of pharmaceuticals and personal care products. Ind. Eng. Chem. Res. 2019, 58, 2899-2913. [CrossRef]

164. Rebekah, A.; Bharath, G.; Naushad, M.; Viswanathan, C.; Ponpandian, N. Magnetic graphene/chitosan nanocomposite: A promising nano-adsorbent for the removal of 2-naphthol from aqueous solution and their kinetic studies. Int. J. Biol. Macromol. 2020, 159, 530-538. [CrossRef] [PubMed]

165. Singh, N.; Riyajuddin, S.; Ghosh, K.; Mehta, S.K.; Dan, A. Chitosan-graphene oxide hydrogels with embedded magnetic iron oxide nanoparticles for dye removal. ACS Appl. Nano Mater. 2019, 2, 7379-7392. [CrossRef]

166. Kharissova, O.V.; Dias, H.V.R.; Kharisov, B.I. Magnetic adsorbents based on micro- and nano-structured materials. RSC Adv. 2015, 5, 6695-6719. [CrossRef]

167. Gul, K.; Sohni, S.; Waqar, M.; Ahmad, F.; Norulaini, N.A.N. Functionalization of magnetic chitosan with graphene oxide for removal of cationic and anionic dyes from aqueous solution. Carbohydr. Polym. 2016, 152, 520-531. [CrossRef]

168. Shan, H.; Peng, S.; Zhao, C.; Zhan, H.; Zeng, C. Highly efficient removal of As(III) from aqueous solutions using goethite/graphene oxide/chitosan nanocomposite. Int. J. Biol. Macromol. 2020, 164, 13-26. [CrossRef]

169. Zhu, H.-Y.; Jiang, R.; Xiao, L.; Li, W. A novel magnetically separable $\gamma$ - $\mathrm{Fe}_{2} \mathrm{O}_{3} /$ crosslinked chitosan adsorbent: Preparation, characterization and adsorption application for removal of hazardous azo dye. J. Hazard. Mater. 2010, 179, 251-257. [CrossRef]

170. Sarkar, A.K.; Bediako, J.K.; Choi, J.-W.; Yun, Y.-S. Functionalized magnetic biopolymeric graphene oxide with outstanding performance in water purification. NPG Asia Mater. 2019, 11, 4. [CrossRef]

171. Xu, L.; Suo, H.; Wang, J.; Cheng, F.; Liu, H.; Qiu, H. Magnetic graphene oxide decorated with chitosan and Au nanoparticles: Synthesis, characterization and application for detection of trace Rhodamine B. Anal. Methods 2019, 11, 3837-3843. [CrossRef]

172. Foroughi, M.; Azqhandi, M.H.A. A biological-based adsorbent for a non-biodegradable pollutant: Modeling and optimization of $\mathrm{Pb}$ (II) remediation using GO-CS-Fe $\mathrm{O}_{4}$-EDTA nanocomposite. J. Mol. Liq. 2020, 318, 114077. [CrossRef]

173. Tasmia Shah, J.; Jan, M.R. Microextraction of selected endocrine disrupting phenolic compounds using magnetic chitosan biopolymer graphene oxide nanocomposite. J. Polym. Environ. 2020, 28, 1673-1683. [CrossRef]

174. Anush, S.M.; Chandan, H.R.; Gayathri, B.H.; Asma Manju, N.; Vishalakshi, B.; Kalluraya, B. Graphene oxide functionalized chitosan-magnetite nanocomposite for removal of $\mathrm{Cu}(\mathrm{II})$ and $\mathrm{Cr}(\mathrm{VI})$ from waste water. Int. J. Biol. Macromol. 2020, 164, 4391-4402. [CrossRef] [PubMed]

175. Tran, H.V.; Hoang, L.T.; Huynh, C.D. An investigation on kinetic and thermodynamic parameters of methylene blue adsorption onto graphene-based nanocomposite. Chem. Phys. 2020, 535, 110793. [CrossRef]

176. Shafaati, M.; Miralinaghi, M.; Shirazi, R.H.S.M.; Moniri, E. The use of chitosan $/ \mathrm{Fe}_{3} \mathrm{O}_{4}$ grafted graphene oxide for effective adsorption of rifampicin from water samples. Res. Chem. Intermed. 2020. [CrossRef]

177. Jiang, X.; Pan, W.; Chen, M.; Yuan, Y.; Zhao, L. The fabrication of a thiol-modified chitosan magnetic graphene oxide nanocomposite and its adsorption performance towards the illegal drug clenbuterol in pork samples. Dalt. Trans. 2020, 49, 6097-6107. [CrossRef]

178. Tang, T.; Cao, S.; Xi, C.; Li, X.; Zhang, L.; Wang, G.; Chen, Z. Chitosan functionalized magnetic graphene oxide nanocomposite for the sensitive and effective determination of alkaloids in hotpot. Int. J. Biol. Macromol. 2020, 146, 343-352. [CrossRef]

179. Huang, Y.; Fulton, A.N.; Keller, A.A. Simultaneous removal of PAHs and metal contaminants from water using magnetic nanoparticle adsorbents. Sci. Total Environ. 2016, 571, 1029-1036. [CrossRef]

180. Pei, S.; Cheng, H.-M. The reduction of graphene oxide. Carbon 2012, 50, 3210-3228. [CrossRef]

181. Zhang, J.; Yang, H.; Shen, G.; Cheng, P.; Zhang, J.; Guo, S. Reduction of graphene oxide vial-ascorbic acid. Chem. Commun. 2010, 46, 1112-1114. [CrossRef] [PubMed]

182. Wang, Z.; Zhou, X.; Zhang, J.; Boey, F.; Zhang, H. Direct electrochemical reduction of single-layer graphene oxide and subsequent functionalization with glucose oxidase. J. Phys. Chem. C 2009, 113, 14071-14075. [CrossRef]

183. Guo, H.-L.; Wang, X.-F.; Qian, Q.-Y.; Wang, F.-B.; Xia, X.-H. A green approach to the synthesis of graphene nanosheets. ACS Nano 2009, 3, 2653-2659. [CrossRef]

184. Shao, Y.; Wang, J.; Engelhard, M.; Wang, C.; Lin, Y. Facile and controllable electrochemical reduction of graphene oxide and its applications. J. Mater. Chem. 2010, 20, 743-748. [CrossRef]

185. Sreeprasad, T.S.; Maliyekkal, S.M.; Lisha, K.P.; Pradeep, T. Reduced graphene oxide-metal/metal oxide composites: Facile synthesis and application in water purification. J. Hazard. Mater. 2011, 186, 921-931. [CrossRef]

186. Sheshmani, S.; Mashhadi, S. Potential of magnetite reduced graphene oxide/chitosan nanocomposite as biosorbent for the removal of dyes from aqueous solutions. Polym. Compos. 2018, 39, E457-E462. [CrossRef]

187. Ciğeroğlu, Z.; Küçükyıldız, G.; Erim, B.; Alp, E. Easy preparation of magnetic nanoparticles-rGO-chitosan composite beads: Optimization study on cefixime removal based on RSM and ANN by using Genetic Algorithm Approach. J. Mol. Struct. 2021, 1224, 129182. [CrossRef]

188. Guo, X.; Qu, L.; Tian, M.; Zhu, S.; Zhang, X.; Tang, X.; Sun, K. Chitosan/graphene oxide composite as an effective adsorbent for reactive red dye removal. Water Environ. Res. 2016, 88, 579-588. [CrossRef] 
189. Liu, F.; Chung, S.; Oh, G.; Seo, T.S. Three-dimensional graphene oxide nanostructure for fast and efficient water-soluble dye removal. ACS Appl. Mater. Interfaces 2012, 4, 922-927. [CrossRef]

190. Cheng, C.; Deng, J.; Lei, B.; He, A.; Zhang, X.; Ma, L.; Li, S.; Zhao, C. Toward 3D graphene oxide gels based adsorbents for high-efficient water treatment via the promotion of biopolymers. J. Hazard. Mater. 2013, 263, 467-478. [CrossRef]

191. Ma, Y.; Chen, Y. Three-dimensional graphene networks: Synthesis, properties and applications. Natl. Sci. Rev. 2015, 2, 40-53. [CrossRef]

192. Sun, Z.; Fang, S.; Hu, Y.H. 3D Graphene materials: From understanding to design and synthesis control. Chem. Rev. 2020, 120, 10336-10453. [CrossRef] [PubMed]

193. Ma, Z.; Liu, D.; Zhu, Y.; Li, Z.; Li, Z.; Tian, H.; Liu, H. Graphene oxide/chitin nanofibril composite foams as column adsorbents for aqueous pollutants. Carbohydr. Polym. 2016, 144, 230-237. [CrossRef] [PubMed]

194. Zhang, D.; Li, N.; Cao, S.; Liu, X.; Qiao, M.; Zhang, P.; Zhao, Q.; Song, L.; Huang, X. A layered chitosan/graphene oxide sponge as reusable adsorbent for removal of heavy metal ions. Chem. Res. Chin. Univ. 2019, 35, 463-470. [CrossRef]

195. Yu, B.; Xu, J.; Liu, J.-H.; Yang, S.-T.; Luo, J.; Zhou, Q.; Wan, J.; Liao, R.; Wang, H.; Liu, Y. Adsorption behavior of copper ions on graphene oxide-chitosan aerogel. J. Environ. Chem. Eng. 2013, 1, 1044-1050. [CrossRef]

196. Zhao, L.; Dong, P.; Xie, J.; Li, J.; Wu, L.; Yang, S.-T.; Luo, J. Porous graphene oxide-chitosan aerogel for tetracycline removal. Mater. Res. Express 2014, 1, 015601. [CrossRef]

197. Wang, Y.; Xia, G.; Wu, C.; Sun, J.; Song, R.; Huang, W. Porous chitosan doped with graphene oxide as highly effective adsorbent for methyl orange and amido black 10B. Carbohydr. Polym. 2015, 115, 686-693. [CrossRef]

198. Salzano de Luna, M.; Ascione, C.; Santillo, C.; Verdolotti, L.; Lavorgna, M.; Buonocore, G.G.; Castaldo, R.; Filippone, G.; Xia, H.; Ambrosio, L. Optimization of dye adsorption capacity and mechanical strength of chitosan aerogels through crosslinking strategy and graphene oxide addition. Carbohydr. Polym. 2019, 211, 195-203. [CrossRef]

199. Mei, J.; Zhang, H.; Mo, S.; Zhang, Y.; Li, Z.; Ou, H. Prominent adsorption of Cr(VI) with graphene oxide aerogel twined with creeper-like polymer based on chitosan oligosaccharide. Carbohydr. Polym. 2020, 247, 116733. [CrossRef]

200. Liu, Y.; Huang, S.; Zhao, X.; Zhang, Y. Fabrication of three-dimensional porous $\beta$-cyclodextrin/chitosan functionalized graphene oxide hydrogel for methylene blue removal from aqueous solution. Colloids Surf. A Physicochem. Eng. Asp. 2018, 539, 1-10. [CrossRef]

201. Yan, J.; Li, X.; Qiu, F.; Zhao, H.; Yang, D.; Wang, J.; Wen, W. Synthesis of $\beta$-cyclodextrin-chitosan-graphene oxide composite and its application for adsorption of manganese ion (II). Mater. Technol. 2016, 31, 406-415. [CrossRef]

202. Li, L.; Fan, L.; Sun, M.; Qiu, H.; Li, X.; Duan, H.; Luo, C. Adsorbent for chromium removal based on graphene oxide functionalized with magnetic cyclodextrin-chitosan. Colloids Surf. B Biointerface 2013, 107, 76-83. [CrossRef] [PubMed]

203. Li, L.; Fan, L.; Sun, M.; Qiu, H.; Li, X.; Duan, H.; Luo, C. Adsorbent for hydroquinone removal based on graphene oxide functionalized with magnetic cyclodextrin-chitosan. Int. J. Biol. Macromol. 2013, 58, 169-175. [CrossRef] [PubMed]

204. Fan, L.; Luo, C.; Sun, M.; Qiu, H.; Li, X. Synthesis of magnetic $\beta$-cyclodextrin-chitosan/graphene oxide as nanoadsorbent and its application in dye adsorption and removal. Colloids Surf. B Biointerface 2013, 103, 601-607. [CrossRef] [PubMed]

205. Salahuddin, N.; EL-Daly, H.; El Sharkawy, R.G.; Nasr, B.T. Synthesis and efficacy of PPy/CS/GO nanocomposites for adsorption of ponceau 4R dye. Polymer 2018, 146, 291-303. [CrossRef]

206. Kamal, S.; Khan, F.; Kausar, H.; Khan, M.S.; Ahmad, A.; Ishraque Ahmad, S.; Asim, M.; Alshitari, W.; Nami, S.A.A. Synthesis, characterization, morphology, and adsorption studies of ternary nanocomposite comprising graphene oxide, chitosan, and polypyrrole. Polym. Compos. 2020, 41, 3758-3767. [CrossRef]

207. Salahuddin, N.A.; EL-Daly, H.A.; El Sharkawy, R.G.; Nasr, B.T. Nano-hybrid based on polypyrrole/chitosan/grapheneoxide magnetite decoration for dual function in water remediation and its application to form fashionable colored product. Adv. Powder Technol. 2020, 31, 1587-1596. [CrossRef]

208. Wang, Z.; Zhang, G.; Li, Y. Preparation of chitosan/polyacrylamide/graphene oxide composite membranes and study of their methylene blue adsorption properties. Materials 2020, 13, 4407. [CrossRef]

209. Chang, Z.; Chen, Y.; Tang, S.; Yang, J.; Chen, Y.; Chen, S.; Li, P.; Yang, Z. Construction of chitosan/polyacrylate/graphene oxide composite physical hydrogel by semi-dissolution/acidification/sol-gel transition method and its simultaneous cationic and anionic dye adsorption properties. Carbohydr. Polym. 2020, 229, 115431. [CrossRef]

210. Hong, S.; Na, Y.S.; Choi, S.; Song, I.T.; Kim, W.Y.; Lee, H. Non-covalent self-assembly and covalent polymerization co-contribute to polydopamine formation. Adv. Funct. Mater. 2012, 22, 4711-4717. [CrossRef]

211. Fu, J.; Xin, Q.; Wu, X.; Chen, Z.; Yan, Y.; Liu, S.; Wang, M.; Xu, Q. Selective adsorption and separation of organic dyes from aqueous solution on polydopamine microspheres. J. Colloid Interface Sci. 2016, 461, 292-304. [CrossRef] [PubMed]

212. Li, L.; Wei, Z.; Liu, X.; Yang, Y.; Deng, C.; Yu, Z.; Guo, Z.; Shi, J.; Zhu, C.; Guo, W.; et al. Biomaterials cross-linked graphene oxide composite aerogel with a macro-nanoporous network structure for efficient Cr (VI) removal. Int. J. Biol. Macromol. 2020, 156, 1337-1346. [CrossRef] [PubMed]

213. Li, T.; Liu, X.; Li, L.; Wang, Y.; Ma, P.; Chen, M.; Dong, W. Polydopamine-functionalized graphene oxide compounded with polyvinyl alcohol/chitosan hydrogels on the recyclable adsorption of $\mathrm{Cu}(\mathrm{II}), \mathrm{Pb}(\mathrm{II})$ and $\mathrm{Cd}(\mathrm{II})$ from aqueous solution. J. Polym. Res. 2019, 26, 281. [CrossRef]

214. Ma, L.; Wang, Q.; Islam, S.M.; Liu, Y.; Ma, S.; Kanatzidis, M.G. Highly selective and efficient removal of heavy metals by layered double hydroxide intercalated with the $\mathrm{MoS}_{4}{ }^{2-}$ ion. J. Am. Chem. Soc. 2016, 138, 2858-2866. [CrossRef] [PubMed] 
215. Wang, R.; Zhang, X.; Zhu, J.; Bai, J.; Gao, L.; Liu, S.; Jiao, T. Facile preparation of self-assembled chitosan-based composite hydrogels with enhanced adsorption performances. Colloids Surf. A Physicochem. Eng. Asp. 2020, 598, 124860. [CrossRef]

216. Priya, V.N.; Rajkumar, M.; Magesh, G.; Mobika, J.; Sibi, S.P.L. Chitosan assisted Fe-Al double layered hydroxide/reduced graphene oxide composites for As(V) removal. Mater. Chem. Phys. 2020, 251, 123108. [CrossRef]

217. Samuel, M.S.; Subramaniyan, V.; Bhattacharya, J.; Parthiban, C.; Chand, S.; Singh, N.D.P. A GO-CS@MOF [Zn(BDC)(DMF)] material for the adsorption of chromium(VI) ions from aqueous solution. Compos. Part B Eng. 2018, 152, 116-125. [CrossRef]

218. Guo, X.; Yang, H.; Liu, Q.; Liu, J.; Chen, R.; Zhang, H.; Yu, J.; Zhang, M.; Li, R.; Wang, J. A chitosan-graphene oxide/ZIF foam with anti-biofouling ability for uranium recovery from seawater. Chem. Eng. J. 2020, 382, 122850. [CrossRef]

219. Li, J.; Wang, X.; Zhao, G.; Chen, C.; Chai, Z.; Alsaedi, A.; Hayat, T.; Wang, X. Metal-organic framework-based materials: Superior adsorbents for the capture of toxic and radioactive metal ions. Chem. Soc. Rev. 2018, 47, 2322-2356. [CrossRef]

220. Zhang, Y.; Chen, S.; Feng, X.; Yu, J.; Jiang, X. Self-assembly of sponge-like kaolin/chitosan/reduced graphene oxide composite hydrogels for adsorption of Cr(VI) and AYR. Environ. Sci. Pollut. Res. 2019, 26, 28898-28908. [CrossRef]

221. Yan, M.; Huang, W.; Li, Z. Chitosan cross-linked graphene oxide/lignosulfonate composite aerogel for enhanced adsorption of methylene blue in water. Int. J. Biol. Macromol. 2019, 136, 927-935. [CrossRef] [PubMed]

222. Zeng, W.; Liu, Y.-G.; Hu, X.-J.; Liu, S.-B.; Zeng, G.-M.; Zheng, B.-H.; Jiang, L.-H.; Guo, F.-Y.; Ding, Y.; Xu, Y. Decontamination of methylene blue from aqueous solution by magnetic chitosan lignosulfonate grafted with graphene oxide: Effects of environmental conditions and surfactant. RSC Adv. 2016, 6, 19298-19307. [CrossRef]

223. Ge, H.; Ma, Z. Microwave preparation of triethylenetetramine modified graphene oxide/chitosan composite for adsorption of Cr(VI). Carbohydr. Polym. 2015, 131, 280-287. [CrossRef] [PubMed]

224. Sirajudheen, P.; Karthikeyan, P.; Ramkumar, K.; Meenakshi, S. Effective removal of organic pollutants by adsorption onto chitosan supported graphene oxide-hydroxyapatite composite: A novel reusable adsorbent. J. Mol. Liq. 2020, 318, 114200. [CrossRef]

225. Azizkhani, S.; Mahmoudi, E.; Abdullah, N.; Ismail, M.H.S.; Mohammad, A.W.; Hussain, S.A. Synthesis and characterisation of graphene oxide-silica-chitosan for eliminating the $\mathrm{Pb}(\mathrm{II})$ from aqueous solution. Polymers 2020, 12, 1922. [CrossRef] [PubMed]

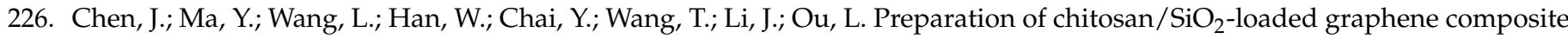
beads for efficient removal of bilirubin. Carbon N. Y. 2019, 143, 352-361. [CrossRef]

227. Kovtun, A.; Campodoni, E.; Favaretto, L.; Zambianchi, M.; Salatino, A.; Amalfitano, S.; Navacchia, M.L.; Casentini, B.; Palermo, V.; Sandri, M.; et al. Multifunctional graphene oxide/biopolymer composite aerogels for microcontaminants removal from drinking water. Chemosphere 2020, 259. [CrossRef]

228. Wu, Z.; Deng, W.; Zhou, W.; Luo, J. Novel magnetic polysaccharide/graphene oxide $@ \mathrm{Fe}_{3} \mathrm{O}_{4}$ gel beads for adsorbing heavy metal ions. Carbohydr. Polym. 2019, 216, 119-128. [CrossRef]

229. Wei, H.; Han, L.; Tang, Y.; Ren, J.; Zhao, Z.; Jia, L. Highly flexible heparin-modified chitosan/graphene oxide hybrid hydrogel as a super bilirubin adsorbent with excellent hemocompatibility. J. Mater. Chem. B 2015, 3, 1646-1654. [CrossRef]

230. Huang, T.; Shao, Y.-W.; Zhang, Q.; Deng, Y.-F.; Liang, Z.-X.; Guo, F.-Z.; Li, P.-C.; Wang, Y. Chitosan-cross-linked graphene oxide/carboxymethyl cellulose aerogel globules with high structure stability in liquid and extremely high adsorption ability. ACS Sustain. Chem. Eng. 2019, 7, 8775-8788. [CrossRef]

231. Tofighy, M.A.; Mohammadi, T. Copper ions removal from aqueous solutions using acid-chitosan functionalized carbon nanotubes sheets. Desalin. Water Treat. 2016, 57, 15384-15396. [CrossRef]

232. Mallakpour, S.; Nezamzadeh Ezhieh, A. Preparation and characterization of chitosan-poly(vinyl alcohol) nanocomposite films embedded with functionalized multi-walled carbon nanotube. Carbohydr. Polym. 2017, 166, 377-386. [CrossRef] [PubMed]

233. Zeng, G.; Liu, X.; Liu, M.; Huang, Q.; Xu, D.; Wan, Q.; Huang, H.; Deng, F.; Zhang, X.; Wei, Y. Facile preparation of carbon nanotubes based carboxymethyl chitosan nanocomposites through combination of mussel inspired chemistry and Michael addition reaction: Characterization and improved $\mathrm{Cu}^{2+}$ removal capability. J. Taiwan Inst. Chem. Eng. 2016, 68, 446-454. [CrossRef]

234. Jung, C.; Heo, J.; Han, J.; Her, N.; Lee, S.-J.; Oh, J.; Ryu, J.; Yoon, Y. Hexavalent chromium removal by various adsorbents: Powdered activated carbon, chitosan, and single/multi-walled carbon nanotubes. Sep. Purif. Technol. 2013, 106, 63-71. [CrossRef]

235. Dai, B.; Cao, M.; Fang, G.; Liu, B.; Dong, X.; Pan, M.; Wang, S. Schiff base-chitosan grafted multiwal led carbon nanotubes as a novel solid-phase extraction adsorbent for determination of heavy metal by ICP-MS. J. Hazard. Mater. 2012, 219-220, 103-110. [CrossRef]

236. Popuri, S.R.; Frederick, R.; Chang, C.-Y.; Fang, S.-S.; Wang, C.-C.; Lee, L.-C. Removal of copper (II) ions from aqueous solutions onto chitosan/carbon nanotubes composite sorbent. Desalin. Water Treat. 2014, 52, 691-701. [CrossRef]

237. Chen, J.-H.; Lu, D.-Q.; Chen, B.; Ouyang, P.-K. Removal of U(VI) from aqueous solutions by using MWCNTs and chitosan modified MWCNTs. J. Radioanal. Nucl. Chem. 2013, 295, 2233-2241. [CrossRef]

238. Nitayaphat, W.; Jintakosol, T. Removal of Silver(I) from Aqueous Solutions by Chitosan/Carbon Nanotube Nanocomposite Beads; Trans Tech Publications Ltd.: Bäch, Switzerland, 2014; Volume 893, ISBN 9783038350255.

239. Huang, Y.; Lee, X.; Grattieri, M.; Macazo, F.C.; Cai, R.; Minteer, S.D. A sustainable adsorbent for phosphate removal: Modifying multi-walled carbon nanotubes with chitosan. J. Mater. Sci. 2018, 53, 12641-12649. [CrossRef]

240. Firozjaee, T.T.; Mehrdadi, N.; Baghdadi, M.; Nabi Bidhendi, G.R.N. The removal of diazinon from aqueous solution by chitosan/carbon nanotube adsorbent. Desalin. Water Treat. 2017, 79, 291-300. [CrossRef] 
241. Gonçalves, J.O.; da Silva, K.A.; Rios, E.C.; Crispim, M.M.; Dotto, G.L.; de Almeida Pinto, L.A. Chitosan hydrogel scaffold modified with carbon nanotubes and its application for food dyes removal in single and binary aqueous systems. Int. J. Biol. Macromol. 2020, 142, 85-93. [CrossRef]

242. Wang, W.; Du, Y.; Liu, M.; Yang, M.; Han, R. Adsorption of congo red from solution using chitosan modified carbon nanotubes. Desalin. Water Treat. 2019, 156, 96-105. [CrossRef]

243. Chen, M.; Zhou, S.; Zhu, Y.; Sun, Y.; Zeng, G.; Yang, C.; Xu, P.; Yan, M.; Liu, Z.; Zhang, W. Toxicity of carbon nanomaterials to plants, animals and microbes: Recent progress from 2015-present. Chemosphere 2018, 206, 255-264. [CrossRef] [PubMed]

244. Song, B.; Chen, M.; Ye, S.; Xu, P.; Zeng, G.; Gong, J.; Li, J.; Zhang, P.; Cao, W. Effects of multi-walled carbon nanotubes on metabolic function of the microbial community in riverine sediment contaminated with phenanthrene. Carbon 2019, 144, 1-7. [CrossRef]

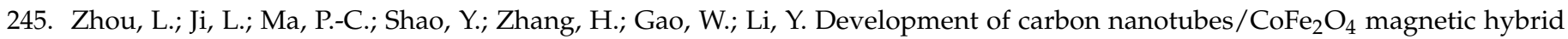
material for removal of tetrabromobisphenol A and $\mathrm{Pb}(\mathrm{II})$. J. Hazard. Mater. 2014, 265, 104-114. [CrossRef] [PubMed]

246. Wang, Y.; Shi, L.; Gao, L.; Wei, Q.; Cui, L.; Hu, L.; Yan, L.; Du, B. The removal of lead ions from aqueous solution by using magnetic hydroxypropyl chitosan/oxidized multiwalled carbon nanotubes composites. J. Colloid Interface Sci. 2015, 451, 7-14. [CrossRef] [PubMed]

247. Kim, M.K.; Shanmuga Sundaram, K.; Anantha Iyengar, G.; Lee, K.-P. A novel chitosan functional gel included with multiwall carbon nanotube and substituted polyaniline as adsorbent for efficient removal of chromium ion. Chem. Eng. J. 2015, 267, 51-64. [CrossRef]

248. Alsabagh, A.M.; Fathy, M.; Morsi, R.E. Preparation and characterization of chitosan/silver nanoparticle/copper nanoparticle/carbon nanotube multifunctional nano-composite for water treatment: Heavy metals removal; kinetics, isotherms and competitive studies. RSC Adv. 2015, 5, 55774-55783. [CrossRef]

249. Li, T.; He, F.; Dai, Y.D. Prussian blue analog caged in chitosan surface-decorated carbon nanotubes for removal cesium and strontium. J. Radioanal. Nucl. Chem. 2016, 310, 1139-1145. [CrossRef]

250. ZabihiSahebi, A.; Koushkbaghi, S.; Pishnamazi, M.; Askari, A.; Khosravi, R.; Irani, M. Synthesis of cellulose acetate/chitosan/ SWCNT $/ \mathrm{Fe}_{3} \mathrm{O}_{4} / \mathrm{TiO}_{2}$ composite nanofibers for the removal of $\mathrm{Cr}(\mathrm{VI})$, $\mathrm{As}(\mathrm{V})$, methylene blue and congo red from aqueous solutions. Int. J. Biol. Macromol. 2019, 140, 1296-1304. [CrossRef]

251. Li, K.; Gao, Q.; Yadavalli, G.; Shen, X.; Lei, H.; Han, B.; Xia, K.; Zhou, C. Selective adsorption of Gd ${ }^{3+}$ on a magnetically retrievable imprinted chitosan/carbon nanotube composite with high capacity. ACS Appl. Mater. Interfaces 2015, 7, 21047-21055. [CrossRef]

252. Mohan, D.; Sarswat, A.; Ok, Y.S.; Pittman, C.U. Organic and inorganic contaminants removal from water with biochar, a renewable, low cost and sustainable adsorbent-A critical review. Bioresour. Technol. 2014, 160, 191-202. [CrossRef] [PubMed]

253. Tan, X.; Liu, Y.; Zeng, G.; Wang, X.; Hu, X.; Gu, Y.; Yang, Z. Application of biochar for the removal of pollutants from aqueous solutions. Chemosphere 2015, 125, 70-85. [CrossRef] [PubMed]

254. Xue, Y.; Gao, B.; Yao, Y.; Inyang, M.; Zhang, M.; Zimmerman, A.R.; Ro, K.S. Hydrogen peroxide modification enhances the ability of biochar (hydrochar) produced from hydrothermal carbonization of peanut hull to remove aqueous heavy metals: Batch and column tests. Chem. Eng. J. 2012, 200-202, 673-680. [CrossRef]

255. Fernandez, M.E.; Ledesma, B.; Román, S.; Bonelli, P.R.; Cukierman, A.L. Development and characterization of activated hydrochars from orange peels as potential adsorbents for emerging organic contaminants. Bioresour. Technol. 2015, 183, 221-228 [CrossRef]

256. Zhou, Y.; Gao, B.; Zimmerman, A.R.; Fang, J.; Sun, Y.; Cao, X. Sorption of heavy metals on chitosan-modified biochars and its biological effects. Chem. Eng. J. 2013, 231, 512-518. [CrossRef]

257. Zhou, Y.; Gao, B.; Zimmerman, A.R.; Chen, H.; Zhang, M.; Cao, X. Biochar-supported zerovalent iron for removal of various contaminants from aqueous solutions. Bioresour. Technol. 2014, 152, 538-542. [CrossRef]

258. Ifthikar, J.; Jiao, X.; Ngambia, A.; Wang, T.; Khan, A.; Jawad, A.; Xue, Q.; Liu, L.; Chen, Z. Facile one-pot snthesis of sustainable carboxymethyl chitosan-Sewage sludge biochar for effective heavy metal chelation and regeneration. Bioresour. Technol. 2018, 262, 22-31. [CrossRef]

259. Liu, S.; Huang, B.; Chai, L.; Liu, Y.; Zeng, G.; Wang, X.; Zeng, W.; Shang, M.; Deng, J.; Zhou, Z. Enhancement of As(V) adsorption from aqueous solution by a magnetic chitosan/biochar composite. RSC Adv. 2017, 7, 10891-10900. [CrossRef]

260. Son, E.-B.; Poo, K.-M.; Mohamed, H.O.; Choi, Y.-J.; Cho, W.-C.; Chae, K.-J. A novel approach to developing a reusable marine macro-algae adsorbent with chitosan and ferric oxide for simultaneous efficient heavy metal removal and easy magnetic separation. Bioresour. Technol. 2018, 259, 381-387. [CrossRef]

261. Deng, J.; Liu, Y.; Liu, S.; Zeng, G.; Tan, X.; Huang, B.; Tang, X.; Wang, S.; Hua, Q.; Yan, Z. Competitive adsorption of Pb(II), Cd(II) and $\mathrm{Cu}(\mathrm{II})$ onto chitosan-pyromellitic dianhydride modified biochar. J. Colloid Interface Sci. 2017, 506, 355-364. [CrossRef]

262. Zhang, L.; Tang, S.; He, F.; Liu, Y.; Mao, W.; Guan, Y. Highly efficient and selective capture of heavy metals by poly(acrylic acid) grafted chitosan and biochar composite for wastewater treatment. Chem. Eng. J. 2019, 378, 122215. [CrossRef]

263. Huang, X.; Liu, Y.; Liu, S.; Tan, X.; Ding, Y.; Zeng, G.; Zhou, Y.; Zhang, M.; Wang, S.; Zheng, B. Effective removal of Cr(VI) using $\beta$-cyclodextrin-chitosan modified biochars with adsorption/reduction bifuctional roles. RSC Adv. 2015, 6, 94-104. [CrossRef]

264. Li, R.; Liang, W.; Huang, H.; Jiang, S.; Guo, D.; Li, M.; Zhang, Z.; Ali, A.; Wang, J.J. Removal of cadmium(II) cations from an aqueous solution with aminothiourea chitosan strengthened magnetic biochar. J. Appl. Polym. Sci. 2018, 135, 46239. [CrossRef] 
265. Zhou, D.; Xie, G.; Hu, X.; Cai, X.; Zhao, Y.; Hu, X.; Jin, Q.; Fu, X.; Tan, X.; Liang, C.; et al. Coupling of Kenaf biochar and magnetic $\mathrm{BiFeO}_{3}$ onto cross-linked chitosan for enhancing separation performance and $\mathrm{Cr}(\mathrm{VI})$ ions removal efficiency. Int. J. Environ. Res. Public Health 2020, 17, 788. [CrossRef] [PubMed]

266. Huang, Y.; Lee, X.; Grattieri, M.; Yuan, M.; Cai, R.; Macazo, F.C.; Minteer, S.D. Modified biochar for phosphate adsorption in environmentally relevant conditions. Chem. Eng. J. 2020, 380, 122375. [CrossRef]

267. Song, Q.; Yang, B.; Wang, H.; Xu, S.; Cao, Y. Effective removal of copper (II) and cadmium (II) by adsorbent prepared from chitosan-modified magnetic biochar. J. Resid. Sci. Technol. 2016, 13, 197-205. [CrossRef]

268. Jiang, X.; Xiang, X.; Hu, H.; Meng, X.; Hou, L. Facile Fabrication of Biochar $/ \mathrm{Al}_{2} \mathrm{O}_{3}$ adsorbent and its application for fuoride removal from aqueous solution. J. Chem. Eng. Data 2019, 64, 83-89. [CrossRef]

269. Liu, D.; Zhu, Y.; Li, Z.; Xiao, M.; Jiang, C.; Chen, M.; Chen, Y. Microfibrillar polysaccharide-derived biochars as sodium benzoate adsorbents. ACS Omega 2017, 2, 2959-2966. [CrossRef]

270. Mojiri, A.; Kazeroon, R.A.; Gholami, A. Cross-linked magnetic chitosan/activated biochar for removal of emerging micropollutants from water: Optimization by the artificial neural network. Water 2019, 11, 551. [CrossRef]

271. Afzal, M.Z.; Yue, R.; Sun, X.-F.; Song, C.; Wang, S.-G. Enhanced removal of ciprofloxacin using humic acid modified hydrogel beads. J. Colloid Interface Sci. 2019, 543, 76-83. [CrossRef]

272. Nguyen, H.T.; Phuong, V.N.; Van, T.N.; Thi, P.N.; Dinh Thi Lan, P.; Pham, H.T.; Cao, H.T. Low-cost hydrogel derived from agro-waste for veterinary antibiotic removal: Optimization, kinetics, and toxicity evaluation. Environ. Technol. Innov. 2020, 20, 101098. [CrossRef]

273. Zhu, C.; Lang, Y.; Liu, B.; Zhao, H. Ofloxacin adsorption on chitosan/biochar composite: Kinetics, isotherms, and effects of solution chemistry. Polycycl. Aromat. Compd. 2019, 39, 287-297. [CrossRef]

274. Kannan, N.; Sundaram, M.M. Kinetics and mechanism of removal of methylene blue by adsorption on various carbons-A comparative study. Dye. Pigment. 2001, 51, 25-40. [CrossRef]

275. Elkady, M.; Shokry, H.; Hamad, H. New activated carbon from mine coal for adsorption of dye in simulated water or multiple heavy metals in real wastewater. Materials 2020, 13, 2498. [CrossRef] [PubMed]

276. Unugul, T.; Nigiz, F.U. Preparation and characterization an active carbon adsorbent from waste mandarin peel and determination of adsorption behavior on removal of synthetic dye solutions. Water. Air. Soil Pollut. 2020, 231, 538. [CrossRef]

277. Hydari, S.; Sharififard, H.; Nabavinia, M.; Parvizi, M.R. A comparative investigation on removal performances of commercial activated carbon, chitosan biosorbent and chitosan/activated carbon composite for cadmium. Chem. Eng. J. 2012, 193-194, 276-282. [CrossRef]

278. Auta, M.; Hameed, B.H. Coalesced chitosan activated carbon composite for batch and fixed-bed adsorption of cationic and anionic dyes. Colloids Surf. B Biointerface 2013, 105, 199-206. [CrossRef]

279. Fatombi, J.K.; Idohou, E.A.; Osseni, S.A.; Agani, I.; Neumeyer, D.; Verelst, M.; Mauricot, R.; Aminou, T. Adsorption of indigo carmine from aqueous solution by chitosan and chitosan/activated carbon composite: Kinetics, isotherms and thermodynamics studies. Fib. Polym. 2019, 20, 1820-1832. [CrossRef]

280. Babel, S.; Kurniawan, T.A. Cr(VI) removal from synthetic wastewater using coconut shell charcoal and commercial activated carbon modified with oxidizing agents and/or chitosan. Chemosphere 2004, 54, 951-967. [CrossRef]

281. Amuda, O.S.; Giwa, A.A.; Bello, I.A. Removal of heavy metal from industrial wastewater using modified activated coconut shell carbon. Biochem. Eng. J. 2007, 36, 174-181. [CrossRef]

282. Amuda, O.S.; Adelowo, F.E.; Ologunde, M.O. Kinetics and equilibrium studies of adsorption of chromium(VI) ion from industrial wastewater using Chrysophyllum albidum (Sapotaceae) seed shells. Colloids Surf. B Biointerface 2009, 68, 184-192. [CrossRef] [PubMed]

283. Jayasantha Kumari, H.; Krishnamoorthy, P.; Arumugam, T.K.; Radhakrishnan, S.; Vasudevan, D. An efficient removal of crystal violet dye from waste water by adsorption onto TLAC/Chitosan composite: A novel low cost adsorbent. Int. J. Biol. Macromol. 2017, 96, 324-333. [CrossRef] [PubMed]

284. Ba, S.; Alagui, A.; Hajjaji, M. Retention and release of hexavalent and trivalent chromium by chitosan, olive stone activated carbon, and their blend. Environ. Sci. Pollut. Res. 2018, 25, 19585-19604. [CrossRef] [PubMed]

285. Sharififard, H.; Zokaee Ashtiani, F.; Soleimani, M. Adsorption of palladium and platinum from aqueous solutions by chitosan and activated carbon coated with chitosan. Asia-Pac.J. Chem. Eng. 2013, 8, 384-395. [CrossRef]

286. Gonçalves, J.O.; Santos, J.P.; Rios, E.C.; Crispim, M.M.; Dotto, G.L.; Pinto, L.A.A. Development of chitosan based hybrid hydrogels for dyes removal from aqueous binary system. J. Mol. Liq. 2017, 225, 265-270. [CrossRef]

287. Ge, H.; Fan, X. Adsorption of $\mathrm{Pb}^{2+}$ and $\mathrm{Cd}^{2+}$ onto a novel activated carbon-chitosan complex. Chem. Eng. Technol. 2011, 34, 1745-1752. [CrossRef]

288. Li, J.; Jiang, B.; Liu, Y.; Qiu, C.; Hu, J.; Qian, G.; Guo, W.; Ngo, H.H. Preparation and adsorption properties of magnetic chitosan composite adsorbent for $\mathrm{Cu}^{2+}$ removal. J. Clean. Prod. 2017, 158, 51-58. [CrossRef]

289. Chang, Y.-H.; Hsieh, K.-H.; Chang, F.-C. Removal of $\mathrm{Hg}^{2+}$ from aqueous solution using a novel composite carbon adsorbent. J. Appl. Polym. Sci. 2009, 112, 2445-2454. [CrossRef]

290. Villarante, N.R.; Bautista, A.P.R.; Sumalapao, D.E.P. Batch adsorption study and kinetic profile of Cr(VI) using lumbang (Aleurites moluccana)-derived activated carbon-chitosan composite crosslinked with epichlorohydrin. Orient. J. Chem. 2017, 33, 1111-1119. [CrossRef] 
291. Huang, R.; Yang, B.; Liu, Q.; Liu, Y. Simultaneous adsorption of aniline and Cr(VI) ion by activated carbon/chitosan composite. J. Appl. Polym. Sci. 2014, 131. [CrossRef]

292. Arumugam, T.K.; Krishnamoorthy, P.; Rajagopalan, N.R.; Nanthini, S.; Vasudevan, D. Removal of malachite green from aqueous solutions using a modified chitosan composite. Int. J. Biol. Macromol. 2019, 128, 655-664. [CrossRef] [PubMed]

293. Nowruzi, R.; Heydari, M.; Javanbakht, V. Synthesis of a chitosan/polyvinyl alcohol/activate carbon biocomposite for removal of hexavalent chromium from aqueous solution. Int. J. Biol. Macromol. 2020, 147, 209-216. [CrossRef] [PubMed]

294. Salehi, E.; Farahani, A. Macroporous chitosan/polyvinyl alcohol composite adsorbents based on activated carbon substrate. J. Porous Mater. 2017, 24, 1197-1207. [CrossRef]

295. Salehi, E.; Soroush, F.; Momeni, M.; Barati, A.; Khakpour, A. Chitosan/polyethylene glycol impregnated activated carbons: Synthesis, characterization and adsorption performance. Front. Chem. Sci. Eng. 2017, 11, 575-585. [CrossRef]

296. Liu, L.F.; Zhang, P.H.; Yang, F.L. Adsorptive removal of 2,4-DCP from water by fresh or regenerated chitosan/ACF/TiO 2 membrane. Sep. Purif. Technol. 2010, 70, 354-361. [CrossRef]

297. Zhang, S.; Li, X.-Y.; Chen, J.P. Preparation and evaluation of a magnetite-doped activated carbon fiber for enhanced arsenic removal. Carbon 2010, 48, 60-67. [CrossRef]

298. Karamipour, A.; Khadiv Parsi, P.; Zahedi, P.; Moosavian, S.M.A. Using $\mathrm{Fe}_{3} \mathrm{O}_{4}$-coated nanofibers based on cellulose acetate/chitosan for adsorption of $\mathrm{Cr}(\mathrm{VI}), \mathrm{Ni}(\mathrm{II})$ and phenol from aqueous solutions. Int. J. Biol. Macromol. 2020, 154, 1132-1139. [CrossRef]

299. Danalığlu, S.T.; Bayazit, S..S.; Kerkez Kuyumcu, Ö.; Salam, M.A. Efficient removal of antibiotics by a novel magnetic adsorbent: Magnetic activated carbon/chitosan (MACC) nanocomposite. J. Mol. Liq. 2017, 240, 589-596. [CrossRef]

300. Çavuşoğlu, F.C.; Akan, S.; Arı, E.A.; Çetinkaya, E.; Çolak, E.; Daştan, G.N.; Deniz, S.; Erdem, D.; Köksal, M.; Korkmaz, S.; et al. Preparation of magnetic activated carbon-chitosan nanocomposite for crystal violet adsorption. Kor. J. Chem. Eng. 2019, 36, 1915-1921. [CrossRef]

301. Malakootian, M.; Nasiri, A.; Mahdizadeh, H. Preparation of $\mathrm{CoFe}_{2} \mathrm{O}_{4}$ /activated carbon@chitosan as a new magnetic nanobiocomposite for adsorption of ciprofloxacin in aqueous solutions. Water Sci. Technol. 2018, 78, 2158-2170. [CrossRef]

302. Sanlier, S.H.; Ak, G.; Yilmaz, H.; Ozbakir, G.; Cagliyan, O. Removal of textile dye, direct red 23, with glutaraldehyde cross-linked magnetic chitosan beads. Prep. Biochem. Biotechnol. 2013, 43, 163-176. [CrossRef] [PubMed]

303. Soni, U.; Bajpai, J.; Singh, S.K.; Bajpai, A.K. Evaluation of chitosan-carbon based biocomposite for efficient removal of phenols from aqueous solutions. J. Water Process Eng. 2017, 16, 56-63. [CrossRef]

304. Mashile, G.P.; Mpupa, A.; Nqombolo, A.; Dimpe, K.M.; Nomngongo, P.N. Recyclable magnetic waste tyre activated carbonchitosan composite as an effective adsorbent rapid and simultaneous removal of methylparaben and propylparaben from aqueous solution and wastewater. J. Water Process Eng. 2020, 33. [CrossRef]

305. Jawad, A.H.; Abdulhameed, A.S.; Mastuli, M.S. Mesoporous crosslinked chitosan-activated charcoal composite for the removal of thionine cationic dye: Comprehensive adsorption and mechanism study. J. Polym. Environ. 2020, 28, 1095-1105. [CrossRef]

306. Gonçalves, J.O.; da Silva, K.A.; Rios, E.C.; Crispim, M.M.; Dotto, G.L.; de Almeida Pinto, L.A. Single and binary adsorption of food dyes on chitosan/activated carbon hydrogels. Chem. Eng. Technol. 2019, 42, 454-464. [CrossRef]

307. Saloglu, D.; Ozcan, N. Activated carbon embedded chitosan/polyvinyl alcohol biocomposites for adsorption of nonsteroidal anti-inflammatory drug-naproxen from wastewater. Desalin. Water Treat. 2018, 107, 72-84. [CrossRef]

308. Amouzgar, P.; Vakili, M.; Chan, E.-S.; Salamatinia, B. Effects of beading parameters for development of chitosan-nano-activated carbon biocomposite for acetaminophen elimination from aqueous sources. Environ. Eng. Sci. 2017, 34, 805-815. [CrossRef]

309. Liu, Q.; Zhang, L.; Hu, P.; Huang, R. Removal of aniline from aqueous solutions by activated carbon coated by chitosan. J. Water Reuse Desalin. 2015, 5, 610-618. [CrossRef]

310. Ji, G.; Bao, W.; Gao, G.; An, B.; Zou, H.; Gan, S. Removal of Cu (II) from aqueous solution using a novel crosslinked aluminachitosan hybrid adsorbent. Chin. J. Chem. Eng. 2012, 20, 641-648. [CrossRef]

311. Jagtap, S.; Yenkie, M.K.N.; Labhsetwar, N.; Rayalu, S. Defluoridation of drinking water using chitosan based mesoporous alumina. Microporous Mesoporous Mater. 2011, 142, 454-463. [CrossRef]

312. Wang, J.; Zhou, Q.; Song, D.; Qi, B.; Zhang, Y.; Shao, Y.; Shao, Z. Chitosan-silica composite aerogels: Preparation, characterization and Congo red adsorption. J. Sol-Gel Sci. Technol. 2015, 76, 501-509. [CrossRef]

313. Nuryono, N.; Miswanda, D.; Sakti, S.C.W.; Rusdiarso, B.; Krisbiantoro, P.A.; Utami, N.; Otomo, R.; Kamiya, Y. Chitosanfunctionalized natural magnetic particle@silica modified with (3-chloropropyl)trimethoxysilane as a highly stable magnetic adsorbent for gold(III) ion. Mater. Chem. Phys. 2020, 255, 123507. [CrossRef]

314. Walcarius, A.; Mercier, L. Mesoporous organosilica adsorbents: Nanoengineered materials for removal of organic and inorganic pollutants. J. Mater. Chem. 2010, 20, 4478-4511. [CrossRef]

315. Shahat, A.; Hassan, H.M.A.; Azzazy, H.M.E.; El-Sharkawy, E.A.; Abdou, H.M.; Awual, M.R. Novel hierarchical composite adsorbent for selective lead(II) ions capturing from wastewater samples. Chem. Eng. J. 2018, 332, 377-386. [CrossRef]

316. Dos Santos, S.M.L.; Nogueira, K.A.B.; De Souza Gama, M.; Lima, J.D.F.; Da Silva Júnior, I.J.; De Azevedo, D.C.S. Synthesis and characterization of ordered mesoporous silica (SBA-15 and SBA-16) for adsorption of biomolecules. Microporous Mesoporous Mater. 2013, 180, 284-292. [CrossRef]

317. Wang, J.; Mao, M.; Atif, S.; Chen, Y. Adsorption behavior and mechanism of aqueous Cr(III) and Cr(III)-EDTA chelates on DTPA-chitosan modified $\mathrm{Fe}_{3} \mathrm{O}_{4} @ \mathrm{SiO}_{2}$. React. Funct. Polym. 2020, 156, 104720. [CrossRef] 
318. Aden, M.; Ubol, R.N.; Knorr, M.; Husson, J.; Euvrard, M. Efficent removal of nickel(II) salts from aqueous solution using carboxymethylchitosan-coated silica particles as adsorbent. Carbohydr. Polym. 2017, 173, 372-382. [CrossRef]

319. Malwal, D.; Gopinath, P. Silica stabilized magnetic-chitosan beads for removal of arsenic from water. Colloids Interface Sci. Commun. 2017, 19, 14-19. [CrossRef]

320. Darvishi Cheshmeh Soltani, R.; Khataee, A.R.; Safari, M.; Joo, S.W. Preparation of bio-silica/chitosan nanocomposite for adsorption of a textile dye in aqueous solutions. Int. Biodeterior. Biodegrad. 2013, 85, 383-391. [CrossRef]

321. Ebisike, K.; Okoronkwo, A.E.; Alaneme, K.K. Adsorption of Cd(II) on chitosan-silica hybrid aerogel from aqueous solution. Environ. Technol. Innov. 2019, 14, 100337. [CrossRef]

322. Zhao, H.; Xu, J.; Lan, W.; Wang, T.; Luo, G. Microfluidic production of porous chitosan/silica hybrid microspheres and its Cu(II) adsorption performance. Chem. Eng. J. 2013, 229, 82-89. [CrossRef]

323. Xu, X.; Dong, P.; Feng, Y.; Li, F.; Yu, H. A simple strategy for preparation of spherical silica-supported porous chitosan matrix based on sol-gel reaction and simple treatment with ammonia solution. Anal. Methods 2010, 2, 546-551. [CrossRef]

324. Wong, J.S.H.; Hicks, R.E.; Probstein, R.F. EDTA-enhanced electroremediation of metal-contaminated soils. J. Hazard. Mater. 1997, 55, 61-79. [CrossRef]

325. Repo, E.; Warchoł, J.K.; Bhatnagar, A.; Sillanpää, M. Heavy metals adsorption by novel EDTA-modified chitosan-silica hybrid materials. J. Colloid Interface Sci. 2011, 358, 261-267. [CrossRef]

326. Blachnio, M.; Budnyak, T.M.; Derylo-Marczewska, A.; Marczewski, A.W.; Tertykh, V.A. Chitosan-silica hybrid composites for removal of sulfonated azo dyes from aqueous solutions. Langmuir 2018, 34, 2258-2273. [CrossRef]

327. Li, Y.; Zhou, Y.; Nie, W.; Song, L.; Chen, P. Highly efficient methylene blue dyes removal from aqueous systems by chitosan coated magnetic mesoporous silica nanoparticles. J. Porous Mater. 2015, 22, 1383-1392. [CrossRef]

328. Ting, C.-C.; Wu, H.-Y.; Vetrivel, S.; Saikia, D.; Pan, Y.-C.; Fey, G.T.K.; Kao, H.-M. A one-pot route to synthesize highly ordered mesoporous carbons and silicas through organic-inorganic self-assembly of triblock copolymer, sucrose and silica. Microporous Mesoporous Mater. 2010, 128, 1-11. [CrossRef]

329. Chen, D.; Hu, B.; Huang, C. Chitosan modified ordered mesoporous silica as micro-column packing materials for on-line flow injection-inductively coupled plasma optical emission spectrometry determination of trace heavy metals in environmental water samples. Talanta 2009, 78, 491-497. [CrossRef]

330. He, H.; Meng, X.; Yue, Q.; Yin, W.; Gao, Y.; Fang, P.; Shen, L. Thiol-ene click chemistry synthesis of a novel magnetic mesoporous silica/chitosan composite for selective $\mathrm{Hg}(\mathrm{II})$ capture and high catalytic activity of spent $\mathrm{Hg}(\mathrm{II})$ adsorbent. Chem. Eng. J. 2021, 405. [CrossRef]

331. Sabourian, V.; Ebrahimi, A.; Naseri, F.; Irani, M.; Rahimi, A. Fabrication of chitosan/silica nanofibrous adsorbent functionalized with amine groups for the removal of $\mathrm{Ni}(\mathrm{II}), \mathrm{Cu}(\mathrm{II})$ and $\mathrm{Pb}(\mathrm{II})$ from aqueous solutions: Batch and column studies. RSC Adv. 2016, 6, 40354-40365. [CrossRef]

332. Gao, Q.; Zhu, H.; Luo, W.-J.; Wang, S.; Zhou, C.-G. Preparation, characterization, and adsorption evaluation of chitosanfunctionalized mesoporous composites. Microporous Mesoporous Mater. 2014, 193, 15-26. [CrossRef]

333. Mousavi, S.J.; Parvini, M.; Ghorbani, M. Adsorption of heavy metals $\left(\mathrm{Cu}^{2+}\right.$ and $\left.\mathrm{Zn}^{2+}\right)$ on novel bifunctional ordered mesoporous silica: Optimization by response surface methodology. J. Taiwan Inst. Chem. Eng. 2018, 84, 123-141. [CrossRef]

334. Du, Q.; Sun, J.; Li, Y.; Yang, X.; Wang, X.; Wang, Z.; Xia, L. Highly enhanced adsorption of congo red onto graphene oxide/chitosan fibers by wet-chemical etching off silica nanoparticles. Chem. Eng. J. 2014, 245, 99-106. [CrossRef]

335. Zhang, L.; Luo, H.; Liu, P.; Fang, W.; Geng, J. A novel modified graphene oxide/chitosan composite used as an adsorbent for $\mathrm{Cr}(\mathrm{VI})$ in aqueous solutions. Int. J. Biol. Macromol. 2016, 87, 586-596. [CrossRef]

336. Shahzad, A.; Miran, W.; Rasool, K.; Nawaz, M.; Jang, J.; Lim, S.-R.; Lee, D.S. Heavy metals removal by EDTA-functionalized chitosan graphene oxide nanocomposites. RSC Adv. 2017, 7, 9764-9771. [CrossRef]

337. Hadi Najafabadi, H.; Irani, M.; Roshanfekr Rad, L.; Heydari Haratameh, A.; Haririan, I. Removal of $\mathrm{Cu}^{2+}, \mathrm{Pb}^{2+}$ and Cr ${ }^{6+}$ from aqueous solutions using a chitosan/graphene oxide composite nanofibrous adsorbent. RSC Adv. 2015, 5, 16532-16539. [CrossRef]

338. Travlou, N.A.; Kyzas, G.Z.; Lazaridis, N.K.; Deliyanni, E.A. Graphite oxide/chitosan composite for reactive dye removal. Chem. Eng. J. 2013, 217, 256-265. [CrossRef]

339. Li, X.; Zhou, H.; Wu, W.; Wei, S.; Xu, Y.; Kuang, Y. Studies of heavy metal ion adsorption on chitosan/sulfydryl-functionalized graphene oxide composites. J. Colloid Interface Sci. 2015, 448, 389-397. [CrossRef]

340. Hosseinzadeh, H.; Ramin, S. Effective removal of copper from aqueous solutions by modified magnetic chitosan/graphene oxide nanocomposites. Int. J. Biol. Macromol. 2018, 113, 859-868. [CrossRef]

341. Sherlala, A.I.A.; Raman, A.A.A.; Bello, M.M.; Buthiyappan, A. Adsorption of arsenic using chitosan magnetic graphene oxide nanocomposite. J. Environ. Manag. 2019, 246, 547-556. [CrossRef]

342. Samuel, M.S.; Shah, S.S.; Subramaniyan, V.; Qureshi, T.; Bhattacharya, J.; Pradeep Singh, N.D. Preparation of graphene oxide/chitosan/ferrite nanocomposite for chromium(VI) removal from aqueous solution. Int. J. Biol. Macromol. 2018, 119, 540-547. [CrossRef] [PubMed]

343. Sun, W.; Li, L.; Luo, C.; Fan, L. Synthesis of magnetic graphene nanocomposites decorated with ionic liquids for fast lead ion removal. Int. J. Biol. Macromol. 2016, 85, 246-251. [CrossRef] [PubMed]

344. Nasiri, R.; Arsalani, N.; Panahian, Y. One-pot synthesis of novel magnetic three-dimensional graphene/chitosan/nickel ferrite nanocomposite for lead ions removal from aqueous solution: RSM modelling design. J. Clean. Prod. 2018, 201, 507-515. [CrossRef] 
345. Subedi, N.; Lähde, A.; Abu-Danso, E.; Iqbal, J.; Bhatnagar, A. A comparative study of magnetic chitosan $\left(\mathrm{Chi} \mathrm{Fe}_{3} \mathrm{O}_{4}\right.$ and graphene oxide modified magnetic chitosan (Chi@ $\mathrm{Fe}_{3} \mathrm{O}_{4} / \mathrm{GO}$ ) nanocomposites for efficient removal of $\mathrm{Cr}(\mathrm{VI})$ from water. Int. J. Biol. Macromol. 2019, 137, 948-959. [CrossRef]

346. Yang, A.; Yang, P.; Huang, C.P. Preparation of graphene oxide-chitosan composite and adsorption performance for uranium. J. Radioanal. Nucl. Chem. 2017, 313, 371-378. [CrossRef]

347. Li, C.; Yan, Y.; Zhang, Q.; Zhang, Z.; Huang, L.; Zhang, J.; Xiong, Y.; Tan, S. Adsorption of Cd $\mathrm{Cd}^{2+}$ and $\mathrm{Ni}^{2+}$ from aqueous single-metal solutions on graphene oxide-chitosan-poly(vinyl alcohol) hydrogels. Langmuir 2019, 35, 4481-4490. [CrossRef]

348. Cheng, J.; Gao, M.; Yang, L.; Zhang, L.; Zhu, B. Coral-inspired "nanotentaclization" porous composite gel for efficient removal of lead(II) from aqueous solution. Mater. Des. 2020, 195. [CrossRef]

349. Dou, J.; Gan, D.; Huang, Q.; Liu, M.; Chen, J.; Deng, F.; Zhu, X.; Wen, Y.; Zhang, X.; Wei, Y. Functionalization of carbon nanotubes with chitosan based on MALI multicomponent reaction for $\mathrm{Cu}^{2+}$ removal. Int. J. Biol. Macromol. 2019, 136, 476-485. [CrossRef]

350. Huang, Y.; Lee, X.; Macazo, F.C.; Grattieri, M.; Cai, R.; Minteer, S.D. Fast and efficient removal of chromium(VI) anionic species by a reusable chitosan-modified multi-walled carbon nanotube composite. Chem. Eng. J. 2018, 339, 259-267. [CrossRef]

351. Ouyang, J.; Wang, Y.; Li, T.; Zhou, L.; Liu, Z. Immobilization of carboxyl-modified multiwalled carbon nanotubes in chitosan-based composite membranes for U(VI) sorption. J. Radioanal. Nucl. Chem. 2018, 317, 1419-1428. [CrossRef]

352. Marques Neto, J.D.O.; Bellato, C.R.; Silva, D.D.C. Iron oxide/carbon nanotubes/chitosan magnetic composite film for chromium species removal. Chemosphere 2019, 218, 391-401. [CrossRef] [PubMed]

353. Xiao, F.; Cheng, J.; Cao, W.; Yang, C.; Chen, J.; Luo, Z. Removal of heavy metals from aqueous solution using chitosan-combined magnetic biochars. J. Colloid Interface Sci. 2019, 540, 579-584. [CrossRef] [PubMed]

354. Arabyarmohammadi, H.; Darban, A.K.; Abdollahy, M.; Yong, R.; Ayati, B.; Zirakjou, A.; van der Zee, S.E.A.T.M. Utilization of a novel chitosan/clay/biochar nanobiocomposite for immobilization of heavy metals in acid soil environment. J. Polym. Environ. 2018, 26, 2107-2119. [CrossRef]

355. Shariful, M.I.; Sepehr, T.; Mehrali, M.; Ang, B.C.; Amalina, M.A. Adsorption capability of heavy metals by chitosan/poly(ethylene oxide)/activated carbon electrospun nanofibrous membrane. J. Appl. Polym. Sci. 2018, 135, 45851. [CrossRef]

356. Li, K.; Wang, Y.; Huang, M.; Yan, H.; Yang, H.; Xiao, S.; Li, A. Preparation of chitosan-graft-polyacrylamide magnetic composite microspheres for enhanced selective removal of mercury ions from water. J. Colloid Interface Sci. 2015, 455, 261-270. [CrossRef] [PubMed]

357. Pourebrahim, F.; Ghaedi, M.; Dashtian, K.; Heidari, F.; Kheirandish, S. Simultaneous removing of $\mathrm{Pb}^{2+}$ ions and alizarin red S dye after their complexation by ultrasonic waves coupled adsorption process: Spectrophotometry detection and optimization study. Ultrason. Sonochem. 2017, 35, 51-60. [CrossRef]

358. Mousavi, S.J.; Parvini, M.; Ghorbani, M. Experimental design data for the zinc ions adsorption based on mesoporous modified chitosan using central composite design method. Carbohydr. Polym. 2018, 188, 197-212. [CrossRef]

359. Liu, J.; Chen, Y.; Han, T.; Cheng, M.; Zhang, W.; Long, J.; Fu, X. A biomimetic $\mathrm{SiO}_{2} @$ chitosan composite as highly-efficient adsorbent for removing heavy metal ions in drinking water. Chemosphere 2019, 214, 738-742. [CrossRef]

360. Zarei, F.; Marjani, A.; Soltani, R. Novel and green nanocomposite-based adsorbents from functionalised mesoporous KCC-1 and chitosan-oleic acid for adsorption of $\mathrm{Pb}$ (II). Eur. Polym. J. 2019, 119, 400-409. [CrossRef]

361. Jin, X.; Li, K.; Ning, P.; Bao, S.; Tang, L. Removal of Cu(II) Ions from aqueous solution by magnetic chitosan-tripolyphosphate modified silica-coated adsorbent: Characterization and mechanisms. Water. Air. Soil Pollut. 2017, 228, 302. [CrossRef]

362. Srinivasan, S.; Chelliah, P.; Srinivasan, V.; Stantley, A.B.; Subramani, K. Chitosan and reinforced chitosan films for the removal of $\mathrm{Cr}(\mathrm{VI})$ heavy metal from synthetic aqueous solution. Orient. J. Chem. 2016, 32, 671-680. [CrossRef]

363. Plohl, O.; Ajdnik, U.; Gyergyek, S.; Ban, I.; Vesel, A.; Glaser, T.K.; Zemljič, L.F. Superior stability and high biosorbent efficiency of carboxymethylchitosan covalently linked to silica-coated core-shell magnetic nanoparticles for application in copper removal. J. Environ. Chem. Eng. 2019, 7, 102913. [CrossRef]

364. Shariatinia, Z.; Esmaeilzadeh, A. Hybrid silica aerogel nanocomposite adsorbents designed for Cd(II) removal from aqueous solution. Water Environ. Res. 2019, 91, 1624-1637. [CrossRef] [PubMed]

365. Lai, K.C.; Hiew, B.Y.Z.; Lee, L.Y.; Gan, S.; Thangalazhy-Gopakumar, S.; Chiu, W.S.; Khiew, P.S. Ice-templated graphene oxide/chitosan aerogel as an effective adsorbent for sequestration of metanil yellow dye. Bioresour. Technol. 2019, 274, 134-144. [CrossRef] [PubMed]

366. Blackburn, R.S. Natural polysaccharides and their interactions with dye molecules: Applications in effluent treatment. Environ. Sci. Technol. 2004, 38, 4905-4909. [CrossRef]

367. Nekouei Marnani, N.; Shahbazi, A. A novel environmental-friendly nanobiocomposite synthesis by EDTA and chitosan functionalized magnetic graphene oxide for high removal of Rhodamine B: Adsorption mechanism and separation property. Chemosphere 2019, 218, 715-725. [CrossRef]

368. Luo, T.; Zhang, L. Comment on "A novel environmental-friendly nanobiocomposite synthesis by EDTA and Chitosan functionalized magnetic graphene oxide for high removal of rhodamine B: Adsorption mechanism and separation property" [Chemosphere, 218 (2019) 715-725]. Chemosphere 2019, 233, 983-984. [CrossRef]

369. Li, Z.; Wang, X.; Zhang, X.; Yang, Y.; Duan, J. A high-efficiency and plane-enhanced chitosan film for cefotaxime adsorption compared with chitosan particles in water. Chem. Eng. J. 2020, 127494. [CrossRef] 
370. Liu, Q.-S.; Zheng, T.; Wang, P.; Jiang, J.-P.; Li, N. Adsorption isotherm, kinetic and mechanism studies of some substituted phenols on activated carbon fibers. Chem. Eng. J. 2010, 157, 348-356. [CrossRef]

371. Wang, Y.; Liu, X.; Wang, H.; Xia, G.; Huang, W.; Song, R. Microporous spongy chitosan monoliths doped with graphene oxide as highly effective adsorbent for methyl orange and copper nitrate $\left(\mathrm{Cu}\left(\mathrm{NO}_{3}\right)_{2}\right)$ ions. J. Colloid Interface Sci. 2014, 416, $243-251$. [CrossRef]

372. Sheshmani, S.; Ashori, A.; Hasanzadeh, S. Removal of Acid Orange 7 from aqueous solution using magnetic graphene/chitosan: A promising nano-adsorbent. Int. J. Biol. Macromol. 2014, 68, 218-224. [CrossRef] [PubMed]

373. Jiang, Y.; Gong, J.-L.; Zeng, G.-M.; Ou, X.-M.; Chang, Y.-N.; Deng, C.-H.; Zhang, J.; Liu, H.-Y.; Huang, S.-Y. Magnetic chitosangraphene oxide composite for anti-microbial and dye removal applications. Int. J. Biol. Macromol. 2016, 82, 702-710. [CrossRef] [PubMed]

374. Omidi, S.; Kakanejadifard, A. Eco-friendly synthesis of graphene-chitosan composite hydrogel as efficient adsorbent for Congo red. RSC Adv. 2018, 8, 12179-12189. [CrossRef]

375. Zhu, H.; Fu, Y.; Jiang, R.; Yao, J.; Liu, L.; Chen, Y.; Xiao, L.; Zeng, G. Preparation, characterization and adsorption properties of chitosan modified magnetic graphitized multi-walled carbon nanotubes for highly effective removal of a carcinogenic dye from aqueous solution. Appl. Surf. Sci. 2013, 285, 865-873. [CrossRef]

376. Wang, S.; Zhai, Y.-Y.; Gao, Q.; Luo, W.-J.; Xia, H.; Zhou, C.-G. Highly efficient removal of acid red 18 from aqueous solution by magnetically retrievable chitosan/carbon nanotube: Batch study, isotherms, kinetics, and thermodynamics. J. Chem. Eng. Data 2014, 59, 39-51. [CrossRef]

377. Abbasi, M. Synthesis and characterization of magnetic nanocomposite of chitosan $/ \mathrm{SiO}_{2} /$ carbon nanotubes and its application for dyes removal. J. Clean. Prod. 2017, 145, 105-113. [CrossRef]

378. Abbasi, M.; Habibi, M.M. Optimization and characterization of Direct Blue 71 removal using nanocomposite of ChitosanMWCNTs: Central composite design modeling. J. Taiwan Inst. Chem. Eng. 2016, 62, 112-121. [CrossRef]

379. Idohou, E.A.; Fatombi, J.K.; Osseni, S.A.; Agani, I.; Neumeyer, D.; Verelst, M.; Mauricot, R.; Aminou, T. Preparation of activated carbon/chitosan/Carica papaya seeds composite for efficient adsorption of cationic dye from aqueous solution. Surf. Interf. 2020, 21, 100741. [CrossRef]

380. Vakili, M.; Zwain, H.M.; Mojiri, A.; Wang, W.; Gholami, F.; Gholami, Z.; Giwa, A.S.; Wang, B.; Cagnetta, G.; Salamatinia, B. Effective adsorption of reactive black 5 onto hybrid hexadecylamine impregnated chitosan-powdered activated carbon beads. Water 2020, 12, 2242. [CrossRef]

381. Luo, X.; Liu, L.; Wang, L.; Liu, X.; Cai, Y. Facile synthesis and low concentration tylosin adsorption performance of chitosan/cellulose nanocomposite microspheres. Carbohydr. Polym. 2019, 206, 633-640. [CrossRef]

382. Yan, H.; Li, H.; Yang, H.; Li, A.; Cheng, R. Removal of various cationic dyes from aqueous solutions using a kind of fully biodegradable magnetic composite microsphere. Chem. Eng. J. 2013, 223, 402-411. [CrossRef]

383. Zhang, B.; Huyan, Y.; Wang, J.; Chen, X.; Zhang, H.; Zhang, Q. $\mathrm{Fe}_{3} \mathrm{O}_{4} @ \mathrm{SiO}_{2} @ C C S$ porous magnetic microspheres as adsorbent for removal of organic dyes in aqueous phase. J. Alloys Compd. 2018, 735, 1986-1996. [CrossRef]

384. Hassan, H.; Salama, A.; El-ziaty, A.K.; El-Sakhawy, M. New chitosan/silica/zinc oxide nanocomposite as adsorbent for dye removal. Int. J. Biol. Macromol. 2019, 131, 520-526. [CrossRef] [PubMed]

385. Mahmoodi, N.M.; Mokhtari-Shourijeh, Z.; Abdi, J. Preparation of mesoporous polyvinyl alcohol/chitosan/silica composite nanofiber and dye removal from wastewater. Environ. Prog. Sustain. Energy 2019, 38, S100-S109. [CrossRef]

386. Afzal, M.Z.; Sun, X.-F.; Liu, J.; Song, C.; Wang, S.-G.; Javed, A. Enhancement of ciprofloxacin sorption on chitosan/biochar hydrogel beads. Sci. Total Environ. 2018, 639, 560-569. [CrossRef] [PubMed] 